\title{
Structure and Discourse: Mapping the Networked Public Sphere in the Arab Region
}

\section{Citation}

Woolery, Liz, Ryan Budish, and Levin Bankston. "The Transparency Reporting Toolkit: Best Practices for Reporting on U.S. Government Requests for User Information." The Berkman Center for Internet \& Society, March 2016.

\section{Published Version}

http://www.arabnps.org/structure-and-discourse/

\section{Permanent link}

http://nrs.harvard.edu/urn-3:HUL.InstRepos:28552579

\section{Terms of Use}

This article was downloaded from Harvard University's DASH repository, and is made available under the terms and conditions applicable to Other Posted Material, as set forth at http:// nrs.harvard.edu/urn-3:HUL.InstRepos:dash.current.terms-of-use\#LAA

\section{Share Your Story}

The Harvard community has made this article openly available.

Please share how this access benefits you. Submit a story.

\section{Accessibility}




\title{
STRUCTURE AND DISCOURSE Mapping the Networked Public Sphere IN THE ARAB REgION
}

\author{
Robert Faris, John Kelly, Helmi Noman, Dalia Othman
}

MARCH 2016

In this study, we employ social network mapping techniques to analyze the shape and structure of the networked public sphere in the Arab region. The analysis is based on four distinct views of digitally connected communities: a regional map of the blogosphere and maps of Twitter networks in three countries: Egypt, Tunisia, and Bahrain. This media ecology mapping across these different platforms and regions offers a detailed view of social, cultural, religious, and political expression through digital media. We observe that the networked public sphere in the Arab region is much different than it was five years ago. With the decline in the blogosphere, Twitter and Facebook now host a large portion of the Arab networked public sphere. By all indications, the networked public sphere is more contentious, more highly polarized, and less conducive to broadly inclusive social mobilization. In Egypt, we see polarized debates on Twitter that divide politically active users into three distinct and largely disconnected groups. In Bahrain, the antagonism between the government and opposition is manifest in a bipolar network structure on Twitter, and the debate is framed in sectarian language that appears intent on deepening the political divide. In comparison, the Twitter network in Tunisia appears to be much more integrated and the discourse between political opponents less hostile, despite the political rivalries there. In each of these countries, the networked public sphere continues to offer a venue for civil society and individual voices that is less restrictive than traditional media. While pro-government actors are now more active in digital spaces compared to several years earlier, the discourse in Egypt, Bahrain, and Tunisia is still tilted towards those that support freedom of speech, civil liberties, and political reform. 


\section{ACKNOWLEDGEMENTS}

The authors gratefully acknowledge the help and support of the many people who contributed to this research. Yochai Benkler provided invaluable guidance and feedback throughout the course of this research. Bruce Etling helped in the development and framing of this research project from the first day and contributed to the research effort over the course of the project. Rebekah Heacock Jones contributed to the research, offered feedback on papers, provided management support and timely insights, and expertly edited this paper. Hal Roberts devoted many hours to studying the link economy in Egypt, helped to shape the research agenda, and along with the Media Cloud technical team, developed an Arabic instance of Media Cloud. Muira McCammon and Jenny Shore contributed excellent research assistance, helped to draft portions of the paper, and conducted analysis of the maps and Twitter feeds. Special thanks to Nadine Weheba, Lina Attalah, and the entire team at the Access to Knowledge for Development Center at the American University in Cairo for their support, advice, and comments, and particularly to Dr. Nagla Rizk for her leadership on this project. We are particularly grateful for the advice and support from our collaborators in Tunisia: Jazem Halioui, Escander Nagazi, and Fares Mabrouk. And abundant thanks to the staff of the Berkman Center for their generous support and limitless patience.

The data and maps used in this paper are courtesy of Graphika, Inc. 


\section{TABLE OF CONTENTS}

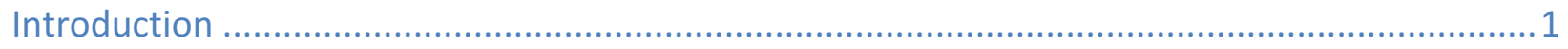

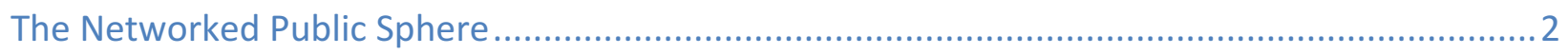

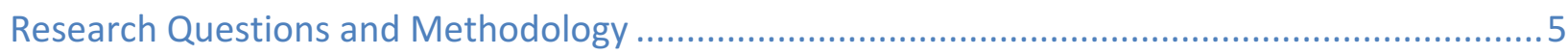

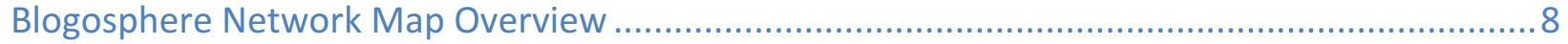

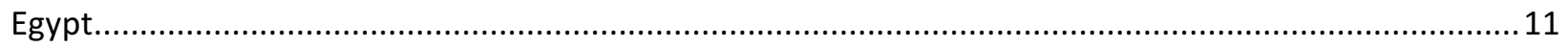

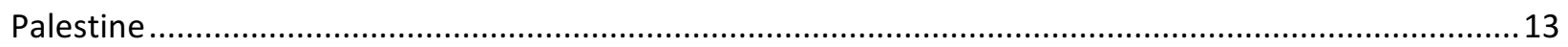

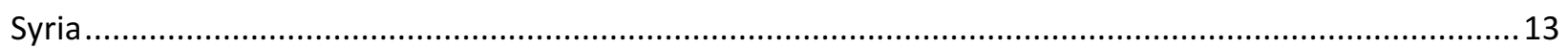

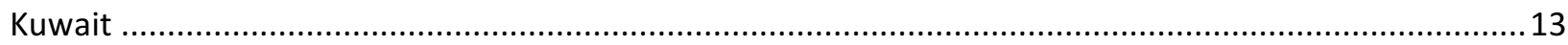

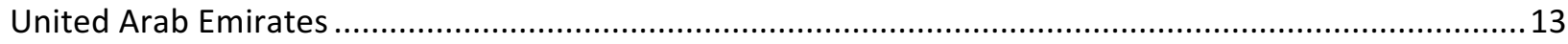

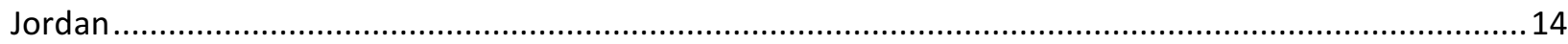

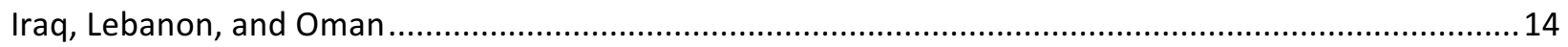

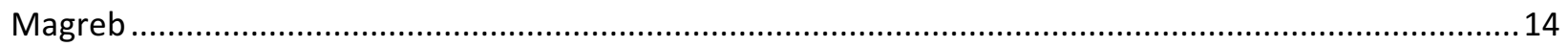

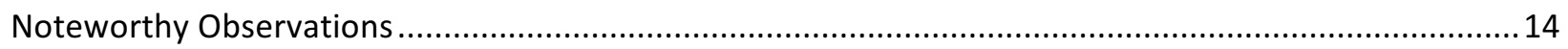

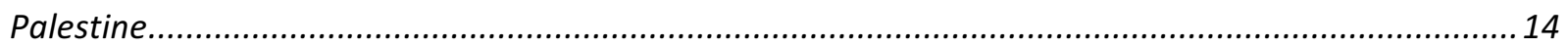

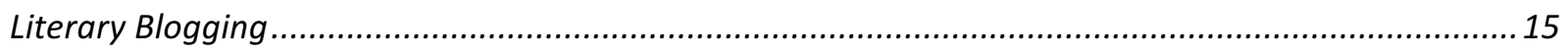

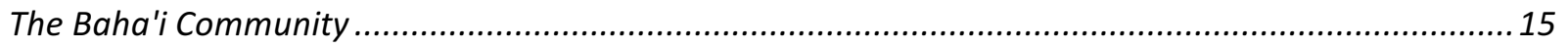

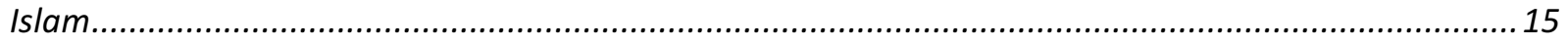

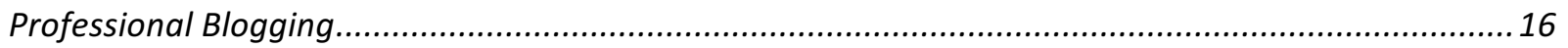

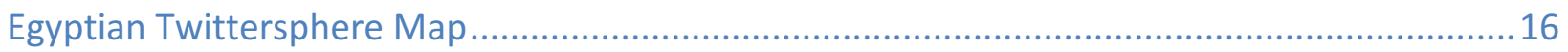

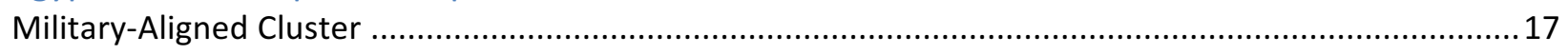

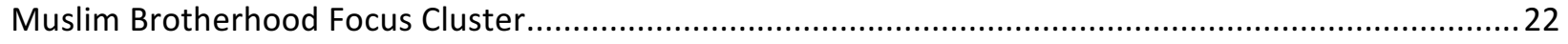

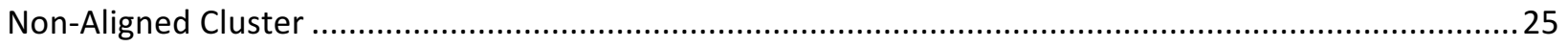

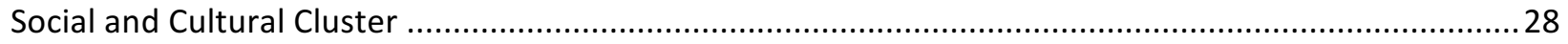

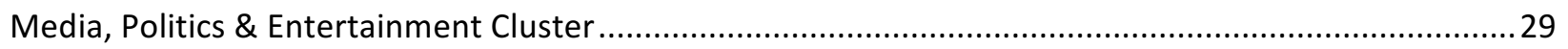

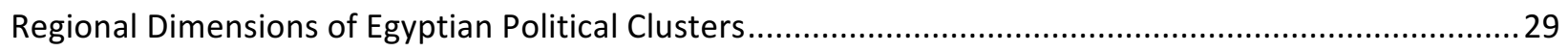

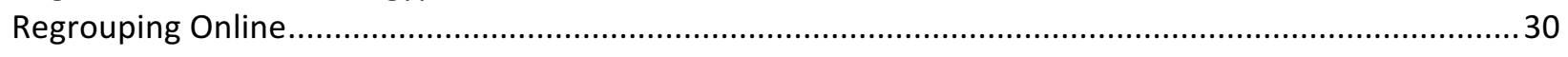

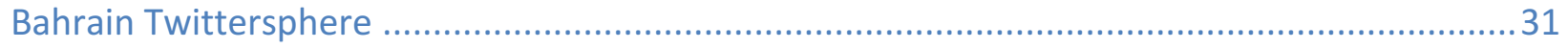

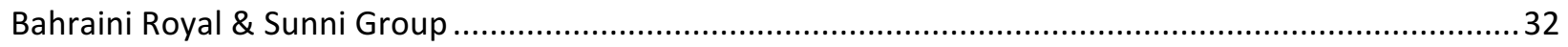

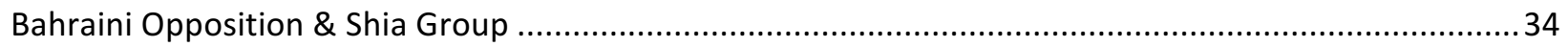

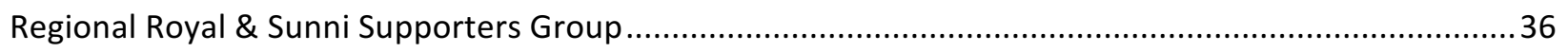

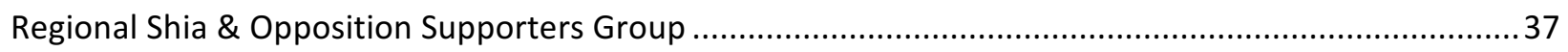

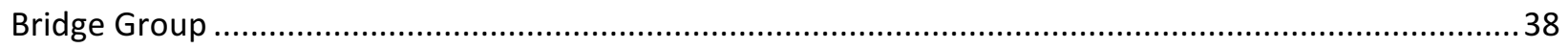

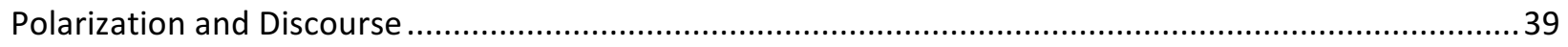

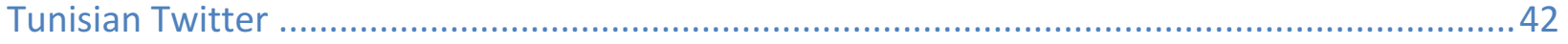

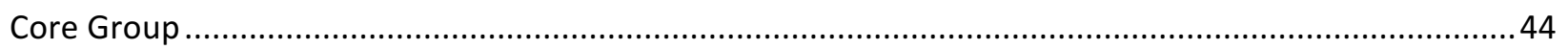

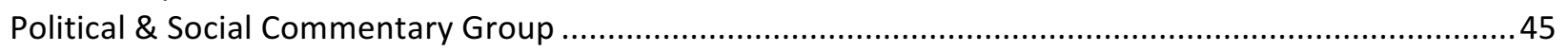

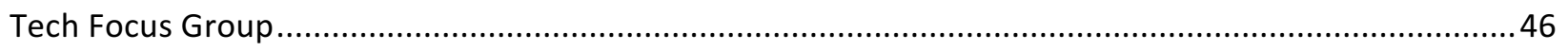

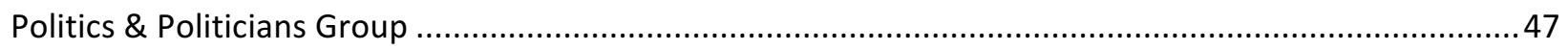

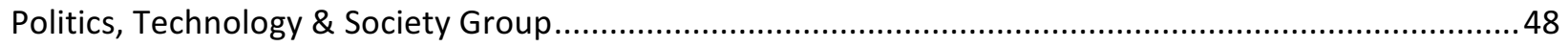

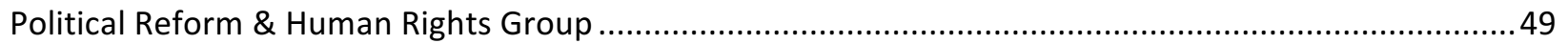

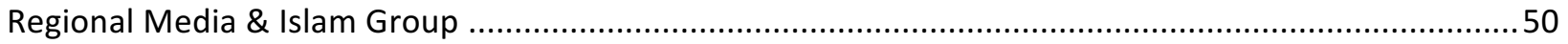

\begin{tabular}{lll}
\hline$(\mathrm{cc}) \mathrm{EY}$ & ARABNPS.ORG \\
&
\end{tabular} 


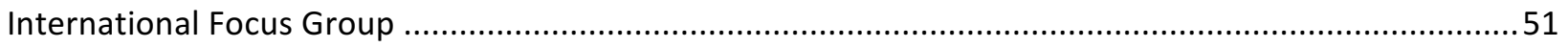

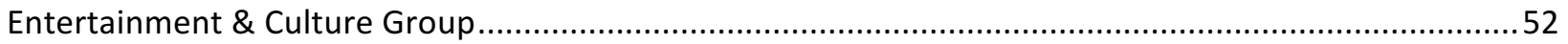

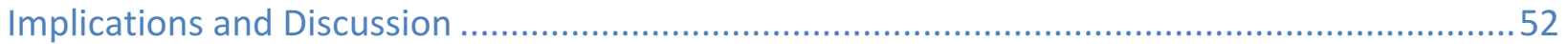

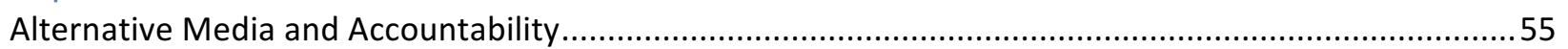

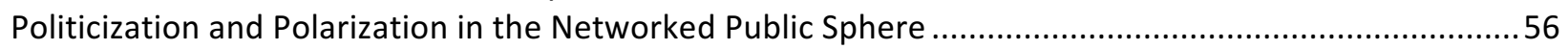

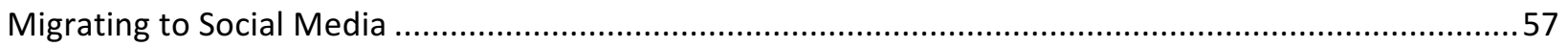




\section{INTRODUCTION}

Several years have passed since a wave of protests swept through the Middle East and North Africa. The ramifications of these events are still being felt across the region. The central role of civil society activists and citizens in the protest movements and their adept use of digital technologies have prompted many questions for researchers and political observers. These events invigorated the debate over the impact of technology on social and political processes. Did the adoption of digital communication tools accelerate the processes of change and expand the scale of the protests? Have these tools shifted the balance of power in favor of civil society activists and organizations?

In this study, we employ social network mapping techniques to analyze the shape and structure of the networked public sphere in the Arab region. We generate and analyze four distinct views of the communities that emerge in the digital sphere: a map of the blogosphere across the region and maps of Twitter networks in three countries: Egypt, Tunisia, and Bahrain.

This media ecology mapping across these different platforms and regions offers a view of social, cultural, religious, and political expression through digital media. Compared to topically focused studies, this mapping offers a systematic approach to understanding the new media landscape at a broad scale and the set of issues and interests that engender discussion and debate in the networked public sphere. This analysis not only offers a perspective on the issues that command attention in the region but also provides a view of the structures and communities that form around different topics in addition to social, religious, and political affiliations. By combining these several approaches into one study, we are able to compare activity and community between different platforms, across different regions, and over time.

Participation in the blogosphere has declined over the past several years, coinciding with an increase in activity on social media, primarily on Facebook and Twitter. Political activity has shifted notably away from the blogosphere to social media. The focus of attention has shifted somewhat as well. Compared to a 2009 blogosphere study, less is written about Palestine, and comparatively more about Syria. It appears that more attention is on domestic issues and less on pan-Arab issues and causes, although militancy and foreign wars are a central focus for some groups.

The networked public sphere in the Arab region is much different than it was five years ago. These differences extend beyond the shift to new platforms - Twitter and Facebook now host a large portion of the Arab networked public sphere-and include profound changes in the political orientation and profile of individuals that participate, as well as shifts in the culture and degree of contention. Many of the early adopters of digital technologies who played a central role in the emergence of the Arab networked public sphere, a substantial portion of whom argued for political change and progressive causes, are still present. The entry of late adopters of social media has served to diversify the networks and level the playing field. The early adopters are now confronted with a wider range of competing voices and opinions, many of whom represent state and state-aligned perspectives. The reform voices now constitute a smaller portion of the overall online discourse and are met with greater opposition online from government and those 
from civil society with opposing views. By all indications, the networked public sphere is more contentious, more highly polarized, and less conducive to broadly inclusive social mobilization.

In Egypt, we see highly polarized debates on Twitter that divide politically active users into three distinct and largely disconnected poles. When they do interact, the discourse is often hostile and defined by sharply conflicting visions over the political future of Egypt. In Bahrain, the antagonism between the government and opposition is manifest in a bipolar network structure on Twitter, and the debate is framed in sectarian language that appears intent on deepening the political divide. In comparison, the Twitter network in Tunisia appears to be much more integrated and the discourse between political opponents less hostile, despite the intense political rivalries there. The Tunisian Twittersphere is better integrated across the different political coalitions and the network does not show the same level of partisanship. The differences in the structure of digital networks and the varying levels of polarization in Egypt, Bahrain, and Tunisia are clearly evident in the network maps, which are described in detail later in this paper.

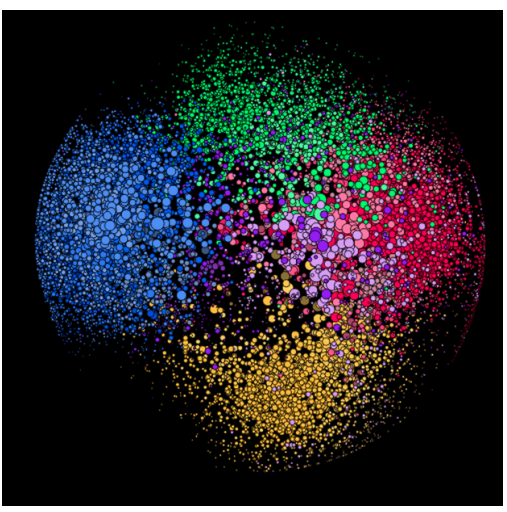

Egypt Twitter Map

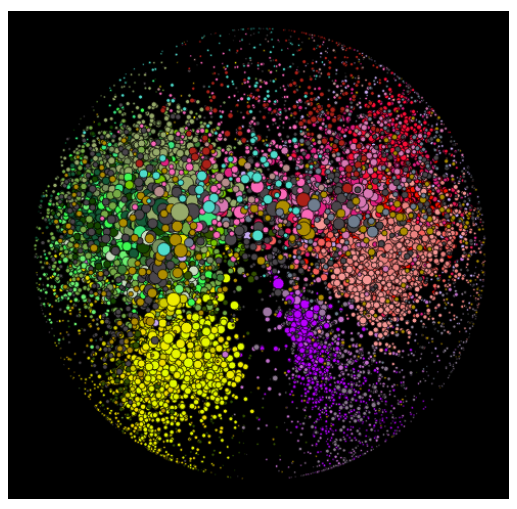

Bahrain Twitter Map

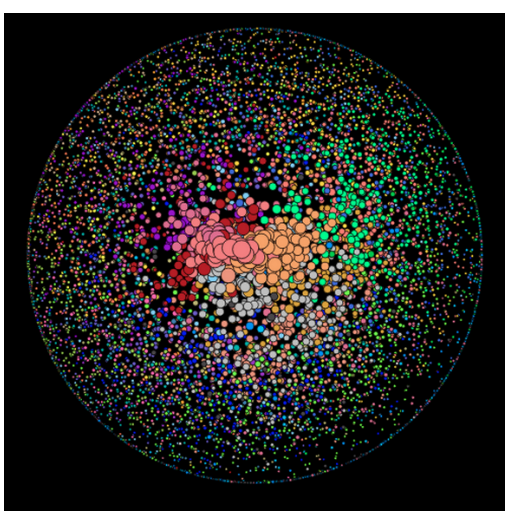

Tunisia Twitter map

Despite the growing presence of communities in the networked public sphere that support the traditional seats of power in the region, we see that the digital sphere still offers an important outlet for non-traditional voices. Among the most followed accounts in each of the three Twitter networks are users who would not be able to gain prominence and reach in national media networks. These include political activists, opposition leaders, reformers, and human rights advocates.

\section{The Networked Public Sphere}

The focus of this study is on the networked public sphere and its role in facilitating social mobilization and the formation of social capital. The networked public sphere, as described by Benkler, forms an alternative arena for public discussions and political discourse that is less dominated by large media entities, is more open to broad participation, and is less subject to government control. This digitally mediated alternative public sphere may feature an agenda that differs in scope and emphasis from government media sources and larger media outlets that are subject to government controls and more highly influenced by traditional sources of economic and social power. Benkler also points to the changes in the mode of media production made possible by digital networks including the emergence of non-market peer-produced structures that rival traditional commercially based media entities. 
Early scholarship in this area included optimistic views of the impact on digital technologies on knowledge production and sharing. Negroponte offered one such optimistic view, asserting that individually tailored media (the "Daily Me") would help citizens to become better informed. ${ }^{1}$ Benkler asserted that the digitally enabled commons would assist in information production and diminish the influence of the state and traditional media in shaping public discourse, ${ }^{2}$ and that decentralized peer production would increase participation and expand the diversity of views. ${ }^{3}$ Others offered more skeptical views. Sunstein argued that the ability to more easily shape one's media diet would lead to fragmentation and polarization, which would erode public discourse. ${ }^{4}$

Many scholars that looked at digital media systems, however, found concentration rather than fragmentation. Linking patterns on the Web tend to follow a power law distribution characterized by a small number of media sources receiving a majority of the attention. ${ }^{5}$ This suggested that while it was getting easier to publish materials available to a wide audience, few of these materials were being noticed. ${ }^{6}$ Benkler posited that broader participation in public debates would still take place, as ideas would propagate through the networked public sphere and less prominent voices with novel perspectives could be amplified and made more visible through linking behavior. ${ }^{7}$ Similarly, Drezner and Farrell claimed that political bloggers who were read by incumbent media could indirectly influence public debates. ${ }^{8}$

The often-cited Adamic and Glance study of partisan linking in the United States political blogosphere offered support for Sunstein's vision of increasing polarization. ${ }^{9}$ Their study found that only one in six links among liberal and conservative bloggers crossed the partisan divide. Benkler questioned whether this was evidence of growing polarization or simply a normal expression of homophily. ${ }^{10}$ Hargittai, Gallo, and Kane demonstrated that many of the links across the aisle were based in substantive debate. ${ }^{11}$ They also found that the blogosphere showed no signs of growing polarization over time. Gentzkow and Shapiro similarly countered arguments over Internet-facilitated polarization with evidence that individuals are exposed to a

\footnotetext{
${ }^{1}$ Negroponte, N. (1995). Being digital. New York: Vintage Books.

${ }^{2}$ Benkler, Y. (1998b). The Commons as a Neglected Factor of Information Policy. $26^{\text {th }}$ Annual

Telecommunications Policy Research Conference. Alexandria, VA September 1998. See also: Benkler, Y. (1999).

Free as the air to common use: First amendment constraints on enclosure of the public domain. New York University Law Review, 74, 354-446.

${ }^{3}$ Benkler, Y. (2000). From Consumers to Users: Shifting the deeper structures of regulation towards sustainable commons and user access. Federal Communications Law Journal, 52, 561-579.

${ }^{4}$ Sunstein, C. (2001). Republic.com. Princeton, NJ: Princeton University Press.

${ }^{5}$ Barabási, A.-L. \& Albert, R. (1999). Emergence of scaling in random networks. Science, 286, 509-512. See also: Shirky, C. (2003, February 10). Power laws, weblogs, and inequality. Retrieved from http://www.shirky.com/writings/powerlaw_weblog.html.

${ }^{6}$ Hindman, M. (2008). The Myth of Digital Democracy. Princeton, NJ: Princeton University Press.

${ }^{7}$ Benkler, Y. (2006). The wealth of networks: How social production transforms markets and freedom. New Haven, CT: Yale University Press.

${ }^{8}$ Drezner, D. \& Farrell, H. The power and politics of blogs. Public Choice, 134, 15-30.

${ }^{9}$ Adamic, L. and Glance, N. (2005). The political blogosphere and the 2004 US election: Divided they blog. In Proceedings of the 3rd International Workshop on Link Discovery. Chiba, Japan: ACM Press.

${ }^{10}$ Benkler, 2006.

${ }^{11}$ Hargittai, E., Gallo, J., \& Kane, M. (2008). Cross-ideological discussions among conservative and liberal bloggers. Public Choice, 134, 67-86.
} 
wider range of viewpoints on the Internet compared to through offline interactions and media exposure. $^{12}$

A distinct but related focus of inquiry looks at the role of digital technologies in fostering civic engagement, social mobilization, and political participation. Bimber, Flanagin, and Stohl describe the development of organizations that are structured in more distributed ways and that offer greater latitude for individual participation. ${ }^{13}$ They posit the emergence of alternatives organizational models that are based less in hierarchical structures and that allow for greater individual agency and distributed collective action. Shirky similarly articulates the diminishing role of traditional organizations as parts of their functional roles are replaced by digitally mediated collective action in what he calls "organizing without organizations." 14 Bennett and Segerberg highlight the heightened role of personal communication in new organizational models. ${ }^{15}$ They emphasize the difference between the "logic of collective action associated with high levels of organizational resources and the formation of collective identities, and the less familiar logic of connective action based on personalized content sharing across media networks."

Farrell points to three key mechanisms that affect the role of the Internet and politics. ${ }^{16}$ First, echoing Bimber and others, the declining costs for organizing collective action enable new opportunities for social mobilization. Second, the ability to more easily locate and communicate with like-minded individuals online facilitates homophilous sorting - the tendency for individuals with common interests to form communities. The third factor is that the Internet might offer a safer arena for individuals to express their true political views.

The work of Mutz brings into question whether deliberation and civil engagement are compatible. She notes that those who are exposed to and more tolerant of opposing views are less politically active. ${ }^{17}$ Lawrence, Sides, and Farrell observe that blog readers tend to be more active in politics but that the most polarized are also the politically engaged. ${ }^{18}$

The use of digital tools by activists and organizers during protest movements over the past several years in countries around the world has garnered much attention and controversy. Activists in a growing number of countries (e.g. Ukraine, Moldova, Iran, Egypt, Tunisia, and Spain, among others) have integrated the use of digital tools into their playbook. While some popular accounts have lauded the advent of such "Twitter revolutions," more careful accounts reject explanations that drift towards technological determinism. Although the introduction of

\footnotetext{
${ }^{12}$ Gentzkow, M. \& Shapiro, J. (2011). Ideological segregation online and offline. The Quarterly Journal of Economics, 126, 1799-839.

${ }^{13}$ Bimber, B., Flanagin, A., \& Stohl, C. (2012). Collective action in organizations: Interaction and engagement in an era of technological change. Cambridge, UK: Cambridge University Press.

${ }^{14}$ Shirky, C. (2008). Here comes everybody: The power of organizing without organizations. New York: Penguin Books.

${ }^{15}$ W. Lance Bennett \& Alexandra Segerberg (2012): The Logic of Connective Action, Information, Communication \& Society, 15:5, 739-768

${ }^{16}$ Farrell, H. (2012). The consequences of the Internet for politics. Annual Review of Political Science, 15, 35-52.

${ }^{17}$ Diana Mutz. (2206) Hearing the Other Side: Deliberative versus Participatory Democracy. Cambridge University Press.

${ }^{18}$ Lawrence, E., Sides, J., \& Farrell, H. (2010). Self-segregation or deliberation? Blog readership, participation, and polarization in American politics. Perspectives on Politics, 8(1), 141-157.
} 
digital tools might alter the balance power in interesting ways, the ultimate successes and limitations of social movements are still a question of human agency. Several studies have looked at the role of digital tools in the protest movements in the Arab region starting in 2011 and concluded that these technologies played a significant role in building networks, organizing protests, and providing an alternative source of reporting of activities on the ground (e.g. Howard \& Hussain, 2011; Tufekci \& Wilson, 2012; Beuer, 2012; Khondker, 2011; Khamis \& Vaughn, 2011; Lynch, 2011). ${ }^{19}$ Other studies that have focused on the Indignados movement in Spain and Occupy Wall Street have come to similar conclusions (e.g. see Pickerill \& Krinsky, 2012). ${ }^{20}$

Some are skeptical about the role of digital technologies in social mobilization and political change. One criticism is that online organizing does not build the stable relationships and ties necessary for maintaining social movements. ${ }^{21}$ And while the most wildly optimistic views of the potential for digitally mediated collective action have predicted the eventual end of authoritarian rule, more measured accounts have pointed out the efforts of governments to rein in freedom of expression online and online activism. ${ }^{22}$ Governments have implemented a broad range of strategies to shape online discourse, including Internet filtering, content removal, cyberattacks, surveillance, restrictive legal environments, extra-legal threats, and pro-government information campaigns. The impact of some of these restrictions are well understood, for example the content blocked by Internet filters by the several dozen countries that implement systematic national filtering policies. ${ }^{23}$ The impact of strategies designed to induce self censorship are more difficult to measure and are not well documented.

\section{Research Questions and Methodology}

We explore in this research the structure of Arabic blogosphere and Twittersphere and the nature of participation in online life. We also examine the content and substance of online discourse in the two spheres, and try to understand the shape and makeup of communities within the context of overall civic engagement. Specifically, we raise the following two research questions:

- What is the structure of the networked public sphere, and how do different segments and platforms interact?

- What content and topics are introduced and disseminated in the networked public sphere?

The analysis in this report is based on a mixed methods research protocol that includes qualitative content analysis supported and guided by algorithmically drawn network maps and a diverse set of quantitative metrics calculated for each of the clusters in the network. This

\footnotetext{
${ }^{19}$ Howard, P. \& Hussain, M. (2011). The upheavals in Egypt and Tunisia: The role of digital media. Journal of Democracy, 22, 35-48. See also: Tufekci, Z. \& Wilson, C. (2012). Social media and the decision to participate in collective action: Observations from Tahrir Square. Journal of Communication, 62, 363-379.

${ }^{20}$ Pickerill, J. \& Krinsky, J. (Eds.). (2012). Occupy! (special issue). Social Movement Studies: Journal of Social, Cultural and Political Protest, 11(3-4).

${ }^{21}$ Van Laer, J. \& Van Aelst, P. (2010). Internet and social movement action repertoires: Opportunities and limitations. Information, Communication \& Society, 13, 1146-1171.

${ }^{22}$ Shanthi Kalathil, Taylor C. Boas (2003) Open Networks, Closed Regimes: The Impact of the Internet on Authoritarian Rule.Carnegie Endowment for International Peace.

${ }^{23}$ See, for example, the research conducted by the OpenNet Initiative: www.opennet.net
} 
methodological approach to this study follows similar efforts in the past to map online networks that correspond to particular geographic areas. ${ }^{24}$

A principal objective of this study is to describe accurately the activity on these different networks and to compare the structures that emerge and the issues that inspire participation and debate. To help make order of this rich, complex, and diverse media landscape, we employ social network mapping techniques to generate network maps. The first step is to generate a network map based on the relationships between users. The Twitter maps are based on the follows relationships between users. The basis of the blogosphere map is the links between blogs. The network structure is visualized using a physics model layout algorithm (FruchtermanRheingold), overlaid with colors representing each account's assignment to a group based on a clustering of network relationships. The resulting network map and structures that emerge reflect the individual decisions of bloggers and Twitter users to follow or link to other users, and the work of the clustering algorithm that transform these relationships into a set of individual groups or segments. Qualitative human judgment is subsequently used to interpret the results, but the generation of the maps is based primarily on algorithms that translate the relationships between the accounts into a network structure.

The process of generating network maps started in the Spring 2013. Each of the maps are based on data collection which occurred over a three-month period: October through December 2013 for the map of the blogosphere, February through April 2014 for the Egypt Twitter map, January through March 2014 for the Bahrain Twitter map, and April through June 2015 for the Tunisia Twitter map. The subsequent review and analysis of accounts that make up these maps took place over a period of 20 months, from January 2014 to August 2015.

The location of nodes on the map is based on observable decisions of individuals to link to others. These follow and linking choices tend to reflect longer term stable relationships. Drawing maps based on mentions and retweets would produce maps based in larger part on shorter term interests and influenced more by the content of tweets within the period in which data is collected.

In the visualization, the size of each node reflects the number of inlinks or follows from within the network to that account. The location of each node relative to the others is based on the collective decisions of all of the nodes in the network; each decision by a user in the network to follow another Twitter user or link to another blog is factored into the creation of the map. ${ }^{25}$ The algorithm applies an outward force on all nodes in the network that pushes the nodes away from each other. A countervailing force is applied to accounts that are linked by a follow or linking relationships that pulls them back together as though by a spring or force of gravity. In this way, densely interconnected network neighborhoods are created in the maps that serve as a picture of the pattern of influence and information flow in the network. In a second process, a clustering

\footnotetext{
${ }^{24}$ Etling, B., Kelly, J., Faris, R., \& Palfrey, J. (2010). Mapping the Arabic Blogosphere: Politics and Dissent Online. New Media \& Society 12 (8), 1225-1243. John Kelly, Vlad Barash, Karina Alexanyan, Bruce Etling, Robert Faris, Urs Gasser, John Palfrey. 2012. Mapping Russian Twitter. Berkman Center Research Publication.

${ }^{25}$ The automated system cannot distinguish "friendly" links - those in which a user would endorse or recommend to others the views of the other account they choose to follow-from links to those that hold opposing views and are chosen to receive news and updates on their activities. In networks where a majority of links are directed towards similar-minded users, the links to opposing views do not impede the emergence of affinity-based clusters.
} 
algorithm assigns each node in the map to a particular cluster; the cluster assignments are shown by the different colors in the maps. These clusters are based on outward facing attention so that each cluster is populated by nodes with a common outlook. For the Twitter maps, this is informed by the accounts that they follow, mention, retweet, and reply to, and the URLs they include in tweets. In the blogosphere map, the attention-based clusters are shaped by outlinks to other blogs and other web resources such as digital media sources and videos.

A variety of metrics are calculated to help researchers understand and describe the contours and structures of the map. These metrics provide a quantitative measure of which activities occur proportionately more often in each cluster compared to the others. For the Twitter maps, this includes:

- Twitter accounts followed

- Twitter accounts mentioned, retweeted and replied to within a timeframe

- URLs cited in tweets and hashtags

- Words used, including bigrams and trigrams (pairs and triples of words that co-occur)

- Countries, cities, and other locations mentioned in user profiles

In mapping the blogosphere, researchers have access to the links to other blogs, the URLs that are cited in blog posts, and the frequency of words that appear in blog posts.

Researchers apply labels to each of the clusters based on a review of this data. These labels are not meant to categorize each account within a given cluster but rather offer concise shorthand descriptions for the various clusters. Each of the accounts within each of the clusters offers a unique perspective. For many of the accounts within a cluster, the cluster label offers a good summary of the primary focus and general orientation of the account; for other accounts, the cluster label does not strongly capture the interests and views of the user.

A multistage process is used to determine which accounts are included in the maps. This same process applies to the creation of blog and Twitter maps. The mapping starts with a seed set of accounts compiled by researchers. ${ }^{26}$ This set is expanded by adding all of the followers of the seeds, and then reduced by removing all accounts with no activity over the prior 90 days. Accounts with fewer than a 100 followers are removed next. The network of connections between these accounts is analyzed, and a k-core analysis is used to find the most connected accounts. The k-core analysis sets a threshold number of connections - the " $\mathrm{k}$ " in $\mathrm{k}$-core-and removes any nodes that fall below this threshold. Inclusion in the network is based on three main criteria: the accounts must be active; accounts must meet a minimum threshold of links with others accounts in the network, whether following or followed by other accounts; and accounts must have at least one follower from within the network. The final maps, which include several thousand nodes, therefore include all the accounts that receive a minimum threshold of attention from the network and remove the accounts with relatively fewer followers in the network. This

\footnotetext{
${ }^{26}$ The seed sets, typically 100 or more accounts, are hand-curated lists of Twitter accounts and blogs. The accounts that are collected are restricted to those that are easily recognized as part of the targeted country or community. The lists are based in part on the domain-specific knowledge of experts and users embedded in the community of users, in part on following links from a starting set, and in part on web searches for relevant accounts. Each seed set includes accounts representative of the political, social, and cultural issues in the country.
} 
produces maps that are both rich in detail and resolution while being of a tractable size for quantitative and qualitative analysis. Removing the peripheral and less prominent accounts reduces somewhat the range of views and ideas represented in the maps, leaving the accounts and clusters that are more squarely in the public view. This is consistent with our focus of attention on the networked public sphere, the major clusters in the network and topics of frequent discussion.

\section{Blogosphere Network Map OVerview}

The analysis of the Arab blogosphere and Twitter in the region are based on a similar set of methods, tools, and protocols with a few key differences. This blogosphere map encompasses the region as a whole rather than the individual country Twitter analyses. This allows us to compare the state of the blogosphere to a 2009 study using the same scope and methods. The other key difference is that the relationships between blogs are based on links rather the follows, mentions, and retweets particular to Twitter. At a conceptual level, the mixed-methods approach we employ to understand activity on Twitter and blogs are the same; social network tools are used to identify and cluster topical communities based on linking behavior of users, and these maps are used as a framework for researchers to explore and describe the content and topical coverage of clusters.

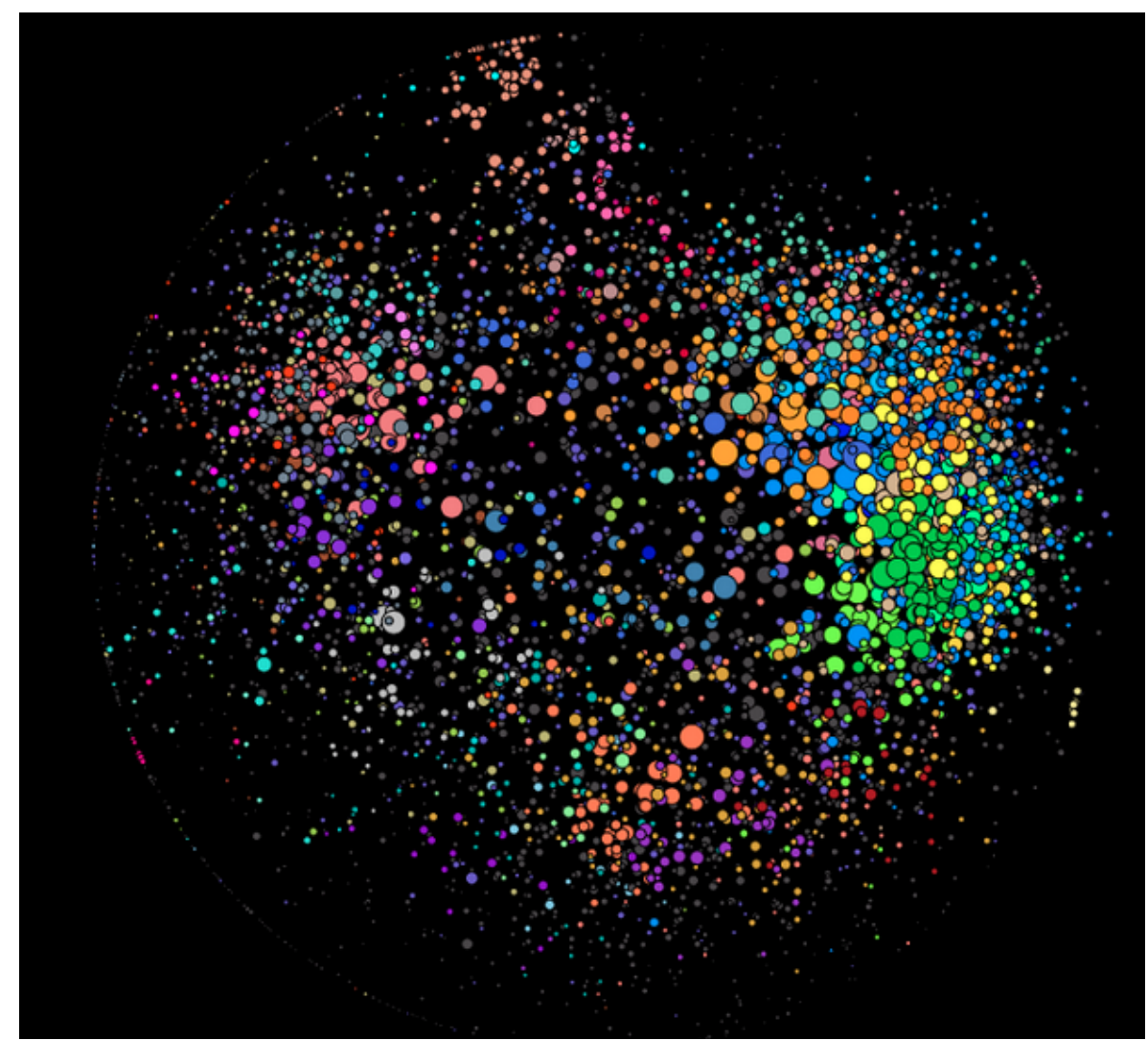

Figure 1: Arab Blogosphere Map 2014

Bloggers use the digital sphere to communicate and offer commentary on a wide variety of topics, including personal matters, public debates, politics, religion, and social issues. In this 
study, we see that the Arab blogosphere still serves as a platform for civic discourse, but there are indications that the blogosphere is declining in size and activity as users adopt social media and microblogging. Activists are increasingly shifting to these new digital tools to expand their influence. The diminution of the blogosphere is not peculiar to the Arab cyberspace. Researchers have found that the size and activity of the Persian blogosphere has also faded since $2009 .^{27}$

The decline of the blogosphere is manifest in several ways. First, fewer countries are now represented in the map. Saudi Arabia, a country that appeared as the second largest network in the 2009 study, no longer has a visible presence in the Arab blogosphere. Much of online discussion and network formation this activity appears to now take place on Twitter, which hosts a vibrant, rich, and dynamic network of Saudi users. ${ }^{28}$ Another manifestation is the decline in overall activity in the blogosphere. Many bloggers have abruptly stopped blogging without leaving final notes. Some blogs have been inactive since 2009, and some blogs have been removed for unknown reasons. Signs of traditional blogging fatigue emerge across the entire Arab blogosphere, but it is more pervasive in some clusters than others.

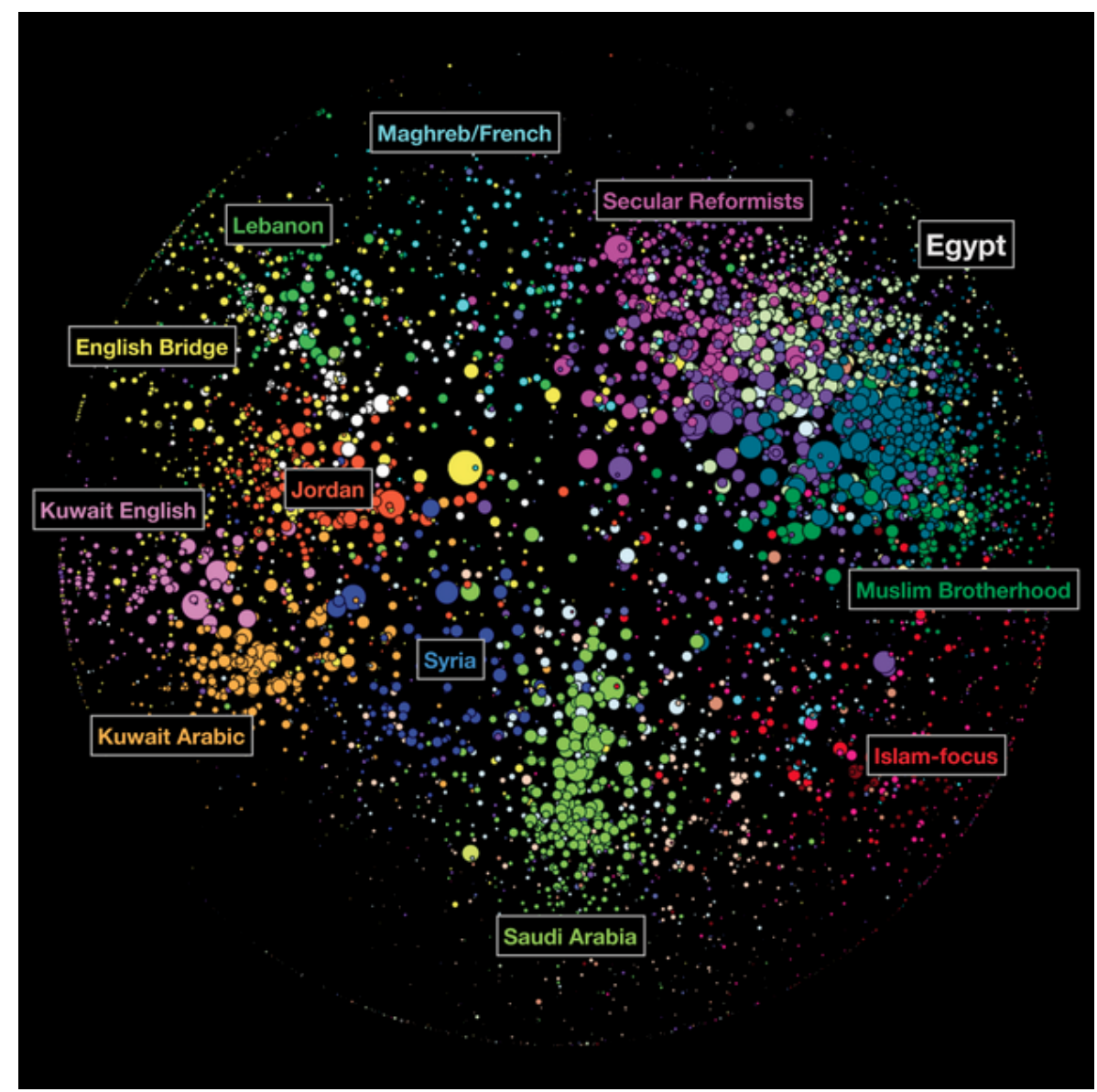

Figure 2: Arab Blogosphere Map 2009

\footnotetext{
${ }^{27}$ Giacobino, L., Abadpour, A., Anderson, C., Petrossian F., and Nellemann, C., "Whither Blogestan: Evaluating Shifts in Persian Cyberspace," March 2014, http://www.iranmediaresearch.org/en/research/download/1607.

${ }^{28}$ Noman, Helmi and Faris, Robert and Kelly, John, "Openness and Restraint: Structure, Discourse, and Contention in Saudi Twitter" (December 2015). Berkman Center Research Publication No. 2015-16. Available at SSRN: http://ssrn.com/abstract=2700944 or http://dx.doi.org/10.2139/ssrn.2700944.
} 
In the 2009 Arab blogosphere study, political discourse in Egypt coalesced into three active clusters (Secular Reformist, Wider Opposition, and Muslim Brotherhood). The Egyptian political blogosphere in 2014 is concentrated in two clusters (Egypt Political Left-Leaning and Muslim Brotherhood). Both are comprised of significantly fewer blogs, and the level of activity has fallen steeply over the past several years. The Left-Leaning cluster is relatively more active than the Muslim Brotherhood cluster, although only a fraction of the blogs have been updated in 2014. A majority of the Muslim Brotherhood blogs were last updated in the period of 20102012. A new cluster of Egyptian educators emerged that was not visible in the 2009 map and is unique to Egypt. The blogs in the cluster are run by educators and teachers from different districts across Egypt. They actively blog about the education sector in the country and voice their frustrations with the educational system and their support for the work being done to improved conditions.

In addition to the disappearance of Saudi Arabian clusters from the map, the shape and composition of other Gulf communities in the blogosphere has also changed. The Kuwaiti cluster remains and continues to be generally active but at a diminished level. Oman, which did not appear as a separate cluster in 2009, is now represented on the map by bloggers who write about a variety of issues that include political, social, and literary commentary.

Another community that has visibly shrunk is the Islam-related cluster. The 2009 map contained significantly more clusters focusing on religion and people's faith in Islam. These blogs were found in stand-alone clusters and embedded in various nation communities. In 2014, many of these communities are no longer as visible or active. Activity in 2014 is reduced to one Islamfocused cluster populated by scholars and clerics from several different countries providing information and research on Islam, especially associated with the Sunni sect. Another cluster populated by bloggers commenting on personal and social issues often from an Islamic perspective.

A clear shift in the topical focus of the blogosphere is the redirection of attention away from the Palestinian conflict to more domestic political and social issues. The 2009 report found that many bloggers would refer to the conflict in Palestine in some manner. Both the uprisings across the Arab world and the general inactivity of many of the bloggers has limited the focus on this conflict, which has featured prominently on the media landscape for decades.

In 2014, we see the adoption of new platforms and a growing array of blog hosting platforms. In 2009, embedding YouTube videos on blogs was seen as a novel approach. In 2014, the use of Tumblr and the shift of bloggers to social media has become the norm, with some bloggers highlighting their social media accounts on their blogs. A distinct cluster, not tied to any country, is comprised of Tumblr users. With the exception of this cluster, the majority of bloggers choose Blogger as their platform, while WordPress is used by a minority of bloggers. Notably, many Islamic scholars and bloggers in the English-speaking Kuwaiti social cluster choose to self-host their sites instead of having them hosted on blogging platforms. 


\section{EGYPT}

Egypt, the most populous Arab country, comprises the largest portion of Arab language blogosphere. The two Egyptian clusters in the map that focus on political issues represent strong and distinct ideologies: Egypt Muslim Brotherhood and Egypt Political Left-Leaning. The Muslim Brotherhood cluster is populated by group members who openly show their affiliation either by displaying the group's banners on their blogs or through opinionated commentary. Many display banners saying "proud to be a member of Ikhwan" or "I am Ikhwan." ${ }^{29}$ The discourse centers on political and social issues in Egypt and offers the group's perspectives and positions on various issues. The cluster however is largely inactive. Many of the blogs have not been updated since as early as 2009 . Very few show any activity in 2014 . It is noteworthy that many of the bloggers in the Muslim Brotherhood cluster, although not contributing new posts to their blogs, have updated banners with the Rabia sign, suggesting the desire to continue to voice their political ideology on their blogs despite blogging fatigue. The Rabia sign is a reference to the location in Cairo-Rabia Square-where a large sit-in took place in August 2013 to protest the removal of the Morsi-led government by the military. Thousands of people were killed or injured when the protests were dispersed by the Egyptian security forces. The Rabia sign is a symbol of solidarity with the Muslim Brotherhood and opposition to the government of President Abdel Fattah el-Sisi.

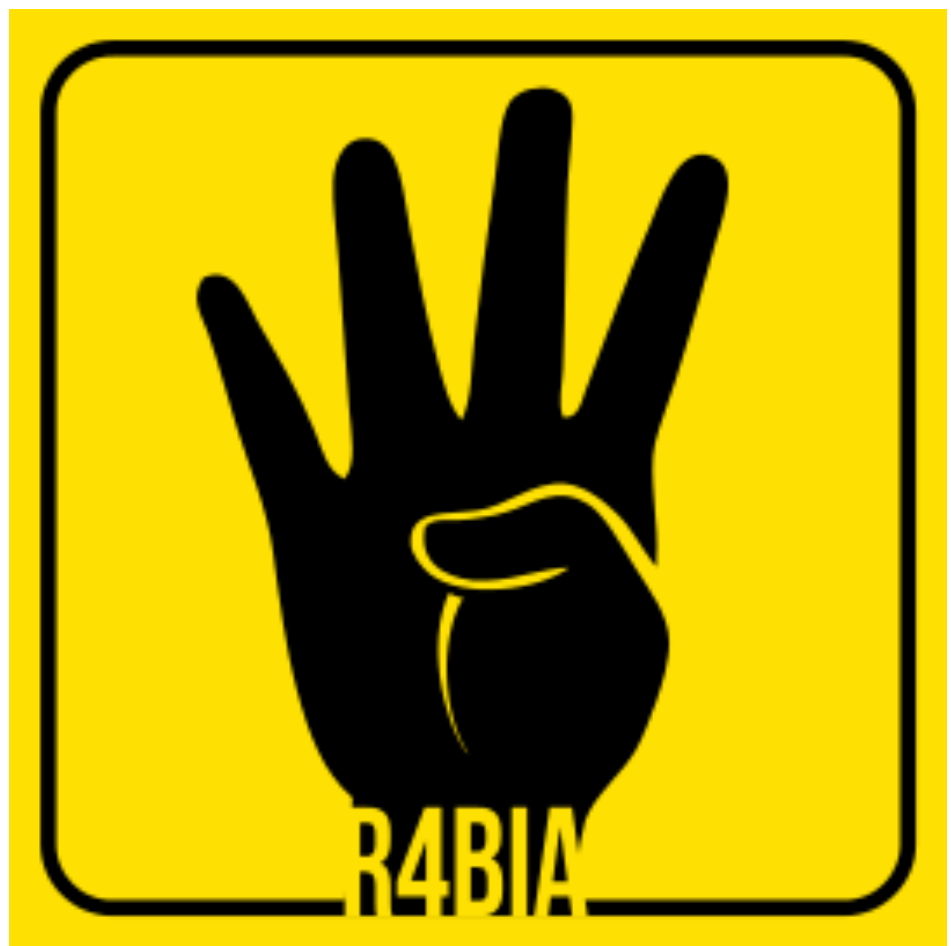

Figure 3: Rabia sign, a symbol of solidarity with the Muslim Brotherhood.

The Egypt Political Left-Leaning cluster is characterized by a mixture of progressive, reformminded, secular, and left-leaning perspectives on Egypt's political issues, including the January 25 revolution and consequent developments, political reform, human rights, and civic engagement. Many of the bloggers embrace an activist stance and discuss socio-political topics

${ }^{29}$ Ikhwan is the Arabic term for Muslim Brotherhood. 
such as sexual harassment in Egypt. With the exception of a few blogs, the cluster has been largely inactive for the past 2 years. The reflections and commentary do not represent the most recent developments in Egypt.

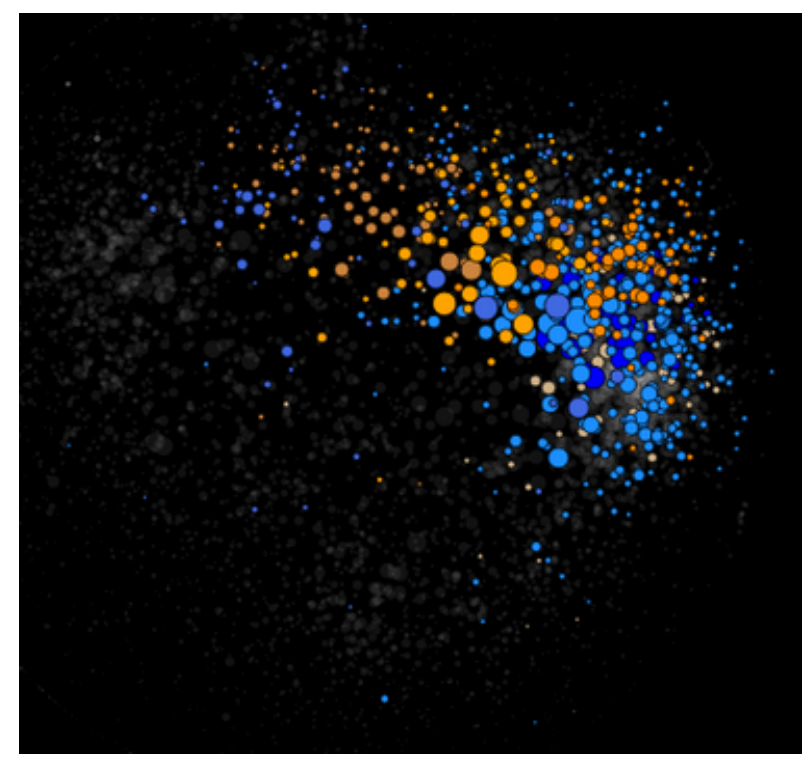

Figure 4: Egyptian Political Blogs

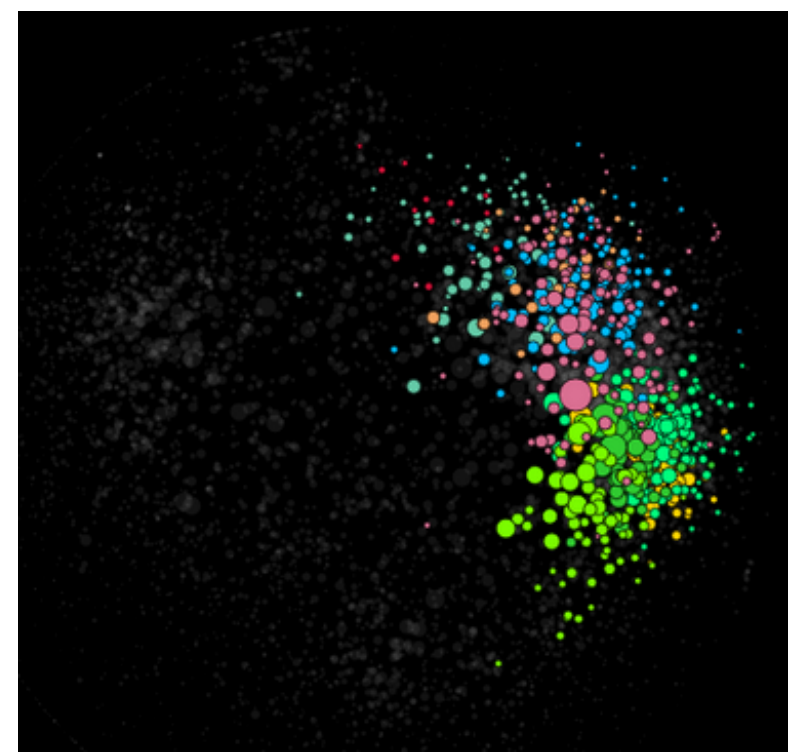

Figure 5: Egyptian Personal Diaries and Literary Blogs

We find one cluster that is devoted to a singular cause. The Egypt Education cluster is comprised of blogs that are dedicated almost entirely to discussing the education sector in Egypt and the grievances of teachers. Additional political clusters on the map do not share a common or coherent political perspective. The cluster Egypt Political \& Social is a community of bloggers commenting on Egyptian political developments as well as on social issues, but by and large, the accounts in this cluster have no strong activist or advocacy positions on any of the issues discussed. Similarly, the discourse in Egypt Political Social Religious includes political, social, and religious commentary, often with overlap between the different perspectives. Another cluster, Egypt Social, is almost entirely made up of reflections on public social life, family matters, and the intersection between personal issues and societal expectations.

Other Egyptian clusters are apolitical, with interests in diaries, literature, love and romance.

Egypt Personal Diaries \& Romance is populated mostly by individuals keeping diaries on various social issues, and who write about love and romance using prose and poetry, often with a tone of anguish. Some of the women bloggers use pseudonyms, possibly to avoid the social repercussions of discussing topics considered sensitive in conservative families. Another cluster, Egypt Personal Diaries, includes reflections on issues of daily life, personal reactions to political and social events, and commentary on entertainment news. Bloggers in the Egypt Social \& Literary cluster reflect on social life in Egypt from personal experiences and observations, while others in the same cluster showcase their literary works, or provide commentary on the work of other writers. Users in the cluster Egypt/Diaries English post diarystyle entries and write about their travels. 


\section{PALESTINE}

Two clusters are directed at Palestine: Palestine English and Palestine Arabic. The blogs in these clusters are primarily centered around the Israeli occupation, although with somewhat different focal areas. The English cluster is more concerned about the struggle for selfdetermination and the organization of campaigns to end the Israeli occupation. Campaigns in this cluster include the US Campaign to End the Israeli Occupation (endtheoccupation.org), the Palestinian Campaign for the Academic and Cultural Boycott of Israel (pacbi.org), and the Prisoner Support and Human Rights Association (addameer.org). On the other hand, the Arabic cluster more generally contains individual bloggers reflecting on life under the occupation and writing about their personal experiences in various formats including political commentary, personal diaries, poetry, and prose. Most recent posts indicate a shift in the discourse around Palestine; it is not discussed as a pan-Arab issue, but rather as local one. This is also apparent when comparing the Arab blogosphere of 2009 to the present day blogosphere. The Palestinian conflict is no longer a common topic of discussion in the Jordanian, Lebanese, and Syrian clusters of the 2014 blogosphere as it was in 2009.

\section{SYRIA}

Syria is the theme of two clusters in the 2014 blogosphere map. Syria Pro-Revolution features Syrian bloggers in support of the revolution against the Syrian regime. The discussion also covers the division among the opposition actors and controversies about the militant groups fighting in Syria. The cluster does not reflect, however, the most recent developments in Syria. Some of the blogs have not been updated since 2012 or 2013. In the other Syrian cluster, Syria Social \& Political, discussion is devoted mainly to Syrian history, culture, food, and social life. The Syrian revolution is not a strong theme in this cluster, but when discussed it is in a supportive tone. English is the main language of this cluster. It is notable that support of the Assad regime is not present in either of the Syrian clusters.

\section{KUWAIT}

Three Kuwaiti clusters are found on the 2014 map. Kuwait Political is comprised mostly of political commentary on local political issues, often with a critical tone. The comments react to government policies, parliamentary affairs, and media stories. Updates are infrequent, and many blogs have not been updated for the past couple of years. The Kuwaiti Social cluster contains mostly Kuwaitis commenting on various social matters, often based on personal experiences. Updates in this cluster also are infrequent. The third cluster, Kuwait Social Media, is populated by both Kuwaitis and expatriates living in Kuwait who post information about fashion, food, nightlife, and smartphones. The cluster is mainly in English. Compared to the other two clusters, posting in this cluster is more frequent and is more current. Unique to the blogosphere, the bloggers in this cluster choose to self-host their sites, as indicated by the domain names of the blogs.

\section{UNITED ARAB EMIRATES}

There is one UAE cluster (UAE Social English) on the 2014 map, which is populated mostly by the expatriate community writing in English about mostly social life in the UAE, sometimes in a critical tone. The fact that only an expatriate cluster from the UAE appeared in the blogosphere 
probably reflects the demographic structure of the UAE, where the expatriate community has been officially estimated to be $88 \%$ of the population. ${ }^{30}$

\section{JORDAN}

Two clusters from Jordan appear in the 2014 blogosphere. Jordan Social \& Political includes commentary on various social and political issues in the country. The other cluster, Jordan Social, focuses attention on social life, observations on individual behavior and societal attitudes towards various issues, and family affairs. Writings in both clusters are in Arabic and English.

\section{IRAQ, LEBANON, AND OMAN}

Only one cluster in the map centers on Iraq appeared in the 2014 map (Iraq English). This cluster consists of Iraqis blogging about social issues and, to a lesser extent, political matters. The cluster is predominantly in English. Similarly, there is only one cluster from Lebanon (Lebanon Political \& Social), which is populated by bloggers commenting on local political and social issues with some coverage of entertainment news. The cluster is in English. Oman is represented by one cluster (Oman Political, Social \& Literary), which offers a mixture of political commentary on local and regional affairs and reflections on social issues, as well as literary criticism and book reviews.

\section{MAGREB}

North Africa has a relatively small presence in the 2014 Arab blogosphere. Only three clusters emerged from the entire region on the 2014 map. One is from Tunisia (Tunisia Political, Social, Art); it is a mixture of discussion on various local issues including politics, social matters, art, and culture. The postings are in Arabic and French, with some in English. Two other clusters that represent voices from the Maghreb offer a mixture of resources related to France and general news from the countries of North Africa.

\section{NOTEWORTHY OBSERVATIONS}

\section{PALESTINE}

We reviewed the discourse on the Arab blogosphere to find if discussion on pan-Arab issues has changed since the 2009 study. We chose the dialogue related to Palestine as an example of a topic that has traditionally been a significant and central regional concern and because it figured prominently in the 2009 study. Compared to our 2009 research on the Arab blogosphere, we found that Palestine and the Israeli-Palestinian conflict no longer command the same level of attention of bloggers across the Arab world. In reviewing the Arab blogosphere after the JulyAugust 2014 Israel war on Gaza and found that there was still no significant posting in response to the war outside the two clusters in the blogosphere that focus on Palestinian issues. More pressing domestic political and social concerns appear to have overshadowed the Palestinian

\footnotetext{
${ }^{30}$ UAE National Bureau of Statistics, http://www.uaestatistics.gov.ae/ReportPDF/Population\%20Estimates\%202006\%20-\%202010.pdf.
} 
issue in the Arab blogosphere. Also, Arab users have taken the discourse on the July-August Israeli war on Gaza to social media. ${ }^{31}$

\section{LITERARY BLOGGING}

Literary blogging is spread across many clusters and is often mixed with political and social writings. There is also an exclusive community of literary bloggers in the blogosphere that includes creative writers and literature lovers. The cluster Literature/Published Authors is populated by literary bloggers and published writers featuring their print and digital publications; literature appreciators and lovers critiquing literary works; and amateur literary essayists. The posts range from opinionated long-form essays to shorter commentary. The discussion is mostly devoted to Arabic modern and contemporary literature and has no focus on any specific genre. The tone of the blogs tends to be formal, and few adopt a conversational style. The blogs are sporadically updated. In contrast, the cluster Literature/Personal Diaries is a community of personal diarists using literary and creative writing styles for expression. The cluster Creative Writing is mostly unpublished writers showcasing their creative poetry and prose. Most of the writing in these clusters is not contextualized or related to specific experiences or events.

\section{THE BAHA'I COMMUNITY}

The Baha'i are the only minority faith community to appear in the 2014 Arab blogosphere map; they were also present in the 2009 blogosphere study. The cluster (Baha'i/Egypt) consists primarily of blogs by Egyptian individuals who self-identify as Baha'i adherents and do not mention their names. Although the bloggers do not mention the reasons that they remain anonymous, it is possible that they, as a persecuted minority faith, are worried about their ability to integrate into the larger society and their access to state services, some of which are apparently off limits to them: in January 2013, Egypt's Minister of Education was quoted by local media as saying that Baha'i students cannot enroll in public schools as that violates the constitution because Baha'i is not among the faiths recognized by the state. ${ }^{32}$

\section{ISLAM}

The Islam cluster is a community of bloggers commenting on personal and social issues with emphasis on Islamic religious identity and religious lifestyle. The cluster does not show any political tendency; it appears to be a zone for individuals seeking spiritual solace in religion who have virtually no interests in religious-based political or social activism. Most of the Muslim sheikhs referred to in this community are notably apolitical spiritual leaders.

Another cluster linked to Islam is the Islam Sunni cluster, which is dominated by Muslim scholars discussing religious matters with emphasis on the Sunni sect and school of thought. There is no indication that these scholars engage in political discourse, however. It is worth noting that many of these scholars are linked to Egypt and Saudi Arabia. Similar to the Kuwaiti Social cluster, the sites in this cluster are self-hosted sites, as indicated by the domain names.

\footnotetext{
${ }^{31}$ Narratives of Conflict: What the 2014 Gaza War Can Tell Us About Discourse on the Internet, https://medium.com/internet-monitor-2014-public-discourse/narratives-of-conflict-what-the-2014-gaza-war-can-tellus-about-discourse-on-the-internet-2275163b728b

32 "Bahais cannot enroll in public schools, education minister says," Egypt Independent, January 6, 2013, http:/www.egyptindependent.com/news/bahais-cannot-enroll-public-schools-education-minister-says.
} 


\section{Professional BLOGgING}

One professional blogging cluster appeared on the map (Regional/Professional Blogs). The blogs in this cluster are pan-Arab, and they provide an Arabic speaking audience with information on technology, how-to advice, marketing strategies, tips on electronic commerce, and book reviews. Some of the blogs are advertising-supported.

\section{EGYPTIAN TWITTERSPHERE MAP}

The structure of the Egypt Twittersphere reflects the deep political divisions in the country. There are three major political clusters: Military-Aligned; Muslim Brotherhood, and NonAligned. ${ }^{33}$ The unifying theme of the first cluster is support for the Sisi government and more generally the role of the military in Egypt public affairs. The Muslim Brotherhood cluster includes members of the organization and supporters of the deposed government of Muhammed Morsi. The Non-Aligned cluster spans a more diverse set of political perspectives and includes left-leaning, self-professed socialists and revolutionaries, libertarians, free speech advocates, and reformers, as well as anti-military junta and anti-Islamic theocracy voices. The common ground that brings together the users in this cluster is a rejection of both the Sisi and Morsi governments. A fourth large cluster in the network covers users that are not defined by their political affiliation but rather by their interest in Social and Cultural issues. A fifth cluster, Media, Politics \& Entertainment, includes accounts that bridge different sets of interests. The map also reveals how each network is connected to other political groups outside of Egypt as manifest by the presence of state and non-state actors from other countries in the region who are aligned with each network overall theme.

\footnotetext{
${ }^{33}$ The network mapping renders a map with 35 clusters. However, for this network map, the most meaningful distinction between the various groups of users in this network occurs across an aggregation of five larger groups of users. The differences between the algorithmically determined clusters within these five groups are nearly indistinguishable and minor compared to the differences across the five large groups in the network. The comparative analysis is therefore carried out at this larger level, and for simplicity, we refer to the five higher level aggregations as clusters.
} 


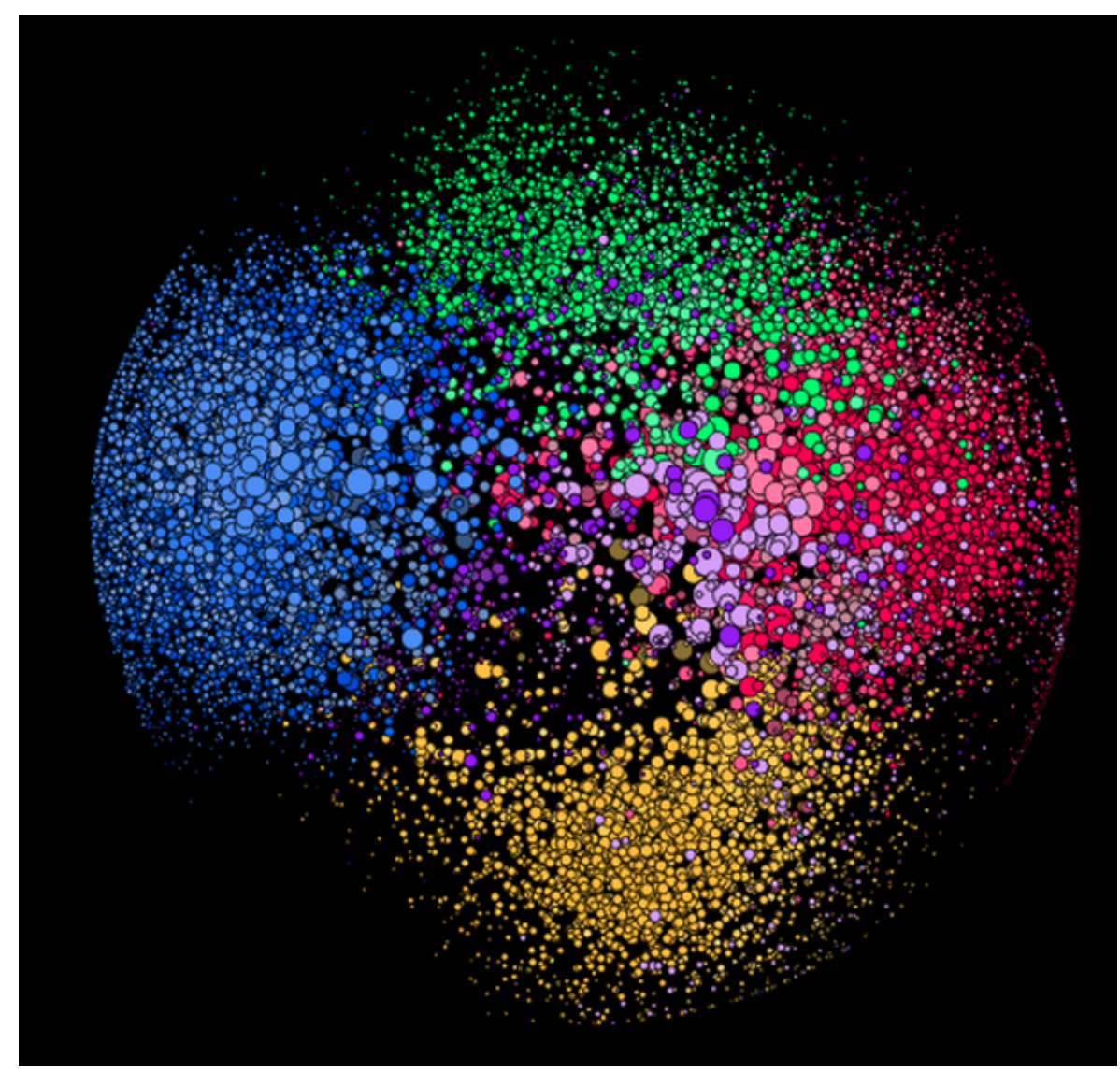

Figure 6: Egyptian Twitter Map

The clear articulation of political poles in this network provides evidence of the increase in political polarization in Egypt that has taken root over the past several years.

\section{MilitARY-ALIGNED CLUSTER}

This cluster is populated by users who assert their support of the military and President Sisi, the former head of the military and current president of Egypt. It is common in this cluster for users to express their pride in being Egyptian in their profile description. Many describe themselves as nationalist. The use of photos of Sisi on their profiles is frequent. The discourse in this cluster is primarily centered around political affairs in Egypt, specifically shedding positive light on Sisi's activities, speeches, and initiatives along with government programs. Users also post content critical of Sisi's local opponents, such as activists, journalists, and international critics such as the president of Turkey and the state of Qatar (both have reportedly exhibited support for the Muslim Brotherhood). Many of the accounts use what sound like real Arabic names; few of the profile names in this cluster are obvious pseudonyms. The clusters also include accounts with the names of public figures such as politicians, journalists, actors, and celebrities. These accounts have not necessarily been verified as belonging to these prominent figures. This cluster also includes the accounts of security organizations such as the police department (@EgyptianPolice0) and the spokesperson of the military (@EgyArmySpox). These accounts disseminate state narratives on various security incidents. They are often retweeted by others in the cluster. 


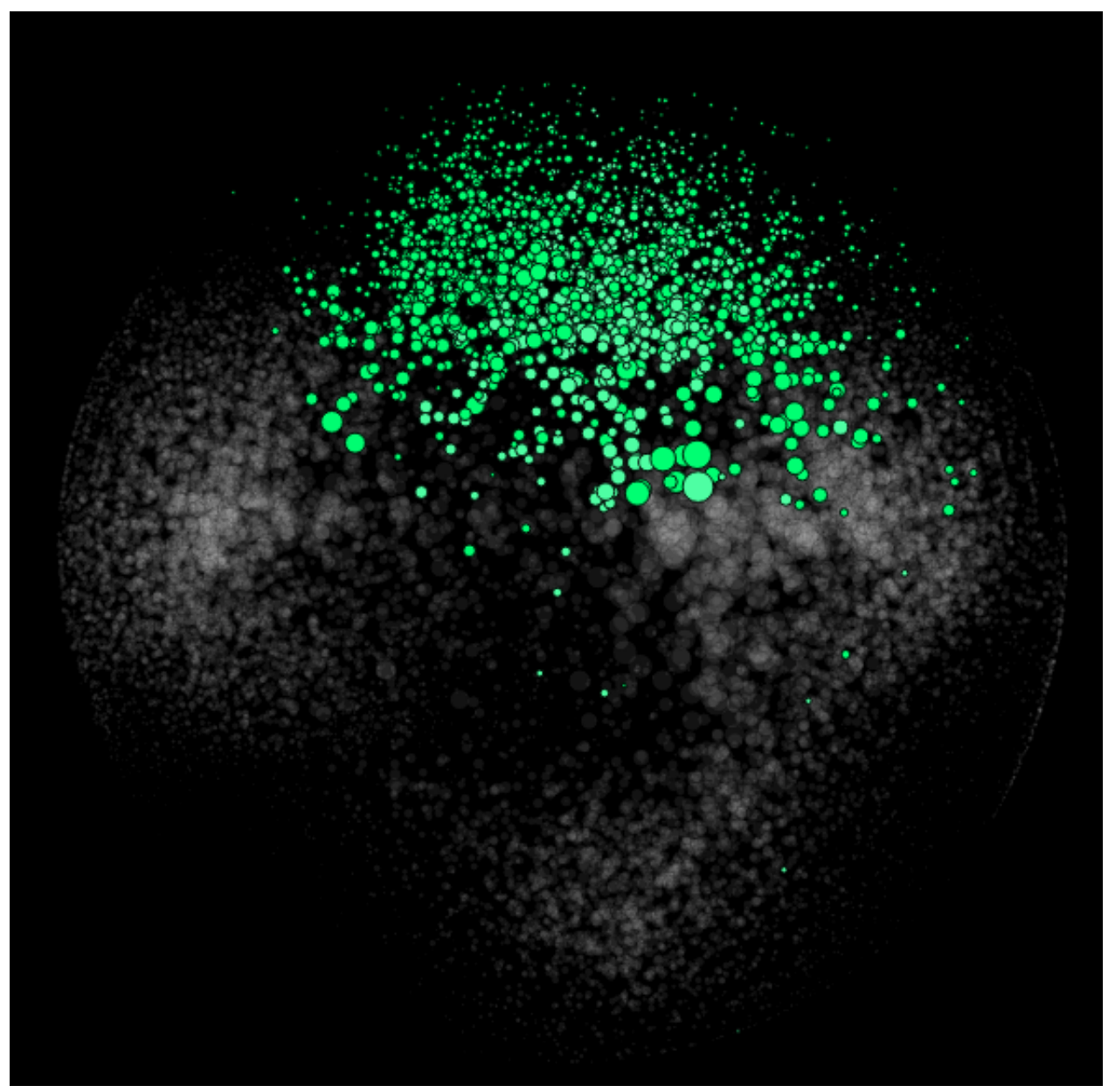

Figure 7: Military-Aligned and Pro-Government Cluster

Users in the military-aligned cluster celebrate Sisi on occasions such as the first anniversary of him taking office ${ }^{34}$ and apolitical occasions such as the holiday month of Ramadan, when users launched the hashtag "Ramadan is better with Sisi [as president]" (translation from Arabic). Users in this cluster also promote government projects that have been initiated under the Sisi regime. One project that received significant coverage is the New Suez Canal, a project undertaken by the government that was started in 2014. It will run alongside the existing 145year-old canal and is expected to open in August $2015 .^{35}$ The project was widely celebrated by users and described as "Egypt's pride." Citizens were urged to follow a Twitter account for the Canal. ${ }^{36}$

Users also actively promote media stories and reports that highlight human rights practices in Egypt in a positive context. For example, a user retweeted a story with the headline: "International Labor Organization: Egypt witnesses notable progress in workers' conditions."

\footnotetext{
${ }^{34}$ Elebrashy News, Twitter post, Jun 8, 2015, 4:12 PM,

https://twitter.com/WaelElebrashy/status/608049012428652544.

35 Reuters, Egypt prepares to open new Suez Canal to run alongside the existing 145-year-old waterway, Jun 14, 2015, http:/www.abc.net.au/news/2015-06-14/egypt-gets-ready-to-open-new-suez-canal/6544430

${ }^{36}$ Abeer, Twitter post, Jun 13, 2015, 10:17 AM https://twitter.com/abero86/status/609771537865003008.

${ }^{37}$ Youm7, Twitter post, Jun 11, 2015, 6:35 AM, https://twitter.com/youm7/status/608990949092507649.
} 
Users in this cluster are engaged in information campaigns and counter-campaigns against groups represented in the other two political clusters, including the Muslim Brotherhood and activists from the largely secular groups that have participated in the demonstrations that led to the January 2011 revolution that removed President Hosni Mubarak from power. Supporters of Sisi express their approval of the restrictions imposed by the government against these two groups. One tweet, for example, demands that the government must stop what it called "foreign funding" from reaching the April 6 Movement, ${ }^{38}$ a youth activist group that helped to organize and promote the 2011 protests. Users in this cluster also defend the state's measures against political opponents and refute reports produced by the local and international human rights organizations on Egypt's human rights practices. One for example tweeted: "[Forget] international opinion, human right watch and activists opinion...crackdown, and let 'em feel you. \#Egypt"39 Another describes Human Rights Watch reports on Egypt as "suspicious" and "promoting lies." 40

Various campaigns against the Muslim Brotherhood continue to emerge in this cluster, with hashtags such as "Cleanse Egypt's institutions from Muslim Brotherhood" (translation from Arabic).

Users in the military-aligned cluster often compare Sisi to former President Mohammed Morsi in a way that is meant to celebrate Sisi and defame Morsi. For example, when Sisi visited Germany in June 2015, users posted two photos. One shows Sisi in a joint press conference with German Chancellor Angela Merkel while she is smiling at him; the other shows then-president Morsialso in a joint press conference with Merkel—but with Merkel looking bored instead of smiling. ${ }^{41}$ The Arabic caption reads: "Sisi's shyness adds dignity to him; the foolishness of Morsi makes those who elected him more foolish."

\footnotetext{
${ }^{38}$ Nancy, Twitter post, Jun 11, 2015, 6:23 AM, https://witter.com/nancykhaliill/status/608987991034318849.

${ }^{39}$ Polly_Purebred, Twitter post, Jun 10, 2015, 2:30 AM, https://twitter.com/Polly_Purebred_/status/608566849001943040.

40 Mohamed Abu Hamed, Twitter post, Jun 9, 2015, 1:49 AM, https://twitter.com/MohamedAbuHamed/status/608194255266435072.

${ }^{41}$ Hoooooos, Twitter post, Jun 3, 2015, 6:05 AM, https://twitter.com/7ossamrasslan/status/606084292540829696.
} 


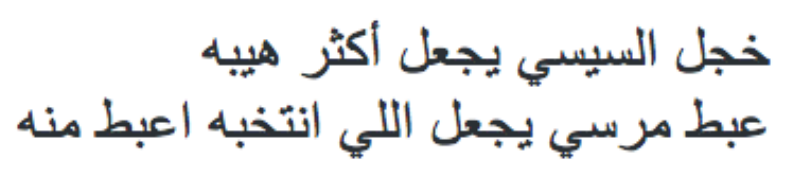

6 View translation

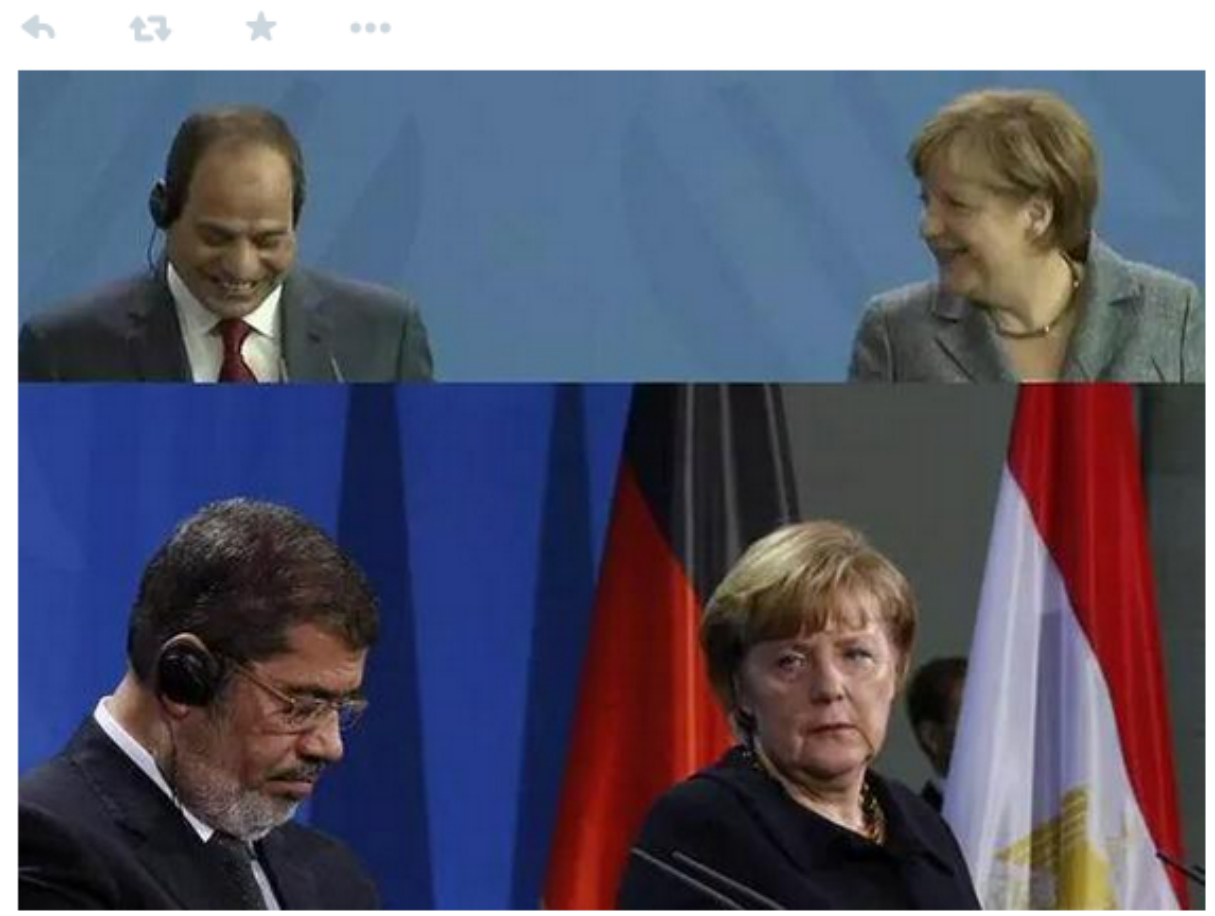

Figure 8: Tweet reads, "Sisi's shyness adds dignity to him; the foolishness of Morsi makes those who elected him more foolish."

Unlike our first review of this network map in the fall of $2014,{ }^{42}$ we find in the spring of 2015 that the users in the military-aligned cluster have started to quote or retweet tweets from their rival clusters along with critical comments or refutations. For example, a user retweeted a statement from the Muslim Brotherhood's Freedom and Justice Party (FJP) that said, "FJP strongly condemns heinous attacks in \#Luxor \& its perpetrators. holds mil coup gov't responsible for the fast deteriorating security." The user added the comment, "you are a bunch of liars."

Users in the military-aligned cluster disseminate government statements, especially those critical of foreign governments that criticize the Sisi government over its human rights record. For example, many users tweeted and celebrated a statement from Egypt's Ministry of Foreign Affairs urging United States authorities to "practice caution in dealing with the protesters in Ferguson, Missouri." Users attached to the statement photos showing confrontation between the police and the protesters and photos showing violence from the riots. The wording of the statement seemed to echo language used by Washington to caution Cairo in dealing with Islamist

\footnotetext{
${ }^{42}$ Initial review of the Twitter maps started in the winter of 2013 and initial review of blogosphere map started in winter of 2014. Additional reviews were conducted in spring and fall of 2014 and final review in spring of 2015. ${ }^{43}$ Nancy, Twitter post, Jun 10, 2015, 5:46 AM, https://twitter.com/nancykhaliill/status/608616216727572481
} 
protesters. ${ }^{44}$ The Arabic caption reads: "We ask the American police to please use self-restraint. Let's tweet this, tweeple."45

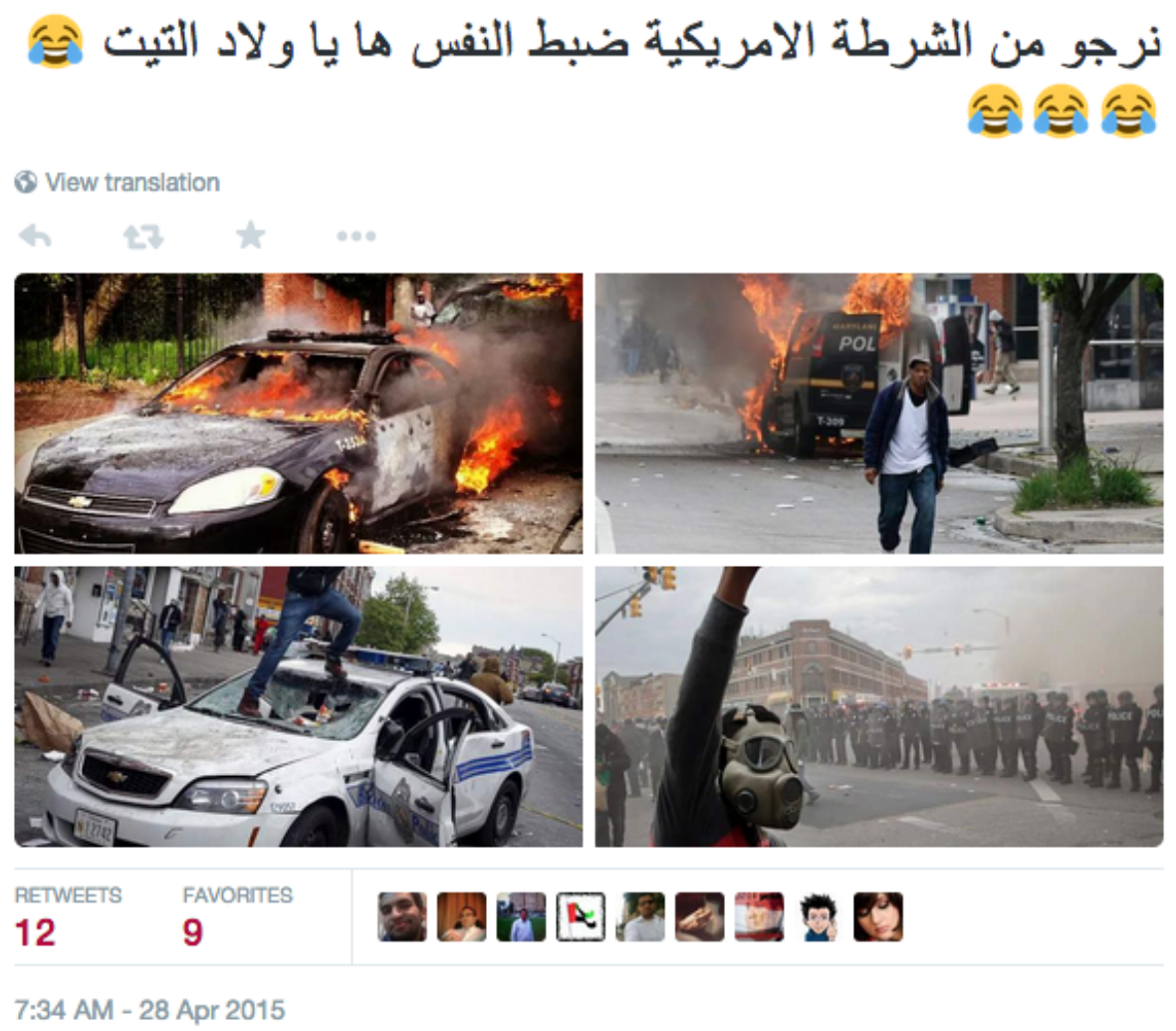

Figure 9: Tweet reads, "We ask the American police to please use self-restraint. Let's tweet this, tweeple."

One recurrent topic that appears frequently in the military-aligned clusters is suspicion of the alNoor Party, despite the party's support of Sisi and the apparent acceptance of the party by the government. Although it is affiliated with the Salafi movement, which is based in Sunni Islam, the al-Noor Party sides with Sisi instead of the Muslim Brotherhood. For example, one user posts what looks like a clipping from an Arabic newspaper printing the headline "al-Noor Party cadre meets 5 CIA officers." The user comments: "be cautious of al-Noor Party; apparently they introduce themselves as alternative to the Muslim Brotherhood."46

Users that support the military frequently express their approval of the government's foreign policies. For example, many accounts supported the government's participation in the Saudi-led military intervention in Yemen, ${ }^{47}$ and frame the Egyptian government's decision to support

\footnotetext{
${ }^{44}$ John Hall, “American Spring? Now Egypt puts the boot in as it urges U.S. authorities to 'exercise restraint' in dealing with Missouri riots," Daily Mail, August 19, 2014, http:/www.dailymail.co.uk/news/article2728831/American-Spring-Now-Egypt-puts-boot-urges-U-S-authorities-exercise-restraint-dealing-Missouririots.html.

${ }^{45}$ Misriya bint elnil, Twitter post, Apr 28, 2015, 7:34 AM, https://twitter.com/samsouma2012/status/593060707308019712.

${ }_{46}$ Maria, Twitter post, Jun 5, 2015, 3:00 AM, https://twitter.com/mariaqueen100/status/606762587796172800.

${ }^{47}$ Amr Adib, Twitter post, Mar 26, 2015, 8:44 AM, https://twitter.com/Amradib/status/581119653835104257.
} 
Saudi Arabia as part of returning the favor of supporting Sisi against the Muslim Brotherhood. ${ }^{48}$ Anti-Iran rhetoric ${ }^{49}$ became visible in this cluster after the government decision to support the Saudi-led airstrikes in Yemen against the Houthi rebels, who have been accused of being a proxy for Iran.

\section{MUSLIM BROTHERHOOD FOCUS CLUSTER}

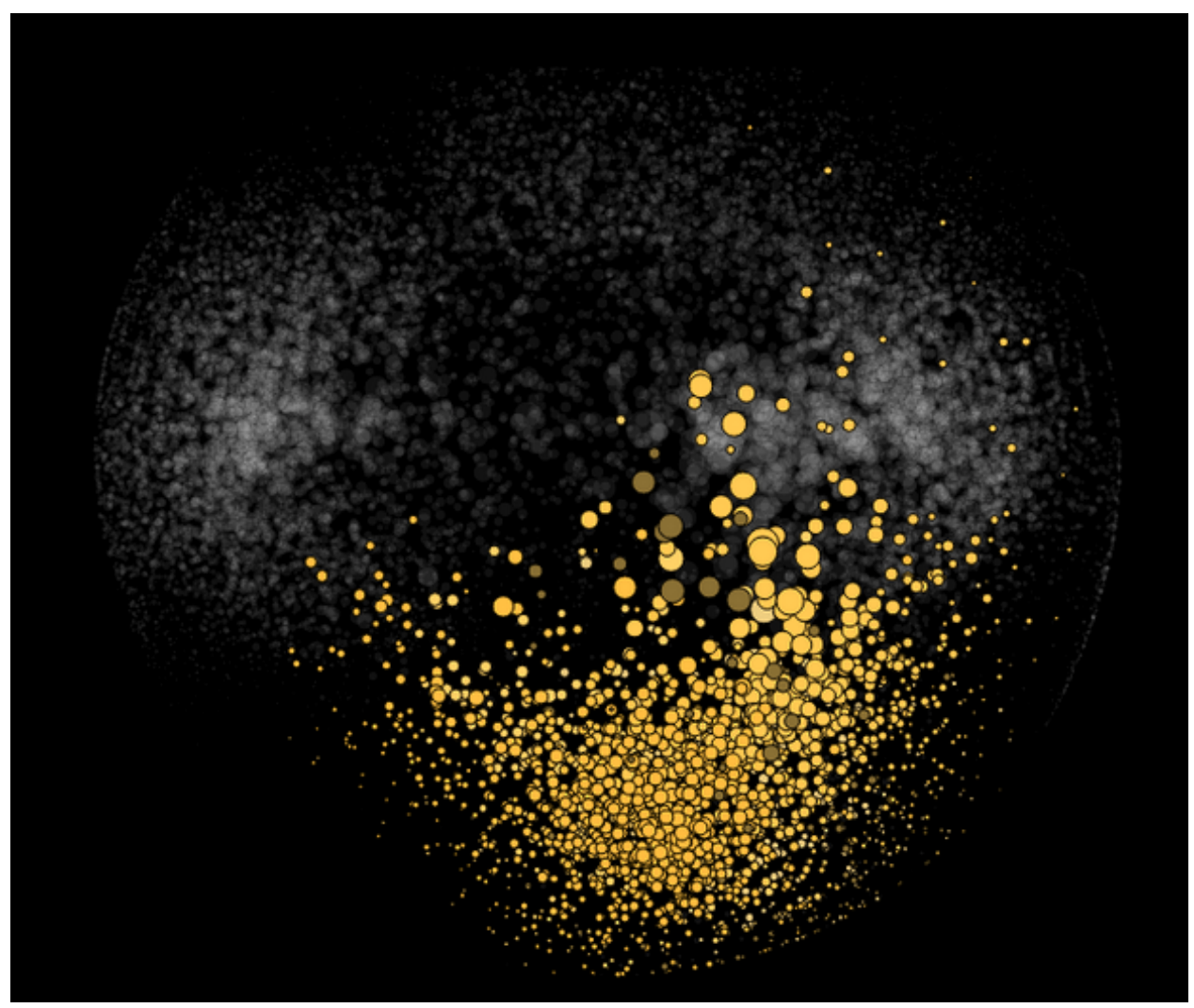

Figure 10: Muslim Brotherhood Cluster

This cluster is populated primarily by users who declare their affiliation with the Muslim Brotherhood, many of whom display the Rabia sign on their profile pictures. Many users in the cluster emphasize their Islamic identity. One user, for example, describes himself as a "Muslim apologist." ${ }^{, 50}$ There are also users who say they are not members of the Muslim Brotherhood but support them ${ }^{51}$ and users to who do not declare any position on the group. The cluster includes inactive accounts belonging to key Muslim Brotherhood leaders who have been imprisoned after the group was ousted from power. Examples include the account of one of the group's senior leaders Essam Elerian. ${ }^{52}$ The cluster also includes several accounts of non-Egyptian political

\footnotetext{
${ }^{48}$ Amr Adib, Twitter post, Mar 26, 2015, 7:56 AM, https://twitter.com/Amradib/status/581107529515708417.

${ }^{49}$ Example Amr Dib, Twitter post, Mar 26, 2015, 8:01 AM, https://twitter.com/Amradib/status/581108818572107776.

$50 @$ FadelSoliman, Twitter account, https://twitter.com/FadelSoliman.

$51 @$ hala_moo, Twitter account, https://twitter.com/hala_moo.

$52 @ E s s a m \_E l e r i a n$, Twitter account, https://twitter.com/Essam_Elerian.
} 
figures known for their support of the group and for criticism of the Sisi government, such as the account of President Recep Tayyip Erdogan of Turkey. ${ }^{53}$

The discourse in this cluster frequently focuses on the removal of the government of Mohammed Morsi from power in 2013. The deposition of Morsi is described by Muslim Brotherhood supporters as a military coup led by Sisi, who was Minister of Defense at the time. Morsi was elected in 2012 in an election that is widely recognized as open and fair. Twitter users in this cluster also focus attention on issues such as economic grievances, unemployment, and social injustice under the Sisi government, stressing complaints that have public appeal such as disseminating photos showing long lines of citizens desperately waiting for cooking gas cylinders. ${ }^{54}$ The Arabic caption reads:

Egypt got a half billion dollar loan from the World Bank to make cooking gas cylinders available

Where are the cylinders? Not there

Ok, where is the loan? Not there

Yet, [we say] Go Egypt. ${ }^{55}$

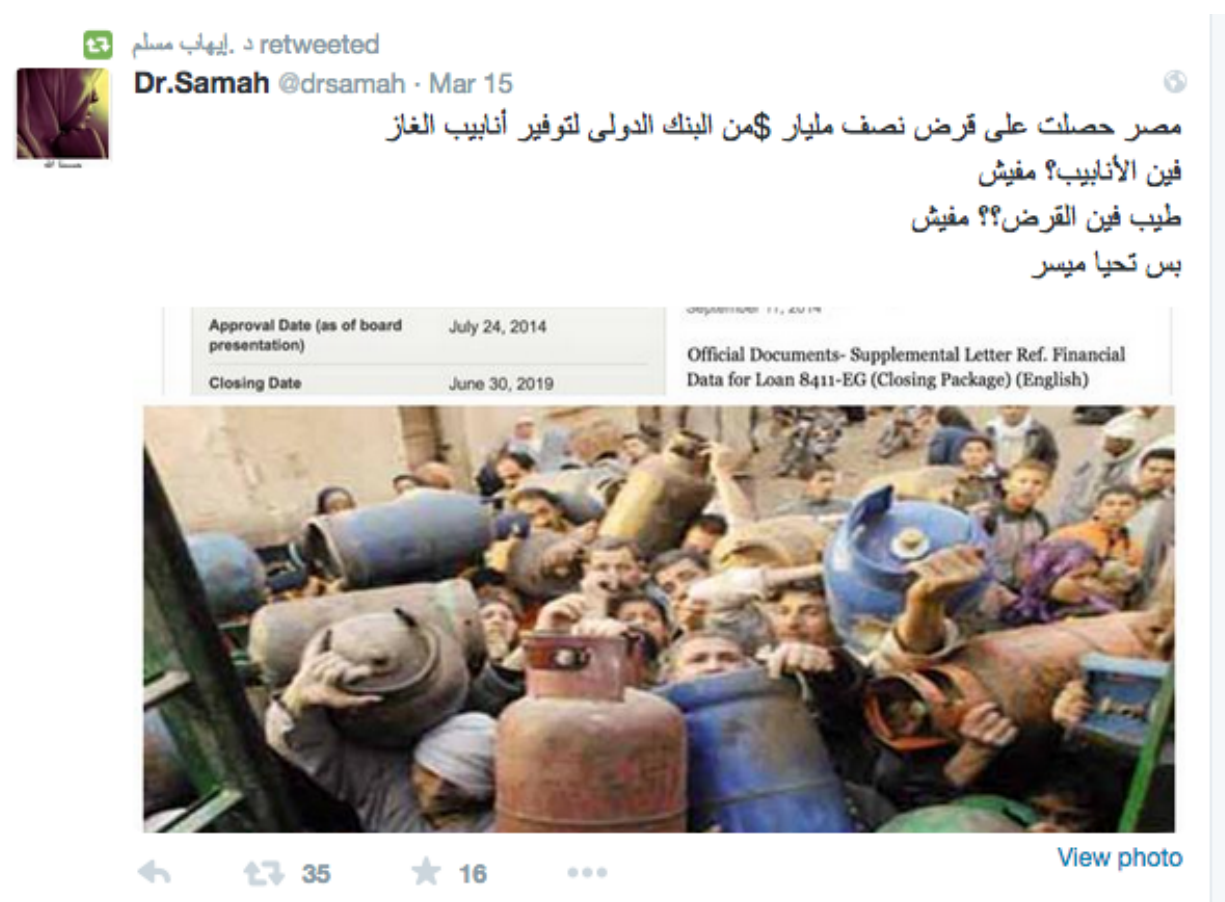

Figure 11: Tweet reads, "Egypt got a half billion dollar loan from the World Bank to make cooking gas cylinders available Where are the cylinders? Not there Ok, where is the loan? Not there Yet, [we say] Go Egypt."

Banned and persecuted in Egypt, Muslim Brotherhood members use Twitter as a parallel and alternative space for political opposition activities. Members and sympathizers highlight their political grievances as well as the vulnerabilities of the Sisi government. Users in this cluster

${ }^{53} @$ RecepT_Erdogan, Twitter account, https://twitter.com/RecepT_Erdogan.

54 Anas Elgendy, Twitter post, Jun 6, 2015, 4:30 PM, https://twitter.com/as043861/status/607328781410443264.

55 Dr. Samaha, Twitter post, Mar 15, 2015, 3:20 PM, https://twitter.com/drsamah/status/577232844487057408. 
often discuss Egypt's "poor" record on freedom of speech and human rights since Sisi became president. It is not uncommon for users in this cluster to cite Western media outlets and disseminate reports that are critical of the Sisi government issued by secular and West-based organizations such as Amnesty International and Human Rights Watch.

Outside of local issues, users in these clusters often express concern about Muslims in other countries, especially Muslim minority groups, such as the Rohingya, who face persecution in Burma. The Rohingya have been the center of a humanitarian crisis as tens of thousands have fled persecution. Raising the visibility of such groups and offering prayers for them is not uncommon in these clusters. ${ }^{56}$

Responding to tweets from Sisi loyalists who supported the Saudi-led coalition to restore the "legitimate president of Yemen," users in the Muslim Brotherhood clusters remind the loyalists that there is a "legitimate" president (i.e., Morsi) imprisoned in Egypt and facing the death penalty.

Muslim Brotherhood cluster members critically comment on Sisi's political activities, at times seeming to match rival activities in the military-aligned cluster. One user posted a caricature from a German publication during Sisi's June 2015 visit showing him walking side by side with Chancellor Merkel to the red carpet with what looks like blood-soaked footsteps. Users often retweet posts from a President Sisi parody account, which posts news and comments on various political and social issues, including arrests of activists, from the point of view of an imagined, ironic, sarcastic version of Sisi. ${ }^{57}$

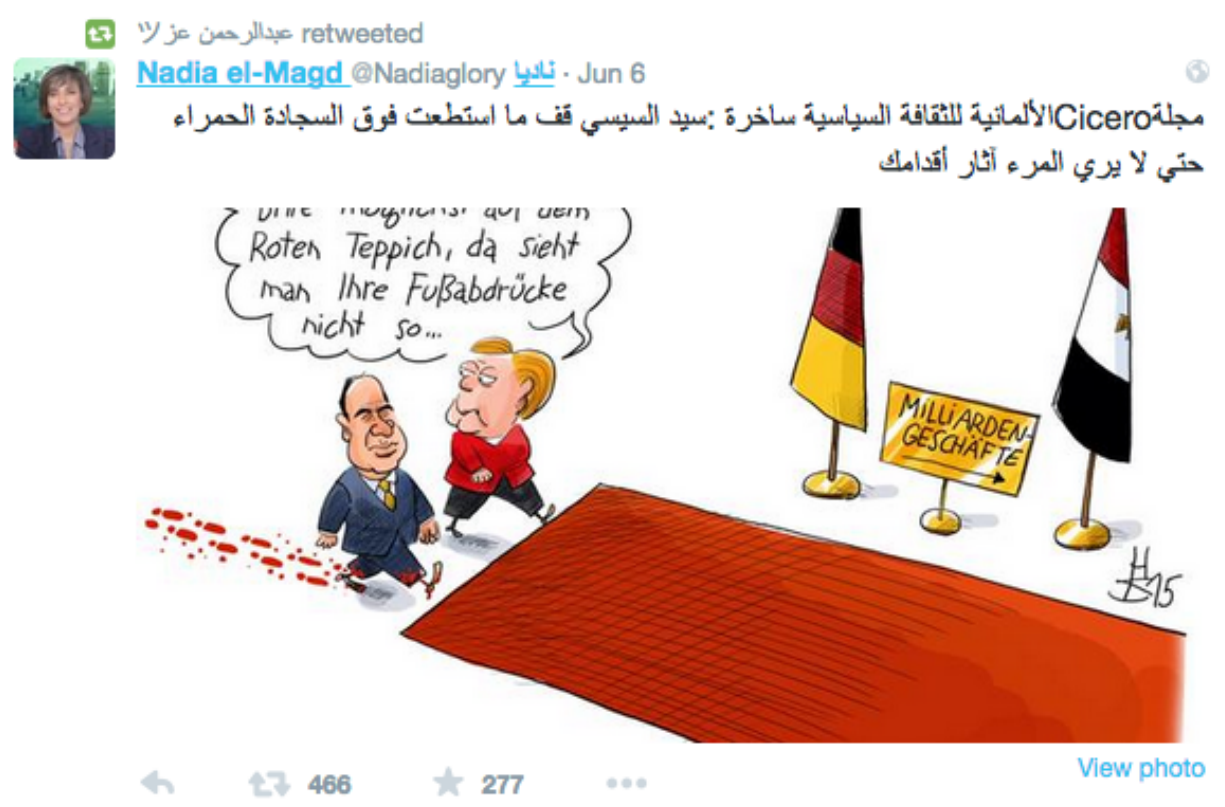

Figure 12: Tweet reads, "German political satirist magazine Cicero: Mr Sisi. Stand as long as you can on the red carpet so that no one will see the traces of your feet."

\footnotetext{
${ }^{56}$ See for example Fadel Soliman, Twitter post, Jun 6, 2015, 4:43 AM, https://twitter.com/FadelSoliman/status/607150833072021504.

${ }^{57}$ Abdelfattah Alsisi, Twitter post, May 15, 2015, 6:28 PM, https://twitter.com/alsiisii/status/599385857770934272.
} 
Users in the Muslim Brotherhood cluster are also critical of the al-Noor Party, which sides with Sisi rather than the Islamist Muslim Brotherhood. One tweet, for example, says "The coup will not abandon al-Noor party because it [the coup] cleans its hands which are full with blood on the beards [of the party members].",58

\section{NON-Aligned CLUSTER}

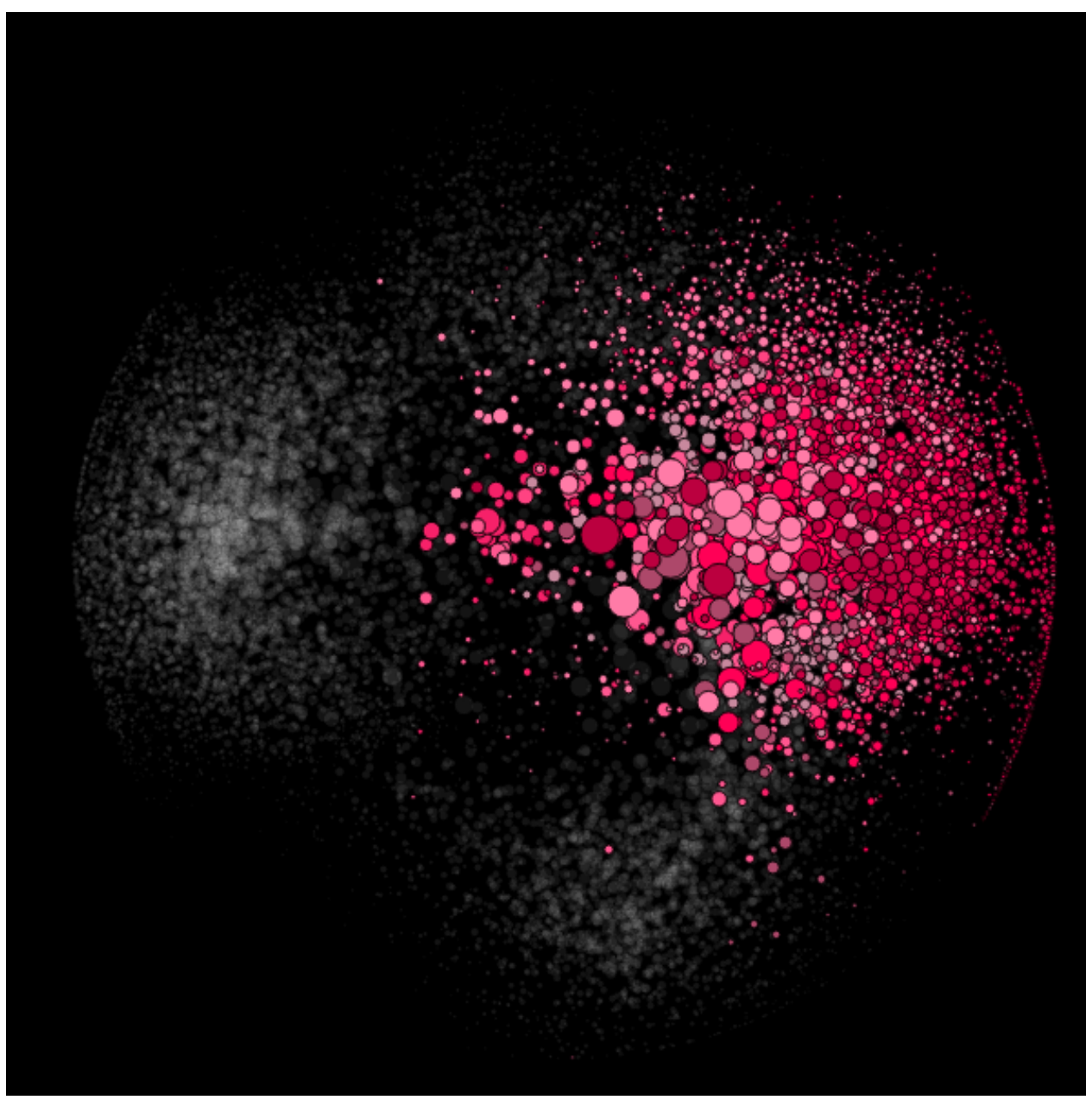

Figure 13: Non-Aligned Cluster

Users in the Non-Aligned ${ }^{59}$ cluster include local human rights advocates, ${ }^{60}$ political reformers, and digital rights activists, ${ }^{61}$ including figures who were associated with Egypt's 2011 revolution such as Wael Ghonim (@ghonim), Alaa Abd El Fattah (@alaa), and Nawara Negm (@nawaranegm). Inactive accounts of activists who have been arrested appear in this cluster, for

\footnotetext{
${ }^{58}$ Mawqi Dr. Mohammed al-Jawady, Twitter post, Feb 3, 2015, 1:36 AM, https://twitter.com/gawadyat/status/562545169615302657.

${ }^{59}$ The label non-aligned is meant to signal that users in this cluster are critical of both the Sisi government and that of former president Morsi. It is not meant to suggest that users in this cluster do not have their own political viewpoints or do not support other political movements and organizations.

${ }^{60}$ For example, https://twitter.com/gamaleid.

${ }^{61}$ For example, https://twitter.com/RamyRaoof.
} 
example the account of Ahmed Douma (@ahmeddouma), a prominent activist who received a life sentence in February 2015 for "rioting, inciting violence and attacking security forces in late 2011."62 Many users are from self-professed liberal and left-leaning backgrounds (e.g., the Socialist Revolutionists ${ }^{63}$ and the Revolutionary Socialists ${ }^{64}$ ).

In addition to taking political positions, users in these clusters tweet about a variety of apolitical issues from around the world. English is used more frequently in the non-aligned cluster and users here are more likely to cite Western media. In the most recent review of this cluster in the spring of 2015, political tweets are less frequent, compared to a similar review in the fall of 2014.

Users in these clusters are critical of what they call the "military regime" and the Muslim Brotherhood. One for example introduces himself in the profile as "against the military regime and the Muslim Brotherhood." 65

Although criticism of Islamist groups, especially the Muslim Brotherhood, continues in this cluster, the focus has shifted to protesting what the users consider repressive measures taken by the Sisi government against political activists, advocacy groups, the media, and both local and international NGOs. Many users express disappointment with what they consider deterioration of human rights after the "coup." As one user puts it, "Seems like the coup created a secular caliphate in Egypt."

The non-aligned cluster is where arrests of activists and journalists from all backgrounds are most frequently discussed, with special attention paid to the activists who participated in the political activities that led to the January 2011 protests and have been imprisoned since then by the Sisi government. Users often tweet news about specific incidents of individuals who have gone missing or been arrested by the security forces. A June 2015 tweet for example reported: "Over the past week, 11 activists have been reported missing or allegedly kidnapped by security forces in \#Egypt." ${ }^{67}$ Users in this cluster also report news about the government crackdown on human rights advocacy groups. One user, for example, tweeted about the government starting an investigation into the Cairo Center for Human Rights Studies after the center criticized Egypt's human rights record in a European Parliament hearing. ${ }^{6}$ Users also report on major restrictive measures against civic groups and media organizations. One post states, "Weekend recap from Egypt: Ultras banned, Reem Magued's new program taken off air, Morsi, 100+ others sentenced to death. So much stability."69 (Ultras are football fan leagues that also engage in politically oriented activities; Reem Magued is a TV presenter whose program on women's issues was suspended by its broadcaster satellite channel ONTV). Users in the non-aligned cluster also highlight what they call the "humanitarian catastrophe" faced by political detainees "due to

\footnotetext{
62 "Egyptian court sends activist Ahmed Douma to jail for life," Reuters, February 4, 2015 , http://www.reuters.com/article/2015/02/04/us-egypt-activist-idUSKBN0L81DI20150204.

$63 @$ RevSocMe, Twitter account, https://twitter.com/RevSocMe.

$64 @ G s q u a r e 86$, Twitter account, https://twitter.com/Gsquare86.

$65 @$ Elmoshir, Twitter account, https://twitter.com/Elmoshir.

${ }^{66}$ Karl Sharro, Twitter post, Dec 8, 2014, 10:17 AM, https://witter.com/KarlreMarks/status/542020215857750017.

${ }^{67}$ Farah Saafan, Twitter post, Jun 3, 2015, 5:54 AM, https://twitter.com/FarahSaafan/status/606081578788392960

${ }^{68}$ Sarah El Sirgany, Twitter post, Jun 10, 2015, 8:04 AM, https://twitter.com/Ssirgany/status/608651039634546688.

${ }^{69}$ Dalia Ezzat, Twitter post, May 16, 2015, 4:06 AM, https://twitter.com/DaliaEzzat_/status/599531481762013184.
} 
medical negligence ${ }^{, 70}$ as well as torture practices by the Egyptian police. ${ }^{71}$ Some users reject the death sentences of Muslim Brotherhood leaders, saying that even political rivals deserve justice. $^{72}$

Hashtag campaigns to free activists and journalists are common in this cluster, e.g., Freedom to \#Yusuf Shaban; Freedom to \#Mahinour el Masry"73 (Shaban is a journalist and el Masry is an activist; both were arrested by security forces). There are also reports about confrontations between activists and supporters of el-Sisi offline. A user for example posted a photo with the caption, "This Sisi lover came and threw rocks at the press syndicate dispersing the stand.and she kept throwing rocks." 74 However, we found no instances of organized campaigns for activists to take to the streets to protest the arrest of activists or journalists; an anti-protest law bans demonstrations without prior permission from the police. A June 2015 presidential decision to pardon 165 detainees who had been jailed for violating the anti-protest law ${ }^{75}$ received little attention in this cluster, and the few who commented on it were critical of the pardon. One user writes: "Congratulations to the released ones but why did the pardon include only Muslim Brotherhood loyalists and not the revolution supporters. The regime hates and fears them because they are sincere, brave and have no personal ambitions." ${ }^{, 76}$

A distinct set of users in this cluster consists of Egyptian bloggers posting primarily in English about local political and social affairs. Egyptian and Western media and journalists covering Egyptian political news can also be found in this cluster.

\footnotetext{
${ }^{70}$ Tahrir Berlin, Twitter post, Jun 1, 2015, 2:40 AM, https://twitter.com/TahrirBerlin/status/605307826882379776.

${ }^{71}$ al-Ishtrakiyoon al-Thawriyoun, Twitter post, Jun 12, 2015, 9:01 AM, https://twitter.com/RevSocMe/status/609390072333488128.

72 Alaa Aswany, Twitter post, May 20, 2015, 5:23 PM, https://twitter.com/AlaaAswany/status/601181498205675520.

${ }^{73}$ Bahaa (Bebo), Twitter post, May 31, 2015, 7:28 AM, https://twitter.com/BahaaEltawel/status/605018127773089792.

${ }^{74}$ Gigi Ibrahim, Twitter post, Jun 1, 2015, 8:47 AM, https://twitter.com/Gsquare86/status/605400267232817152.

${ }^{75}$ Heba Afify, “Anti-Protest Law campaigners say Ramadan pardons are not enough,” Mada Masr, June 17, 2015 , http:/www.madamasr.com/sections/politics/anti-protest-law-campaigners-say-ramadan-pardons-are-not-enough.

${ }^{76}$ Alaa Aswany, Twitter post, Jun 18, 2015, 5:11 PM, https://twitter.com/AlaaAswany/status/611687749272358912.
} 


\section{SOCIAL AND CUltural CLUSTER}

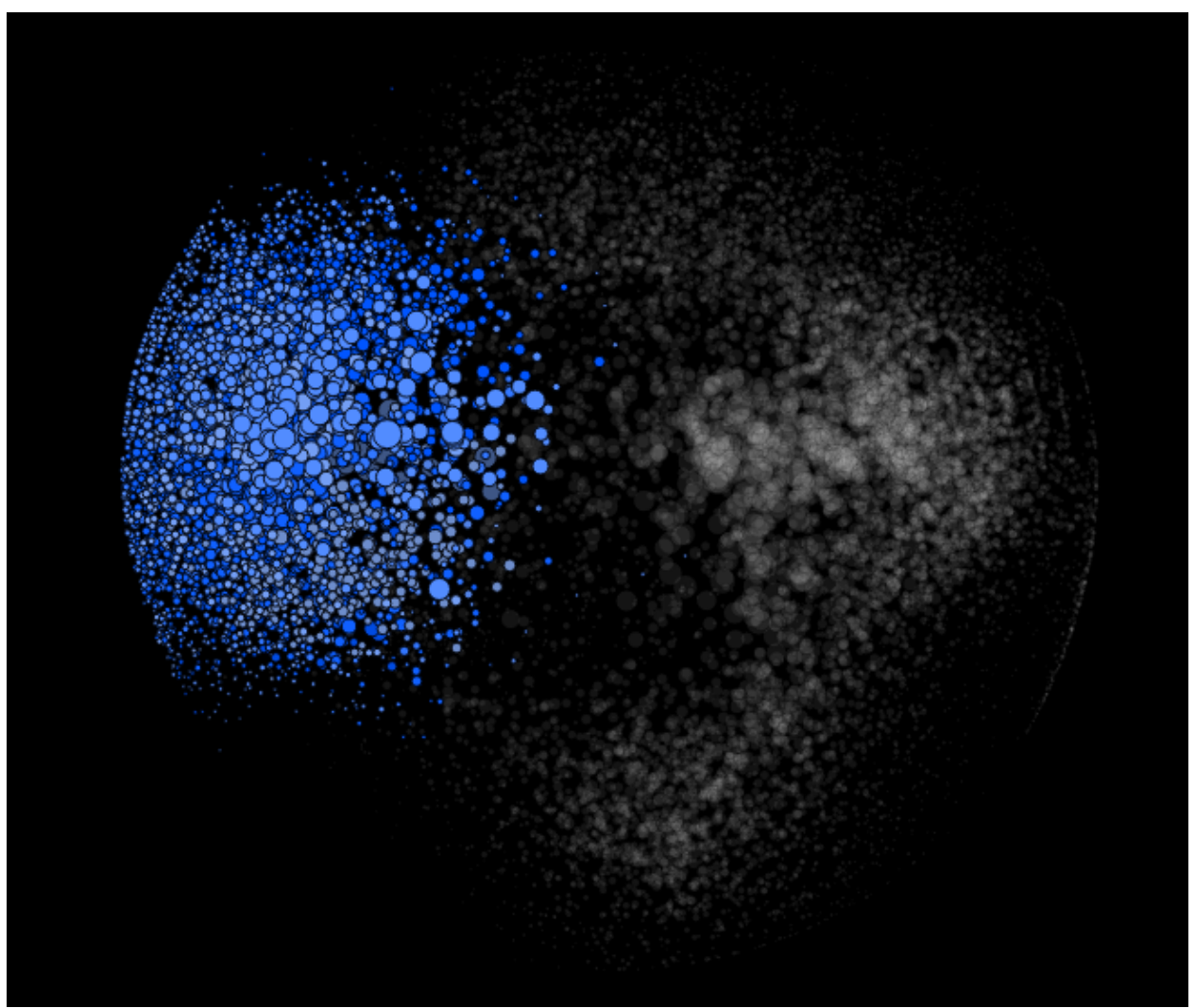

Figure 14: Social and Cultural Cluster

The non-political portion of the Egyptian Twitter map is comprised of users who discuss personal and cultural issues. This cluster is populated largely by teenagers and young people who often talk about issues associated with their generation, performance in school, and future ambitions. The discourse also includes entertainment and literary topics. In the most recent review of this cluster, we found instances of political commentary seeping into the discourse, often with a critical but humorous tone. Some comments are leveled at Sisi, but they are mostly comical and do not amount to political opposition. One, for example, writes "Hey guys, I have not started writing about politics and all of a sudden a police car is following me on the ring road asking me to pull over :))."”7

\footnotetext{
${ }^{77}$ MOLY, Twitter post, Nov 8, 2014, 7:45 AM, https://twitter.com/MoLY_HaNeM/status/531110391309692928.
} 


\section{Media, POLITICS \& ENTERTAINMENT CLUSTER}

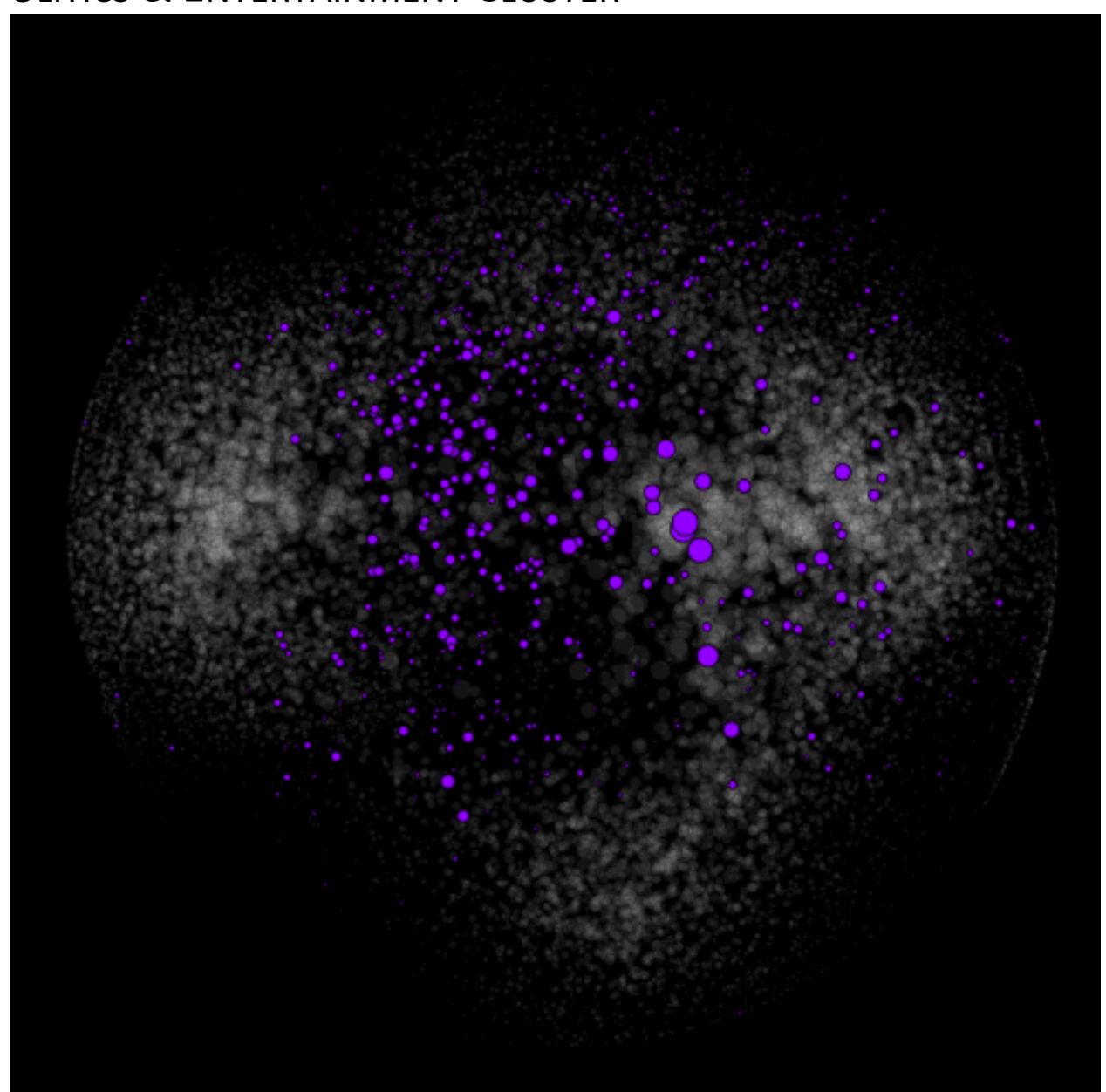

Figure 15: Media, Politics \& Entertainment Cluster

The Media, Politics \& Entertainment cluster is comprised of users that represent different sectors. It includes prominent politicians, TV presenters, actors, entertainers, and sports personalities. Some of the entertainers are also engaged in political activity; this group includes the movie director Khaled Youssef (@khaledyoussef_1) and political satirist Bassem Youssef (@DrBassemYoussef). Former president Muhammed Morsi and former presidential candidate Mohamed ElBaradei (@ElBaradei) both appear in this cluster, as does Barack Obama.

The discourse is mixed, ranging from commentary on Egyptian political and social topics to the discussion of TV programs, movies, and personal experience. This cluster appears to provide a partial but weak bridge across the highly polarized political communities in Egypt.

\section{Regional Dimensions of EgYPTIAN POLITICAL CLUSTERS}

A significant number of non-Egyptian users appear in the three political clusters, highlighting the regional and international followers of these different political groups. The Military-Aligned cluster includes accounts from the Gulf region that showed support for the removal of Morsi from power and continue to support Sisi. Examples include the account of the Head of General Security for the Emirate of Dubai Dhahi Khalfan (@Dhahi_Khalfan), who is known for his anti- 
Muslim Brotherhood tweets. In one tweet, for example, he describes the Brotherhood as "very stupid." 78

The Muslim Brotherhood cluster includes accounts of Islamists and sympathizers from the region. A set of prominent Muslim clerics from the Gulf countries whose followers are in the millions are in this cluster, including Mohamad Alarefe (@MohamadAlarefe, 12.1 million followers), Aaidh Alqarnee (@Dr_alqarnee, 9.45 million), Salman Alodah (@salman_alodah, 9.34 million), and Nabil Alawadhy (@NabilAlawadhy, 6.11 million).

The Non-Aligned cluster is more highly integrated with Western audiences, especially media that have been covering local human rights issues such as state restrictions on activities of human rights organizations and civil society. The Western media that appear in this cluster are more highly engaged with Egyptian bloggers who write in English.

The Social and Cultural cluster is less integrated with users outside of Egypt, although there are links with scattered like-minded individuals in the region.

\section{REGROUPING ONLINE}

The Twittersphere in Egypt has emerged as a space for campaigns and counter campaigns between the competing political rivals in Egypt. The government actors and loyalists to Sisi government compete on the online space to promote the government policies, amplify state viewpoints, and criticize oppositional voices.

The Egyptian authorities banned the Muslim Brotherhood in September 2013 after president Morsi was ousted from power and a court upheld a ruling banning the group in November 2013. ${ }^{79}$ Twitter serves as a parallel space for the Muslim Brotherhood to air its political grievances against the regime and to voice dissident views that are now restricted offline in Egypt. The group harnesses unfettered access to Twitter in Egypt to sustain its voice in opposition to the government.

Supporters of a civilian government continue to oppose both the military-aligned government and Islamists. They too maintain political protests on Twitter as a law enacted in November 2013 restricts street protests. Article 8 of the law states that: "Anyone wanting to organize a public meeting, march or protest must notify in writing the police station whose jurisdiction includes the public meeting's location or the starting point of a march or protest, the notification must be

given in a minimum of three working days prior to the public meeting, march or protest ...."80 The law requires protesters to submit to government authorities information about the location and subject of the march or protest, and names and addresses of the organizing individuals or organizations. Twitter has become an alternative space for civil society actors who oppose restrictions to freedom to assembly to protest the law itself and to campaign for the release of activists who have been arrested for presumably violated this law. These actors also use Twitter

\footnotetext{
${ }^{78}$ Dhahi Khalfan Tamim, Twitter post, Jun 7, 2015, 7:18 PM, https://twitter.com/Dhahi_Khalfan/status/607733364024483840.

${ }^{79} \mathrm{http}: / /$ www.aljazeera.com/news/middleeast/2013/11/egypt-court-upholds-muslim-brotherhood-ban2013116101936365849.html

${ }^{80}$ Full English translation of Egypt's new protest law, http://english.ahram.org.eg/News/87375.aspx
} 
as a virtual civil society space to highlight human rights violations and freedom of speech restrictions. In Egypt, as offline protests are actively suppressed by the government, online spaces are again the center of social mobilization.

\section{BAHRAIN TWITTERSPHERE}

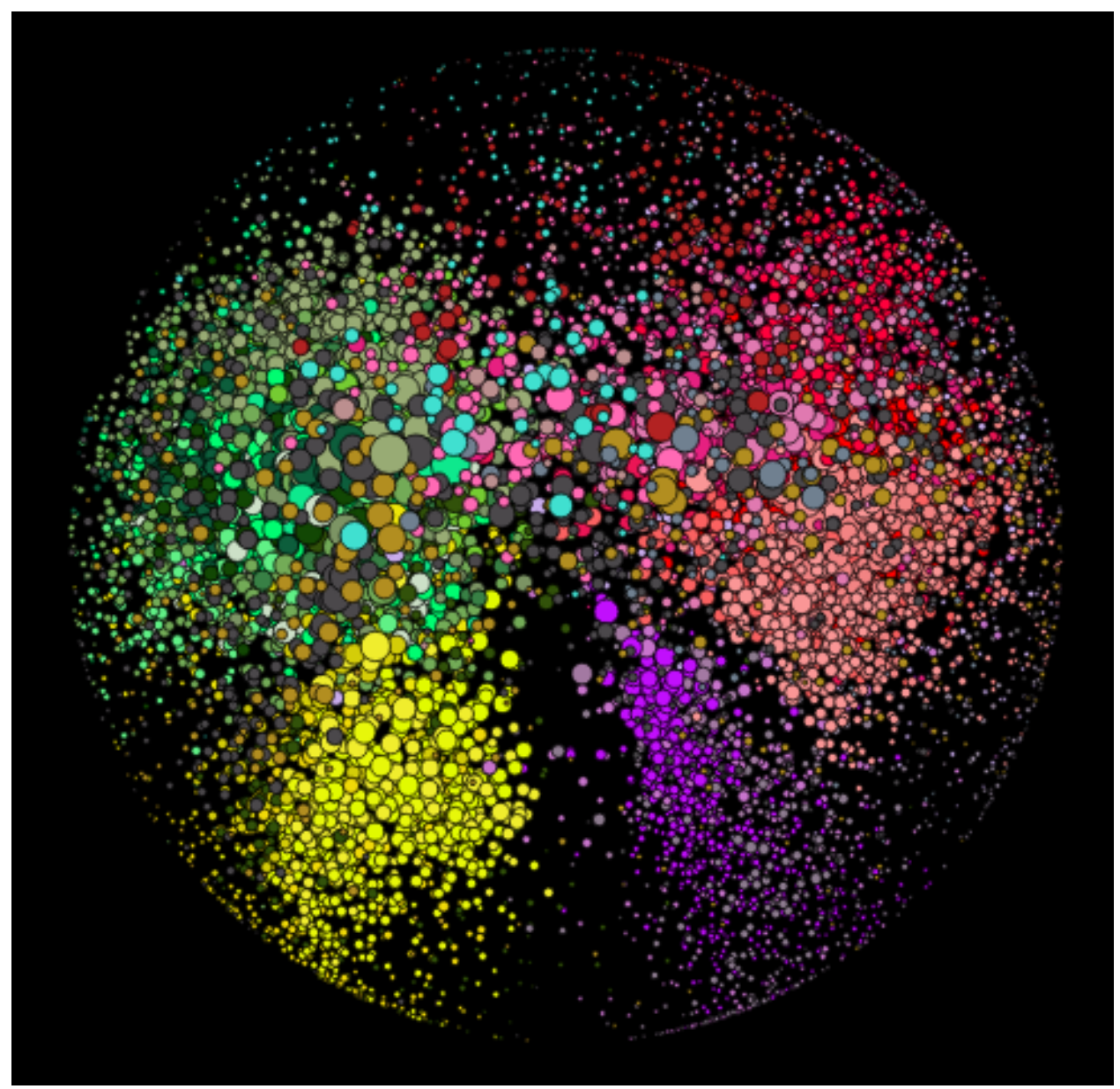

Figure 16: Bahrain Twittersphere Map

The mapping of discourse on Twitter in Bahrain reflects a nation divided across political and religious lines. The structure of the Bahraini Twitter map also reveals interesting and rich layers of detail. It not only shows the overall political and social divisions and tendencies in the country, but also highlights the variety within each of political groups, and the regional players and added dimensions of the discourse associated with each group.

The debates on Twitter in Bahrain are fueled by the use of pseudonymous accounts to express unpopular political or religious sectarian sentiments. This practice is prevalent on both sides of the debates.

The Bahraini network on Twitter is structured into four major groups with a focus on political issues, each of which is comprised of a number of clusters: the Bahraini Royal \& Sunni Group, the Bahraini Shia \& Opposition Group, the Regional Royal \& Sunni Supporters Group, and 
the Regional Shia \& Opposition Supporters Group. A fifth group comprised primarily of media organizations is cited by accounts from both sides.

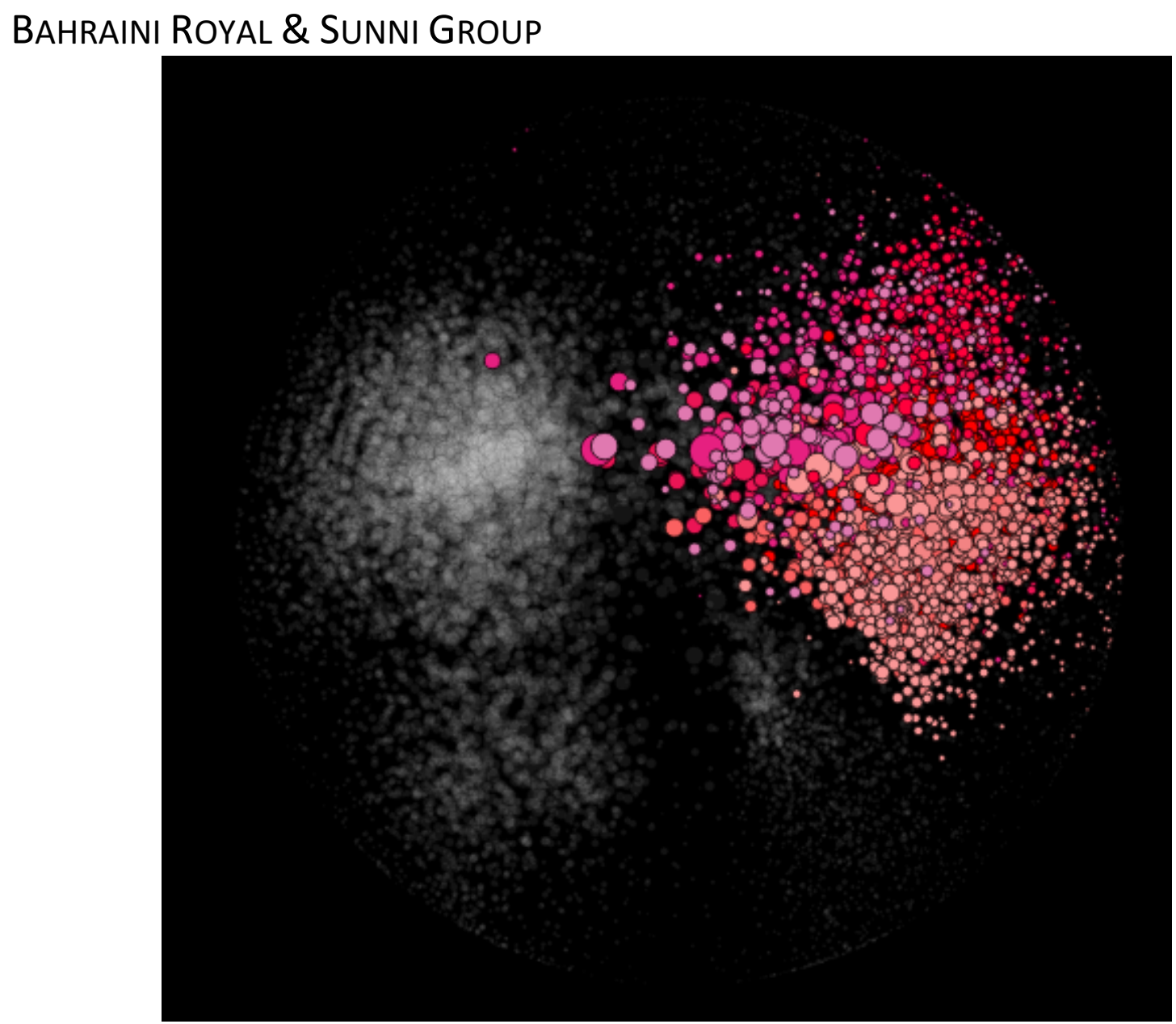

Figure 17: Bahrain Royal \& Sunni Group

The Bahrain Royal \& Sunni Group is made up of eight clusters comprised of individuals and institutions that are affiliated with or supportive of the current rulers in Bahrain. The users are sometimes critical of the government, but not of the regime.

Four closely related clusters are populated by journalists, politicians, parliamentarians, and private citizens, along with accounts used for Twitter information campaigns. These accounts typically discuss local political and social issues in Bahrain as well as news from the region. There is particular emphasis on countries where there are political or armed conflicts, such as Syria, Iraq, Lebanon, Egypt, and most recently Yemen. While discussion covers considerable political ground, one distinct feature of these clusters is that many of the users post news and views that are supportive of the monarchy and critical of the opposition. The clusters include pseudonymous accounts dedicated almost entirely to "defending" Bahrain ${ }^{81}$ and to criticizing the

${ }^{81}$ Example https://twitter.com/ElaAlBa7rain 
opposition. These accounts often use religiously demeaning terms ${ }^{82}$ and terms linking them to Iran, such as "Iran's mercenaries." 83 For example, when Hizbullah's Secretary General Hassan Nasrallah called his Shiite rivals in Lebanon "Shiites of the U.S. Embassy" and labeled them "traitors, collaborators and idiots," 84 users in these clusters posted a photo allegedly showing a Bahraini Shiite leader meeting with the US Ambassador in Bahrain, ${ }^{85}$ implying that Nasrallah's description applies to the Bahraini Shiite leader.

Users in these clusters express support for campaigns against Shiite groups in the region that are perceived as threats. For example, users support the Saudi-led military intervention in Yemen against the Shiite rebels known as Houthis, with many portraying the conflict as having a religious dimension, saying the war against Houthis is in defense of the Holy Mosque in Mecca. ${ }^{86}$

On the other hand, some users describe the conflict between Sunnis and Shiite as purely political, not sectarian, and support protection of their citizenship rights. ${ }^{87}$ In this context, many users condemned the bombing of a Shiite Mosque in Kuwait that killed 27 people in June 2015.

A separate set of four clusters in this group with similar users and content engage in stronger Sunni rhetoric. A higher proportion of accounts in these clusters use obvious Arabic pseudonyms. One account for example describes its objective as "Defending the Sunni community and exposing the Rafida" ${ }^{\prime 88}$ (a defamatory term for Shiites). Other examples include the Private Network to Defend Sunni Community (@Al3AMEED 70) and the Bahrain Defense Group (@BHRdefense). These accounts often commend the Sunni belief system and criticize Shiite doctrines.

$82 @ 7$ areghum, Twitter account, https://twitter.com/7areghum.

${ }^{83}$ Mohammed Khalid Boammar, Twitter post, Jun 25, 2015, 6:53 PM, https://witter.com/boammar/status/614250175884689409.

84 "Everyone has role to play in 'existential' Syria battle: Nasrallah," The Daily Star, May 23, 2015, http:/www.dailystar.com.lb/News/Lebanon-News/2015/May-23/299087-everyone-has-role-to-play-in-existentialsyria-battle-nasrallah.ashx.

${ }^{85}$ Muwatin Khaliji, Twitter post, May 28, 2015, 11:58 AM, https://twitter.com/Lion King Bhr/status/603998905211060224.

${ }^{86}$ Amani Alabsi, Twitter post, Mar 31, 2015, 8:12 AM, https://twitter.com/amanialabsi/status/582923375082754049.

${ }^{87}$ Mohammed al-Othman, Twitter post, Jun 27, 2015 2:31 AM, https://twitter.com/m_alothman/status/614727677430231044.

$88 @$ @bahraindefence, Twitter account, https://twitter.com/bahraindefence. 


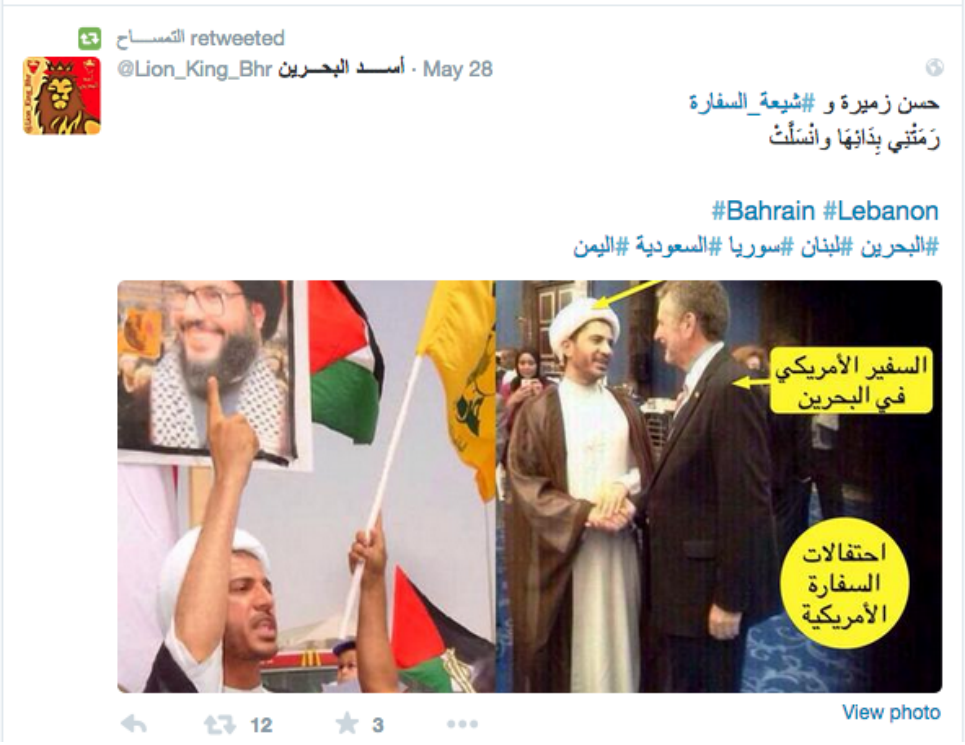

Figure 18: Users in Bahraini loyalist clusters posted a photo allegedly showing a Bahraini Shiite figure with the US Ambassador in Bahrain. The photo was posted after Hizbullah's leader criticized his Shiite rivals for being "Shiites of the US Embassy."

\section{BAHRAINI OPPOSITION \& SHIA GROUP}

Figure 19: Bahraini Opposition \& Shia Group 
This group includes 11 clusters of individuals, groups, and organizations opposing the monarchy. Two related clusters are populated by opposition groups, leaders, and activists. Some of the accounts in these clusters describe themselves as representatives of the revolution against the monarchy in Bahrain ${ }^{89}$ and say their mission is to remove the Bahraini regime. ${ }^{90}$ The clusters also include accounts of prominent Bahraini human rights activists such as Nabeel Rajab (@NABEELRAJAB). The users disseminate information about alleged arrests and torture of Bahraini state opponents ${ }^{91}$ and often call for political demonstrations against the state ${ }^{92}$ and post photos of protest events. Several accounts are dedicated to campaigns to free jailed opposition leaders. ${ }^{93}$ The use of Shiite rhetoric is common in these clusters.

Four clusters in this group contain accounts that focus on grassroots-level activism and locationspecific news at the village ${ }^{94}$ and municipality levels, ${ }^{95}$ and include youth-led activist groups. ${ }^{96}$ The use of Shiite rhetoric is strong in these clusters, and many accounts use profile names that are obvious pseudonyms. Two additional clusters with similar users and content contain more human rights activists and lawyers, whose online activities are dedicated to exposing what they call the regime's violence against dissidents and calling for legal representation to defend the victims of such violence.

Regional issues are occasionally discussed, especially topics related to other Shiite groups. A number of users express support for the Yemeni Shiite Houthi rebel movement and its leaders, despite the fact that Bahrain is part of the Saudi-led coalition fighting the Houthis. In June 2015, a court in Bahrain sentenced a political opposition leader to 5 years in prison for tweeting comments critical of Bahrain's participation in the coalition. ${ }^{97}$

\footnotetext{
${ }^{89}$ Examples: https://twitter.com/14FebTV; https://twitter.com/BaniJamrah_News; and https://twitter.com/COALITION14.

$90 @$ MahazzaMedia, Twitter account, https://twitter.com/MahazzaMedia.

${ }^{91}$ Broken Angel, Twitter post, Aug 10, 2014, 12:34 AM, https://twitter.com/BrokenAngeL077/status/498371862313725954.

${ }^{92}$ Mohamed Ali Altal, Twitter post, Jun 12, 2015, 2:38 PM, https://witter.com/mohdaltal/status/609474914056278016.

${ }^{93}$ Example: https://twitter.com/BAHRAINDOCTOR.

${ }^{94}$ Example: https://twitter.com/alkawarahnews.

${ }^{95}$ Example: https://twitter.com/juffair14media.

$96 @$ DurazYouth, Twitter account, https://twitter.com/DurazYouth.

${ }^{97}$ al-Rai Media, "al-Bahrain: al-sijn khams sanawat lisiyasi muared bisabab tagridah hawl al-yaman”, Bahrain: 5year prison sentence for a political opponent over a tweet about Yemen, http://www.alraimedia.com/Articles.aspx?id=602834 Jun 28, 2015, [Arabic]
} 


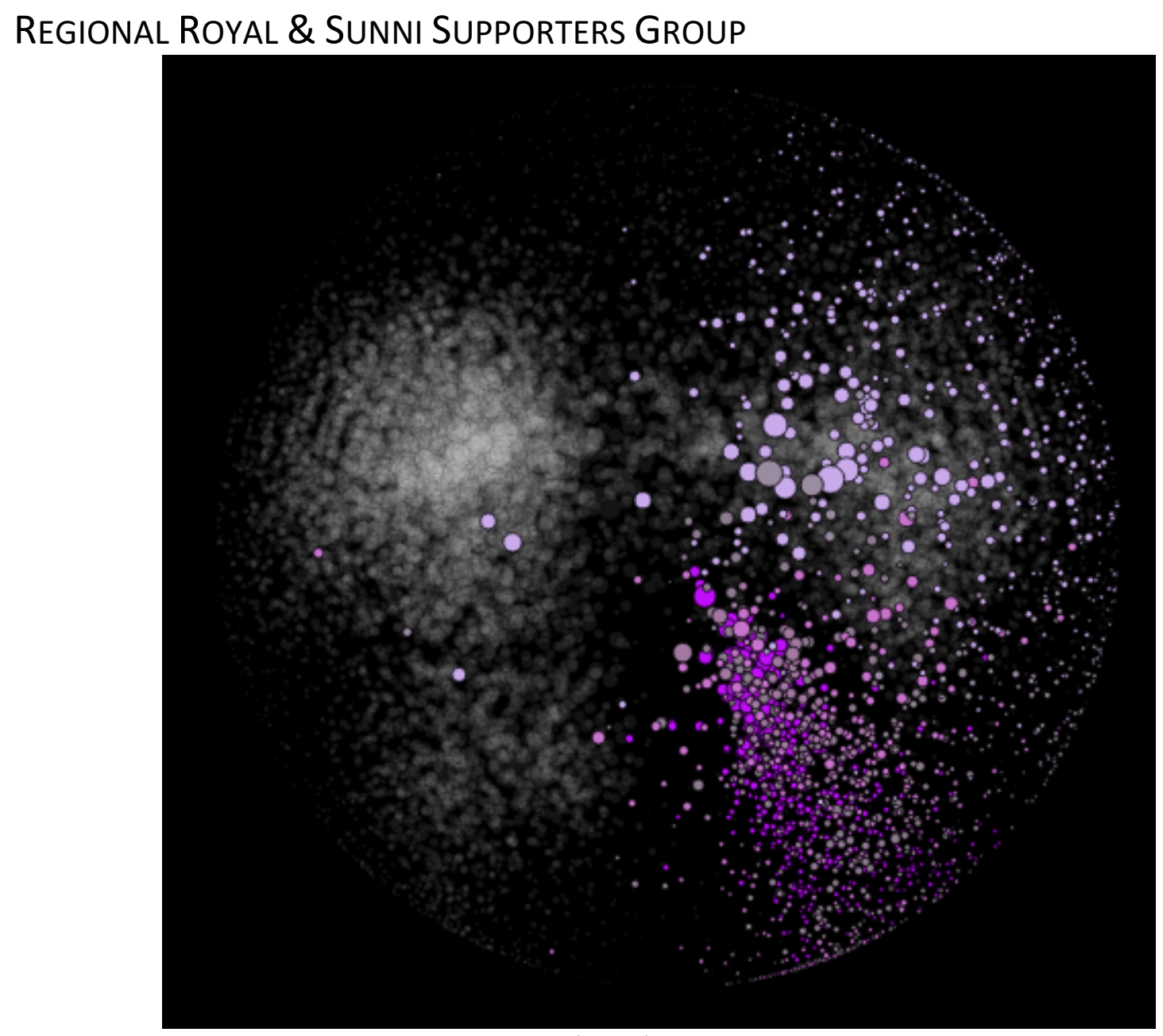

Figure 20: Regional Royal \& Sunni Supporters Group

Regional clusters aligned with the state have an extended presence in the form of 6 clusters that are populated by non-Bahrain users who express support for the Bahraini state and criticize the opposition, usually with a sectarian slant. Some of these clusters have content that appeals to Sunnis in general but do not proactively support the monarchy in Bahrain. The users come from Sunni communities mostly in the Gulf countries.

Accounts in the Gulf Islam cluster include Muslim clerics from the Arab Gulf countries and Arab political commentators tweeting about religious issues in relation to politics in the region. A Gulf media cluster is comprised of accounts of media outlets, journalists, and celebrities from the region, including Bahrain, posting news and views on current affairs in the region. 
Three clusters are populated by accounts from the Gulf states, which includes Bahrain. They tend to tweet Sunni Islam religious texts, most of which are generic in nature and do not address specific events or issues. They also post commentary on various cultural aspects on their societies, such as behavior, values, and beliefs. A large proportion of a mixed cluster of accounts from the Arab Gulf countries focus on social media marketing. There are also accounts tweeting content about sports, poetry, and culture, which have general appeal to Arab speakers from the region.

\section{REGIONAL SHIA \& OPPOSITION SUPPORTERS GROUP}

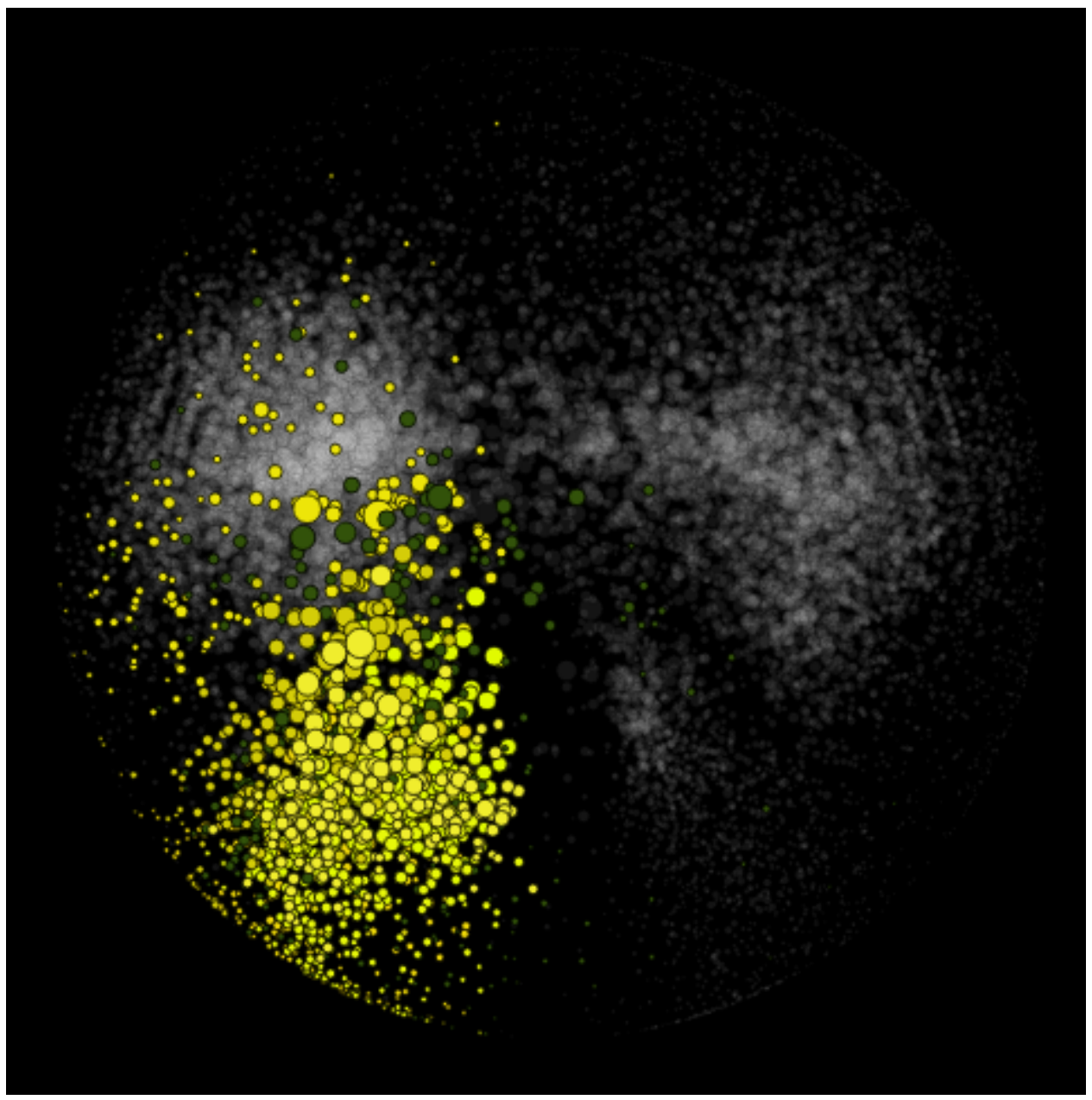

Figure 21: Regional Shia \& Opposition Supporters Group

Like the loyalists group, this network has a regional non-Bahraini dimension in the form of seven distinctively Shiite clusters that consist of users expressing sympathy with the opposition movement in Bahrain, often along sectarian lines. Some of these clusters have content that attracts Shiites in general but do not proactively support the opposition in Bahrain.

One cluster is populated by accounts of Shiite leaders from Saudi Arabia such as Hasan AlNemer (@alnemernet); pseudonymous accounts promoting grievances of Shiites in the Kingdom such as "The Frees of Qatif” (@qatifpower) and "Revolution in Sharqia” (@Sharqiyah) (Eastern Province), which are areas with Shiite concentration; users discussing what they call the anti- 
Shiite environment in Saudi Arabia (one example cited was in academia) ${ }^{98}$ and accounts of Saudis critical of what they consider Saudi Arabia's sponsorship of Wahhabism. ${ }^{99}$ The cluster also includes Saudi accounts with broader interests and several Shiite individuals and organizations from the region. Mentions of Shiite grievances in Bahrain occasionally feature in this cluster. Two additional clusters are populated by accounts from Iraq, Kuwait, and Lebanon, along with many accounts that do not mention specific locations. These accounts tweet religious Shiite texts, prayers, songs, and poetry that do not address specific events, and are similar to literature posted by Shiites in Bahrain. There is little commentary on political and social issues in these clusters. Another cluster is devoted to Kuwaiti politics and social affairs. It is populated predominantly by accounts from Kuwait, most of which discuss local political affairs. Some of the accounts belong to self-professed Kuwaiti Shiite individuals or organizations, with discussion focusing primarily on issues related to the Shiite community there.

\section{BRIDGE GROUP}

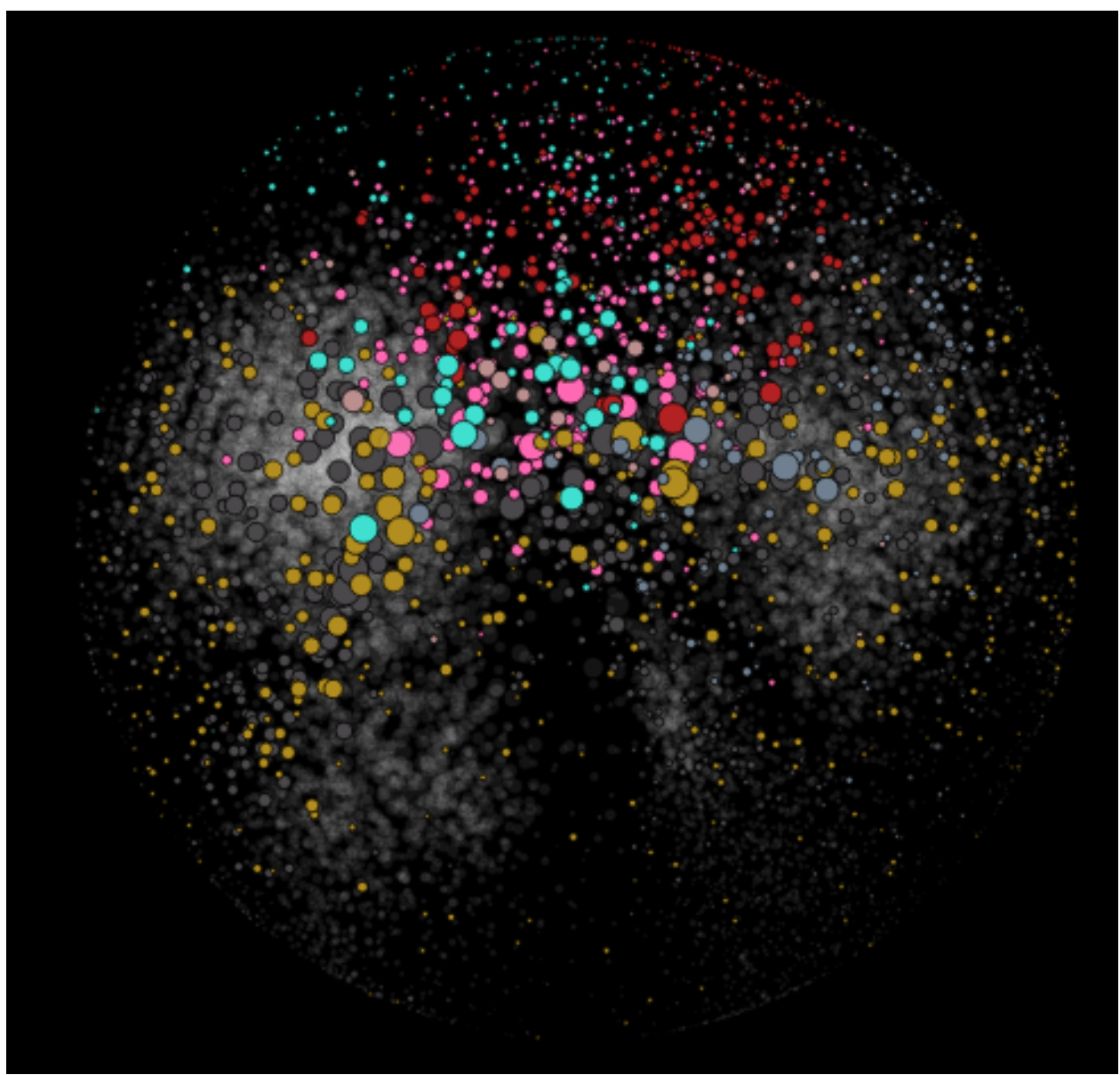

Figure 22: Bridge Group

\footnotetext{
${ }^{98}$ Fuad Ibrahim, Twitter post, May 30, 2015, 12:50 PM, https://twitter.com/fuadibrahim2011/status/604736570080555008.

${ }_{99}$ Hamza al-Hassan, Twitter post, Jun 17, 2015, 2:22 AM, https://twitter.com/hamzaalhassan/status/611101639467003904
} 
The map includes seven clusters from the region with religious, political, and/or cultural relevance to the clusters in the Bahrain map.

A cluster in this group contains several government media sources such as the Ministry of Interior (@moi_bahrain) and government officials such as the Minister of Information Affairs (@iBahrain), all of which disseminate state official statements. The cluster also includes accounts of various media outlets and a few bloggers and entrepreneurs. There is no single common theme of discussion in this cluster; it is instead defined largely by its institutional participants. Another cluster contains accounts of Saudi Sunni religious clerics, media organizations, and journalists. Discussion is centered around local political, social, and religious issues with occasional commentary on regional affairs, including Bahrain. A Kuwaiti political cluster is populated by Kuwaiti parliament members, politicians, and political commentators as well as religious figures whose posts address political affairs in the country, the Gulf states, and the Middle East. A cluster within this group that pays particular attention to Egyptian politics is populated by Egyptian politicians, journalists, activists, and bloggers. The users in this cluster, especially the activists and bloggers, occasionally refer to political affairs in Bahrain. Another cluster is populated primarily by accounts of media organizations, many of which are pan-Arab, as well as accounts of individuals commenting on stories from those media outlets. Another cluster is populated by technology companies and accounts focused on international foreign policy. This cluster includes accounts of US technology companies such as Google and Twitter; media such as NY Times and CNN; politicians such as President Barack Obama and UK Prime Minister David Cameron; and a mix of accounts from the region from different backgrounds. The cluster is not conversational. There is also a cluster populated almost exclusively by accounts of English language and international media from Europe and North America, most of which cover global affairs and foreign policy.

\section{POLARIZATION AND DISCOURSE}

Some official government accounts promote collegiality between the Sunni and Shiite sects. Such content is not uncommon in accounts such as that of Khalid Al-khalifa, Foreign Minister of Bahrain. In one tweet he posts a complimentary quote from a prominent historical Sunni figure about a Shiite scholar, ${ }^{100}$ and in another he says Sunni and Shiite sectarian schools learn from and respect each other and blames politics for polluting the relationship between the two sects. ${ }^{101}$ Commenting on the terror attack that killed worshippers in Kuwait in June 2015, a Sunni religious cleric from Bahrain said the dispute with the Shiites does not justify killing them. ${ }^{102}$ Opposition leaders tweet similar statements and make a distinction between the Sunni sect and politicians. For example, the account of the opposition group Alwefaq Society tweeted a statement from opposition leader Khalil Al-Marzouki saying: "When mosques are demolished we say the state did it, not the Sunnis. The state oppresses, not the Sunnis."103

\footnotetext{
${ }^{100}$ Khalid bin Ahmed, Twitter post, Jun 29, 2015, 4:44 PM, https://twitter.com/khalidalkhalifa/status/615667218580287490.

${ }^{101}$ Khalid bin Ahmed, Twitter post, Jun 29, 2015, 5:16 PM, https://twitter.com/khalidalkhalifa/status/615675317168902145.

${ }_{102}$ Dr. Hasan al-Husaini, Jun 26, 2015, 3:27 PM, https://twitter.com/7usaini/status/614560602086715392.

${ }^{103}$ Alwefaq Society, Twitter post, Mar 16, 2014, 11:37 AM, https://twitter.com/ALWEFAQ/status/445267528169058304.
} 
However, a sectarian narrative appears in the Bahraini Twittersphere in both the loyalists and the opposition networks. It is most visible in the accounts that use pseudonyms. Many accounts in the loyalist networks frame the loyalist-opposition tension as a Sunni-Shiite conflict. These accounts do not merely state that they are supporting the state, but explicitly say in their account descriptions that they are defending the Sunni community ${ }^{104}$ against what they call Rafida, ${ }^{105}$ a derogatory term used by some Sunni Muslims to refer to Shiite Muslims. Others in this network refer to Shiite political activists as Safavid ${ }^{106}$ (a dynasty in Persia), also a derogatory term used by Sunnis, which implies that the person is not originally Arab, but rather is of Persian origin.

Some loyalists rhetorically connect opposition figures and activities to an Iranian agenda. For example, accounts supporting the monarchy welcomed the government order to block a forum website run by the opposition, and one user said the forum is affiliated with Iran's Guardianship of the Jurist. One tweet twisted the Arabic name of the Iranian body to mean the "Guardianship of the Lewd Ones." ${ }^{107}$ It is not uncommon for pseudonymous accounts in the loyalists network to refer to Bahraini Shiites using offensive terms, for example comparing them to animals, ${ }^{108}$ or for them to criticize Shiite religious concepts sarcastically, for example by referring to the "Guardianship of the Islamic Jurists."109

On the other side of the divide, users in the opposition network often accuse the state of sectarian bias. For example, some accounts accused the state security forces of protecting a newspaper building and preventing protests against the newspaper after it published what the tweet called an article insulting the Shiite sect in Bahrain. ${ }^{110}$ Other tweets said the Bahraini regime does not recognize and honor Shiite religious occasions such as Ashora, ${ }^{111}$ which is commemorated by Shiite Muslims as a day of mourning for the martyrdom of al-Hussein, the grandson of prophet Mohammed. Al-Hussein was killed in 680, an event that fueled a Shiite-Sunni rift and later a Shiite movement. Others critique the Sunni Muslim establishment in the country. For example, an activist tweeted that unlike the Sunni mosques, the Shiite mosques are more politically independent and thus not subject to regime's political influence. ${ }^{112}$ Moreover, some accounts frame the rift between the state and the opposition in the context of the historical dispute between Shiites and Sunnis. For example, an account ${ }^{113}$ that highlights the plight of the Shiite population

\footnotetext{
${ }^{104}$ Examples: https://twitter.com/AL3AQEED_85, https://twitter.com/A13AMEED_70, https://twitter.com/ALNAQ33B, and https://twitter.com/ALMO8ADAM_77.

${ }^{105}$ Example: https://twitter.com/bahraindefence.

${ }^{106}$ Examples: bahrainiriffai, Twitter post, Jan 3, 2013, 9:47 AM, https://witter.com/bahrainiriffai/status/286891495745806337. and bahrain iriffai, Twitter post, Jan 9, 2013, 1:30 PM, https://twitter.com/bahrainiriffai/status/289121963459350529.

107 Samahat alsiyyd harikhum, Twitter post, Aug 3, 2013, 4:23 PM, https://twitter.com/7areghum/status/363802255121592320.

${ }^{108}$ Soqur alkhasah albahrainiyah, Twitter post, Sep 28, 2014, 1:15 PM, https://twitter.com/sagor565/status/516320194243723264.

${ }^{109}$ Wikalat anbaa yegoloon, Twitter post, Sep 1, 2014, 12:29 AM, https://twitter.com/YegoloonNews/status/506343108443787264.

${ }^{110}$ Elaam madinat alshuhada, Twitter post, Jul 24, 2014, 2:28 PM, https://twitter.com/Martyrs14Feb/status/492421123313659904.

${ }^{111}$ South elhak, Twitter post, Sep 21, 2014, 4:13 AM, https://witter.com/14FEBRiGhTVoiCe/status/513647077599895552.

${ }^{112}$ Nabeel Rajab, Twitter post, Jul 30, 2014, 12:22 AM, https://twitter.com/NABEELRAJAB/status/494382505248964608.

$113 @ A l M o d m o r$, Twitter account, https://witter.com/AlModmor.
} 
in Bahrain and reports stories of what it calls the victims and martyrs of the regime's violence attaches to its tweets religiously loaded Arabic hashtags such as "al-Hussein is the leader of the revolutionaries."

The Twitter map seems to reflect deep-rooted divisions between the government loyalists and the opposition in Bahrain. We do not find strong evidence that the online space is bridging gaps between the rivals. In contrary, inflammatory rhetoric is loud, and collective action in the form of information campaigns from the adversaries against each other is strong. Also, there is limited conversation between the competing actors on how best to build cohesion, and when such conversation occurs it indicates that the division is more than just rhetorical. When the Foreign Minister of Bahrain tweeted that the presence of separate Mosques for Sunnis and other ones for Shiites invites schism and that Muslims should have one mosque and one prayer, a critical reply claimed discrimination at a wide level, saying there were government ministries for Sunnis and other ones for Shiites; schools for Sunnis and other ones for Shiites; job opportunities and scholarships for Sunnis and other ones for Shiites. Another one sarcastically asked the government official, "Is that why you demolished the Shiite mosques?"114 Similarly, when the Alwefaq Society opposition leader tweeted about blaming the state rather than the Sunnis for demolishing Shiite mosques, a user replied: "damn the Nawasib Sunnis of Bahrain." ("Nawasib" is a religiously derogatory term used by some Shiites to refer to Sunnis.)

On the other hand, the space does serve as a platform for citizens to express speech on various political and nonpolitical issues. Users within the loyalists clusters do often criticize the government on local policies, though most of the criticism is not addressed at the regime itself. For example, one tweet criticizes the government policy permitting the sale of alcohol in the local market. Discourse in these clusters is not strictly regime-aligned on foreign affairs. The perspectives of private citizens at times diverge from the positions put forth by the official accounts of government media outlets and officers. For example, it is not uncommon for private citizens to condemn and criticize Egyptian President Abdel Fattah al-Sisi's regime for various reasons. When Al-Sisi allegedly mocked oil-rich Arab states in a leaked audio recording, ${ }^{115}$ one tweet read "Al-Sisi despises the Gulf states. Ok, the Gulf states despise Al-Sisi."116

\footnotetext{
${ }^{114}$ Khalid bin Ahmed, Twitter post, Jun 26, 2015, 4:37 AM, https://twitter.com/khalidalkhalifa/status/614396944706711552.

115 “Egypt's president allegedly mocks Gulf wealth,” BBC, February 10, 2015, http://www.bbc.com/news/blogstrending-31301903.

${ }^{116}$ Mansoor biezenellah, Twitter post, Feb 7, 2015, 1:44 PM, https://twitter.com/Mansor_Tariq/status/564177847363715072.
} 


\section{TUNISIAN TWITTER}

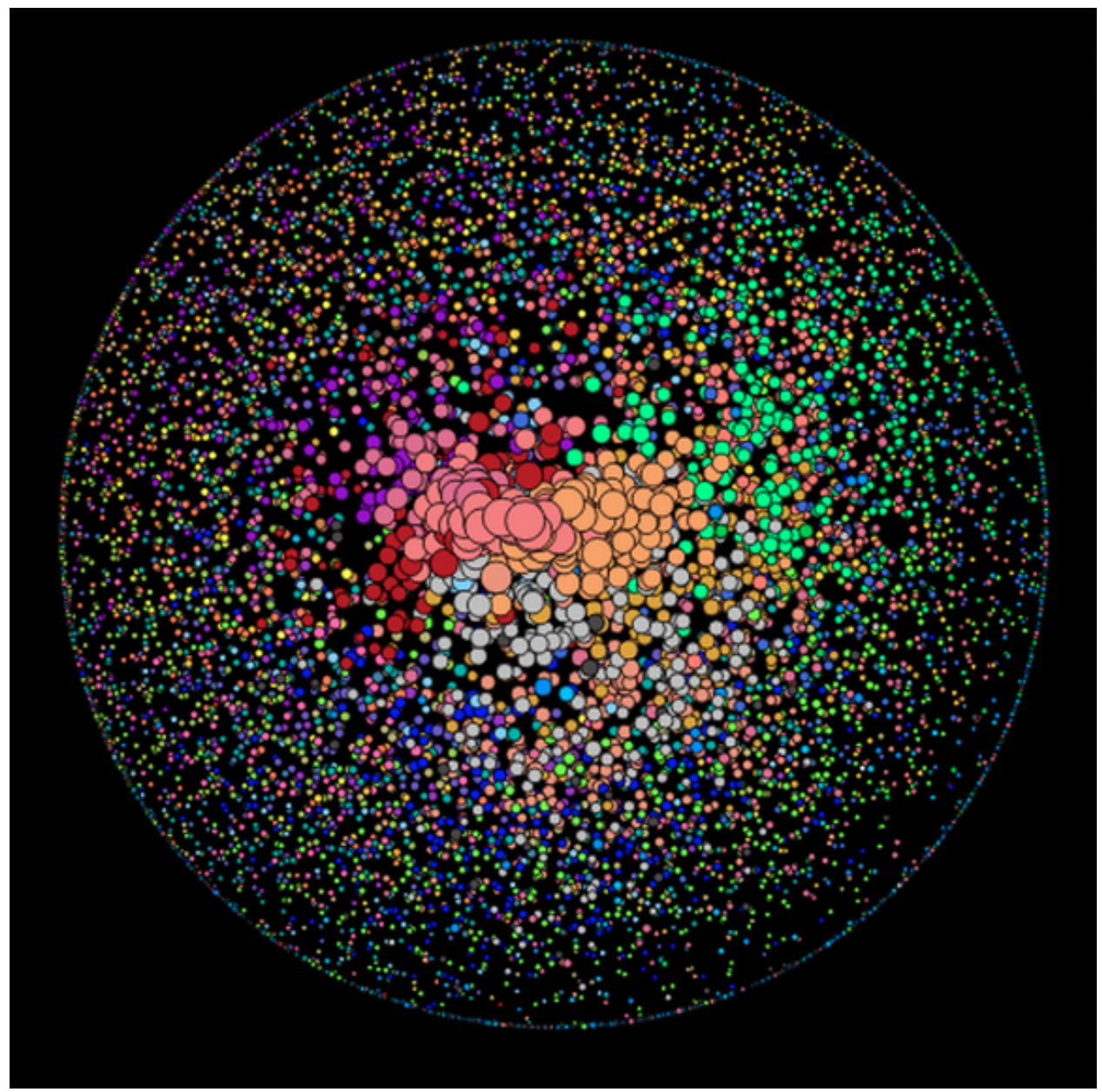

Figure 23: Tunisian Twitter Map

Participation and dialogue on Twitter in Tunisia is heavily slanted towards activists and individual civil society voices and those with an interest in net freedom and human rights. Many of the most prominent users in the network were bloggers and early Internet adopters who pushed for Internet freedom and political reform in Tunisia. These users appear in a group of clusters where most of their activities promote human rights and democracy ${ }^{117}$ and anticensorship. ${ }^{118}$ Progressive movements such as Ettajdid (@ettajdid_tn) populate this group, and the discussion has a liberal outlook. The discourse has evolved to include new national concerns such as radicalism and corruption during incumbent governments. For example, users often express concern over what they consider radical religious practices in the society and within the government affiliated authorities; ${ }^{19}$ run initiatives to fight corruption and enhance transparency; ${ }^{120}$ support campaigns such as "Where is the oil" (a campaign that claimed

\footnotetext{
$117 @$ freetunisia, Twitter account, https://twitter.com/freetunisia.

$118 @$ Astrubaal, Twitter account, https://twitter.com/Astrubaal.

${ }^{119}$ Haythem El Mekki, Twitter post, Jul 1, 2015, 3:18 PM, https://twitter.com/ByLasKo/status/616370191929356288.

120 @ IwatchTn, Twitter account, https://twitter.com/IwatchTn.
} 
mismanagement and corruption in the government handling of the country's national wealth in Tunisia); and report what they describe as police harassing and arresting activists. ${ }^{121}$

Technology entrepreneurs, ${ }^{122}$ digital marketers, hackers, ${ }^{123}$ and techies ${ }^{124}$ whose interests are more on the social and entrepreneurial side of technology feature prominently in the map. Such users often engage in political discourse but not extensively. Also active in the map is a large community of private citizens who come from different backgrounds and do not seem to be involved in public or organized activities. The users post political and social commentary, but do not have a strong political agenda or focus and are not engaged in proactive activism. Their comments are often critical of politicians and politics but do not amount to committed activism.

Politicians, political parties, and those with specific political agendas are less prominent on the map, and unlike in the Egypt and Bahrain maps, they do not occupy distinct sets of clusters. Accounts of government officials and institutions and of political parties and their leaders populate the same set of clusters. One cluster, for example, includes accounts of members from Al Massar Démocratique et Social (@samirtaiebTN), Al-Nahda party (@NahdhaTunisie), Le Congrès Pour la République (@CPRTunisie), bureau politique d'Ettakatol (@KhelilEzzaouia), former president Moncef Marzouki (@Moncef_Marzouki), parliamentarians (@iyeddahmani), and the Tunisian general Union of labor (@UGTT_TN). The tweets in this cluster are primarily official statements from the account holders. Also, unlike in the Egypt and Bahrain maps, political state and non-state rivalries do not translate into political clusters and define the structures of the networks; among the politically-interested users in the map, following leaders from different political perspectives is not unusual. Moreover, the political discourse in clusters populated by politicians and political parties is not conversational; it is limited to mostly official statements and commentary.

The structures of the map (and lack thereof) appear to be driven more by personal and social interests among a more homogenous network of users (compared to Egypt and Bahrain), which results in a less segmented network space. Worth noting is that Facebook has a much higher penetration rate compared to Twitter in Tunisia. As a Tunisian journalist puts it, "In Tunisia, Internet is Facebook." 125 The demographics of Twitter in Tunisia skew towards better educated professionals and those with secular and progressive world views. This appears still to be an elite discussion space, and thereby a poor reflection of the overall political and social sentiments in Tunisia. Politically and socially conservative voices do not have visible presence on the map. Because of the less than representative set of users, we are unable to conclude that the Twitter map is a clear reflection of lower political polarization in Tunisia.

${ }^{121}$ Bassam, Twitter post, Jun 6, 2015, 12:39 PM, https://twitter.com/tounsiwaftakhir/status/607270548608032769.

$122 @$ nayzek, Twitter account, https://twitter.com/nayzek.

$123 @$ @urbopape, Twitter account, https://twitter.com/turbopape.

$124 @$ aliboulila, Twitter account, https://twitter.com/aliboulila.

125 Abdulmagsood Khadr, Masr al-Arabia, "Sahifa fransiya: Facebook yohaimin ala misr wa tunis wa almagrib," French newspaper: Facebook dominates in Egypt, Tunisia, and Morocco, Jun 5, 2015, http://brk.mn/masralarabia (Arabic). 


\section{CORE GROUP}

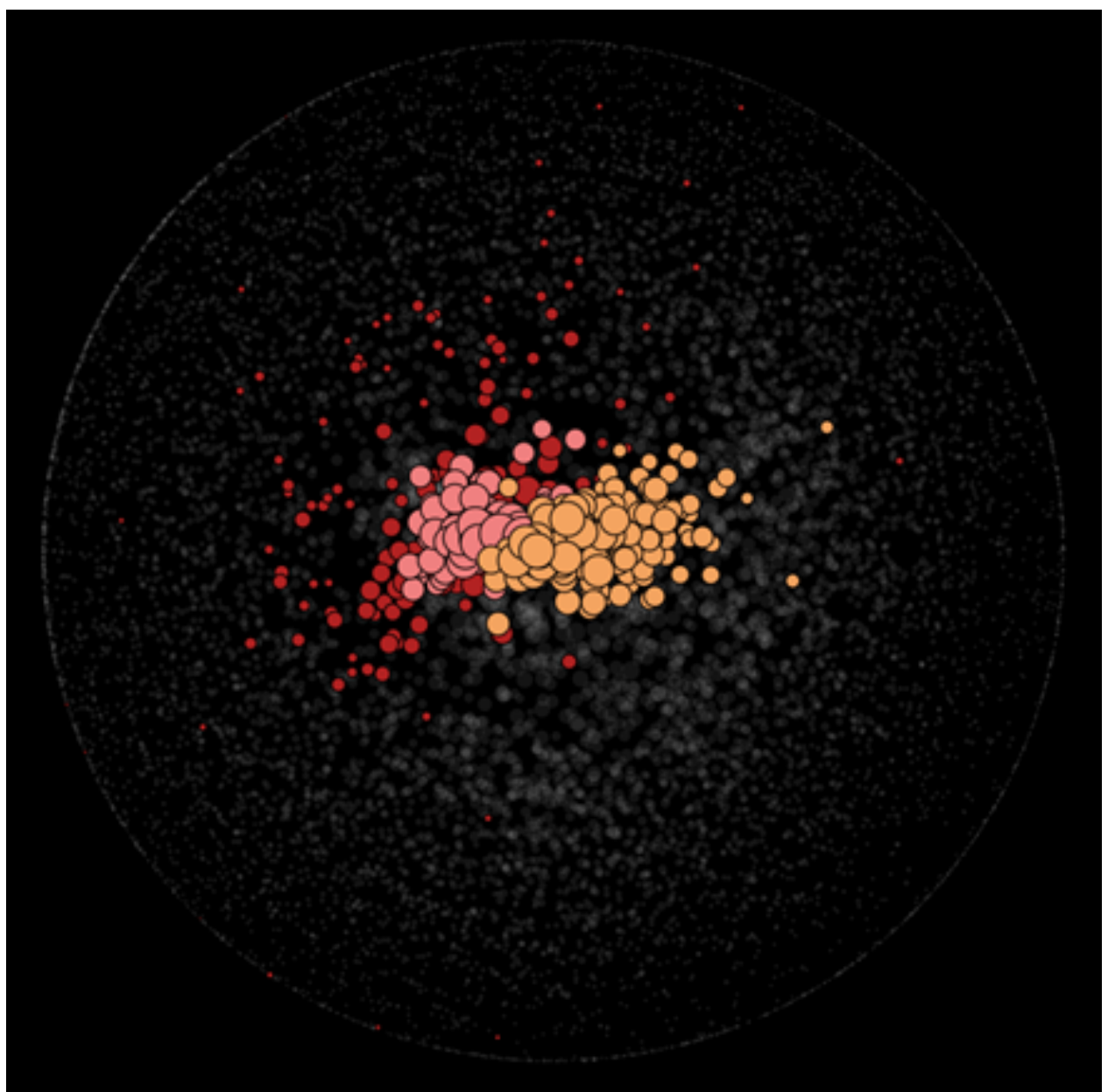

Figure 24: Core Group

Three clusters populated by the most popular accounts in the network occupy the center of map, with followers coming from across the network. The Core Group includes representation of the themes and communities found throughout the map, with the exception of few governmental voices. Users in this group are located primarily in Tunisia. They post in French, Arabic, and English and draw upon international news and conversations. Users in this group average several thousand followers from the overall network, which consists of just over ten thousand accounts. Discourse is centered around local political and social affairs as well as the intersection of technology and political and social development. Many users in this group advocate for political reform, digital rights, and net freedom.

One of these clusters consists largely of free speech advocates and freelance reporters, and includes a number of satirists. Many followed accounts are protected. The general slant of discourse indicates support for Tunisia-based political and social organizations. Hashtags include "\#nawaat" in reference to the Tunisian human rights organization. A second cluster shows a high interest in politics, including the Ennahda Party, and contains the accounts of prominent political figures and tech-focused users. The third cluster at the center of the map is populated predominantly by young, tech-oriented Tunisians. The discourse slants towards liberal and 
progressive viewpoints. Users in this cluster are informed by diverse online resources such as Tunisian social media marketing pages and Bloomberg View.

\section{POLITICAL \& SOCIAL COMMENTARY GROUP}

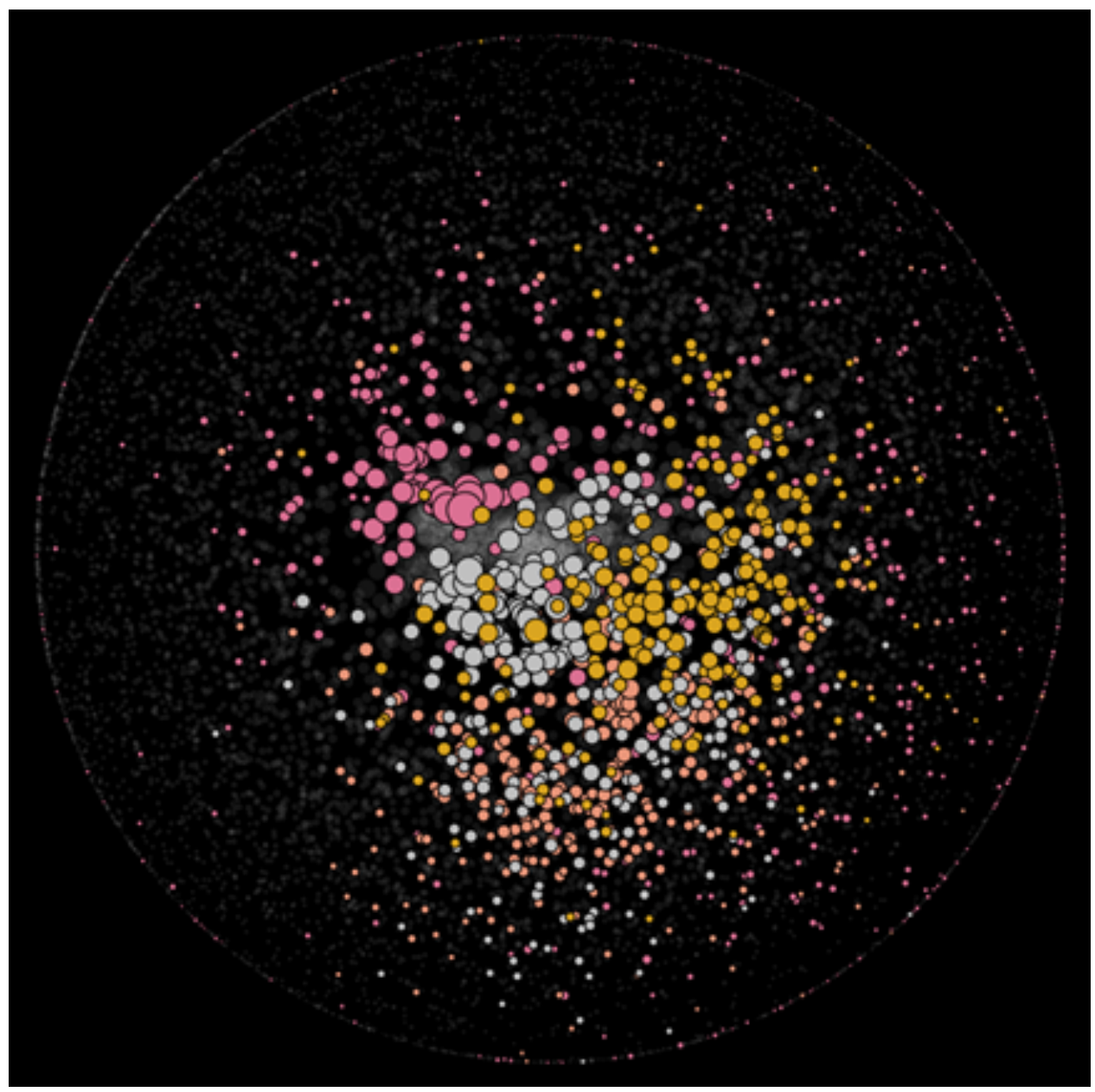

Figure 25: Political \& Social Commentary Group

The group is populated by users from diverse backgrounds, most of whom do not align themselves with any particular political agenda. Many of the users reside in Tunisia; others live in France and other countries. The users tweet about personal matters but comment on various local political and social affairs, entertainment, and sports. They also post reactions to events and media stories in the region and in the world. Though the commentary can be critical, the group as a collective does not adopt any particular political slant or agenda, nor does it engage in proactive activism on the various issues discussed.

One of the three clusters in this group appears to consist predominantly of female voices and preferentially follow political commentators and politicians who are women. Some of the topics found in this group include Internet governance, European debates concerning international relations, and advice on using Twitter to reach audiences effectively. Many users in this group show an interest in technology and engineering. Others focus on popular culture, music, and sports. This group appears to be a younger demographic, given that some indicate affiliation with 
a university in Tunisia and one of the most popular hashtags is "\#reformecollege [reform university]." Finally, there is indication of a peripheral interest in mainstream, progressive politics (e.g., retweeting the Socialist Party of France and France 24 anchor @,FrancoisF24, and linking to mainstream news sites) and world events (e.g., the "\#cuba" hashtag). Several of the most popular accounts in this group are mainstream media sources from France, such as Le Monde.

\section{TECH FOCUS GROUP}

This group is a community of mostly technology entrepreneurs, digital marketers, hackers, and techies, as well as bloggers and journalists. The group's common interests center around the social and entrepreneurial side of technology, the use of digital tools for communication and marketing, and open source code. Political discourse is occasional and is often in reaction to major events.

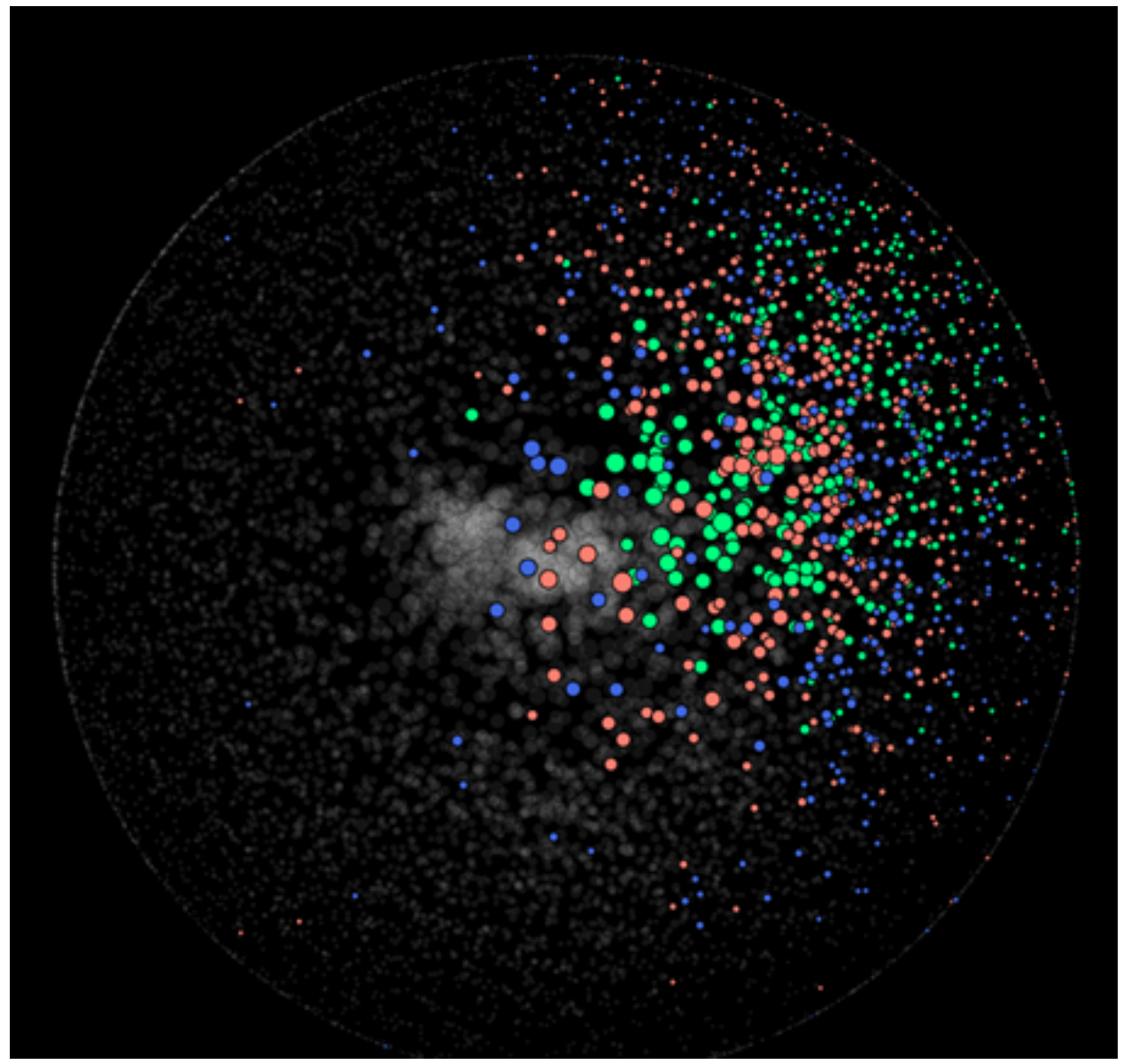

Figure 26: Tech Focus Group

Users in this group display an interest in open innovation, Internet policy, and politics through a tech prism (e.g., Anonymous, the French Pirate Party). Many users tend to have a hacker ethos and support issues related to a free and open Internet. Topics of interest include net neutrality and the first Arab Wikipedia conference (WikiArabia Tunisia), among other similar topics. 
Twitter users in this group frequently link to news resources focused on social media, the Web, and entrepreneurship-focused publications, such as Kim Dotcom, Verge, The Next Web, and Business Insider. Compared to other clusters, users in this group tend to share links with English language and US sources, including business and tech oriented news coverage like Mashable and Fortune, and more academic sources like CFR and academia.edu.

\section{POLITICS \& POLITICIANS GROUP}

This group is comprised of accounts of government institutions and officials, parliamentarians, partisan politicians, and political parties from a wide political spectrum, including Al Massar Démocratique et Social, the Al-Nahda party, Le Congrès Pour la République, and bureau politique d'Ettakatol. The accounts tweet mostly official statements, and there is limited conversation and interaction between the users. Accounts of local and French political media appear among users in this group.

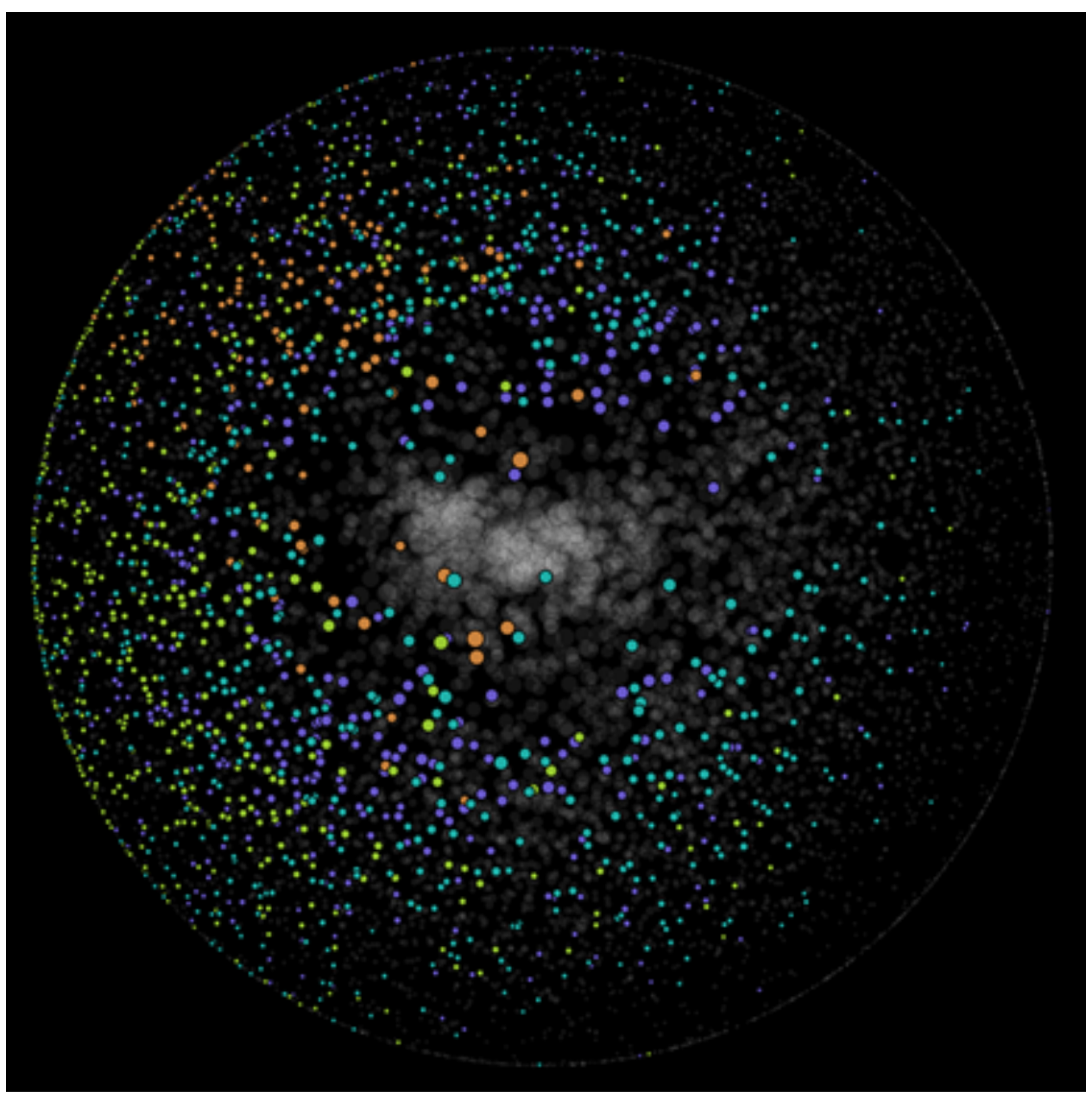

Figure 27: Politics \& Politicians Group

Users in these clusters are engaged with political stances and parties representing a diverse range of views. Both progressive secularist and Islamist representation exists in this group. Attention to the press in this group is also diverse, split between French mainstream news media, Tunisian mainstream news media, and popular opposition channels. Posts are in both Arabic and French 
and are about matters of national (and regional) relevance to Tunisia, such as oil and ISIS. A majority of the users are not public figures (few have over 1000 followers), but rather appear to be professionals or students.

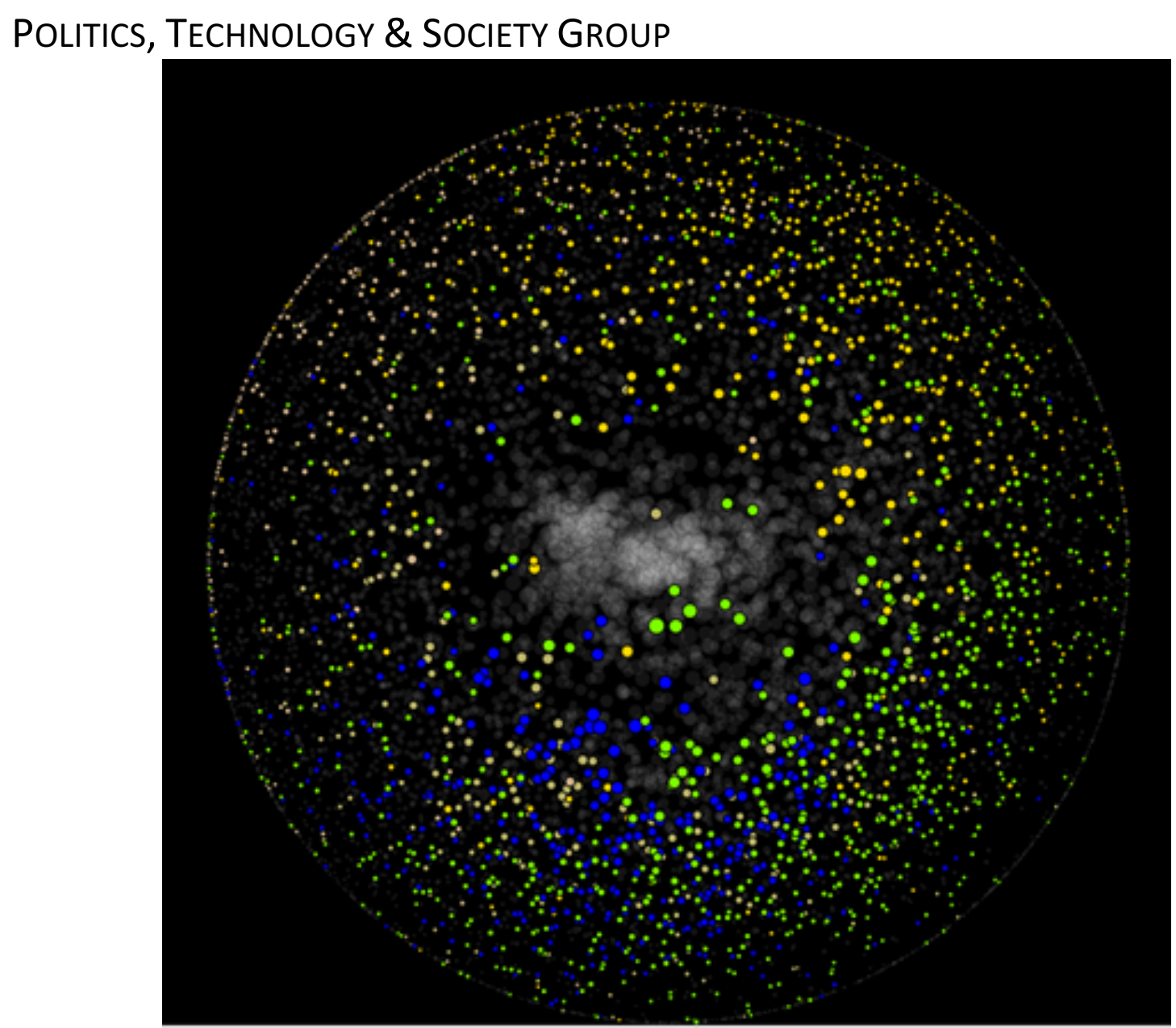

Figure 28: Politics, Technology \& Society Group

The group includes bloggers, activists, journalists, and political reformers posting about political progress and democratic transition in the country. The users are also interested in the use of technology for political and social development and promote protection of digital rights that have been acquired after the removal of President Ben Ali. Some of the accounts in this group include self-identified hackers and makers. Interest in cyberculture is common. Popular Twitter accounts followed include Nawaat, Takriz ("a cyber think/fight tank"), and the French Left Party. Users in this group tend to identify most often with progressive political viewpoints and show an interest in topics related to social justice. French is the most common language. 


\section{POLITICAL REFORM \& HUMAN RIGHTS GROUP}

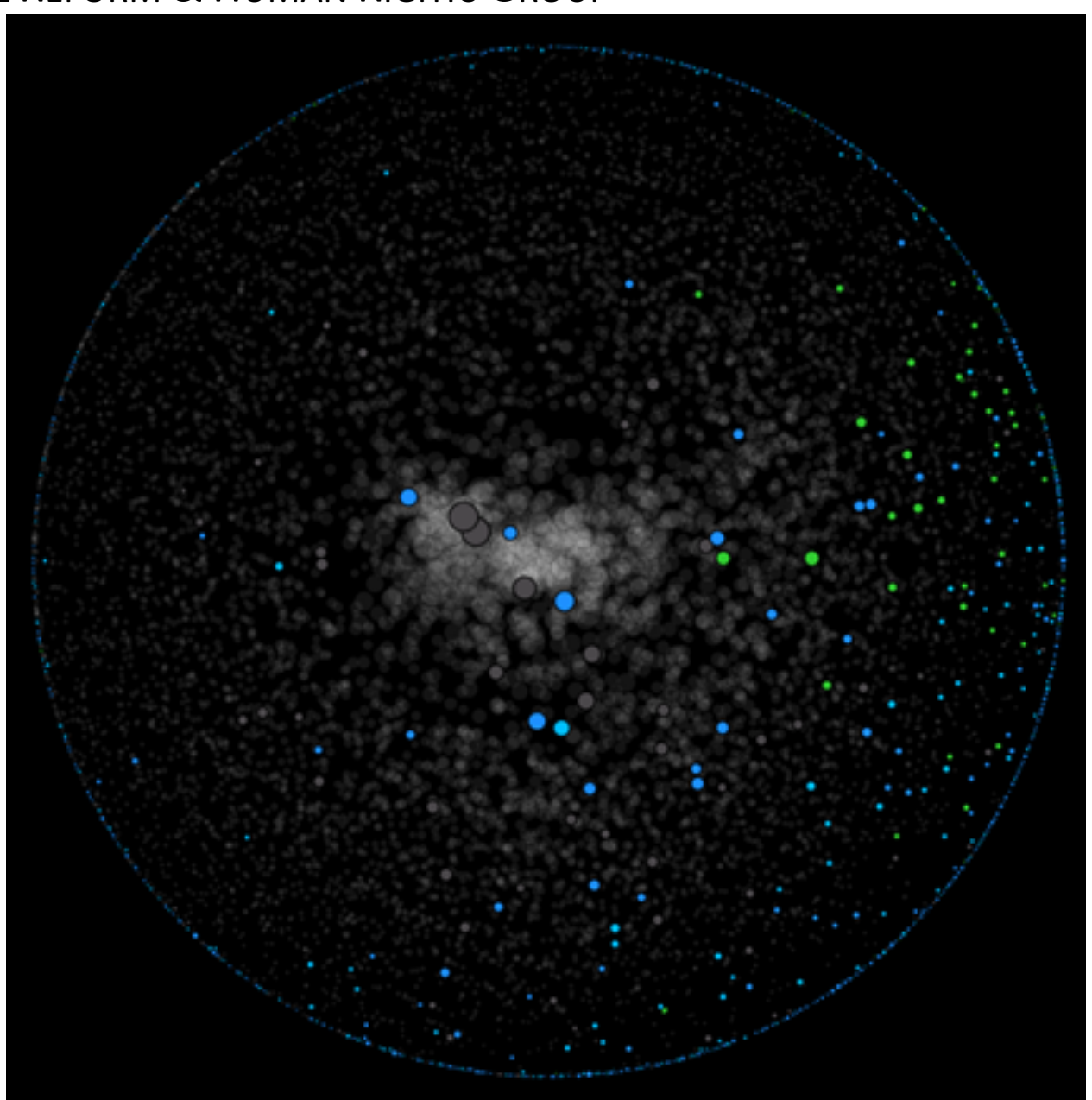

Figure 29: Political Reform \& Human Rights Group

This group is populated by prominent bloggers and early adopters who pushed for political reform, human rights, and Internet freedoms in Tunisia. The clusters also include civil society activists and journalists who discuss political and social progress in the country after the revolution that ousted Ben $\mathrm{Ali}$, and the subsequent democratic transition process. Users express concern about progress in human rights practices, digital freedoms, and government transparency. New pressing issues such as terror activities in the country occupy the most recent discussions. The group has a generally progressive outlook on the government system.

Users in this group are engaged with movements such Ettajdid and follow digital rights and anticensorship activists, as well as local watchdog organizations (e.g., I Watch) and human rights advocacy groups (e.g., Free Tunisia). A large majority of the users in this group are not well integrated with the overall network; they have a relatively small number of follows and followers. 


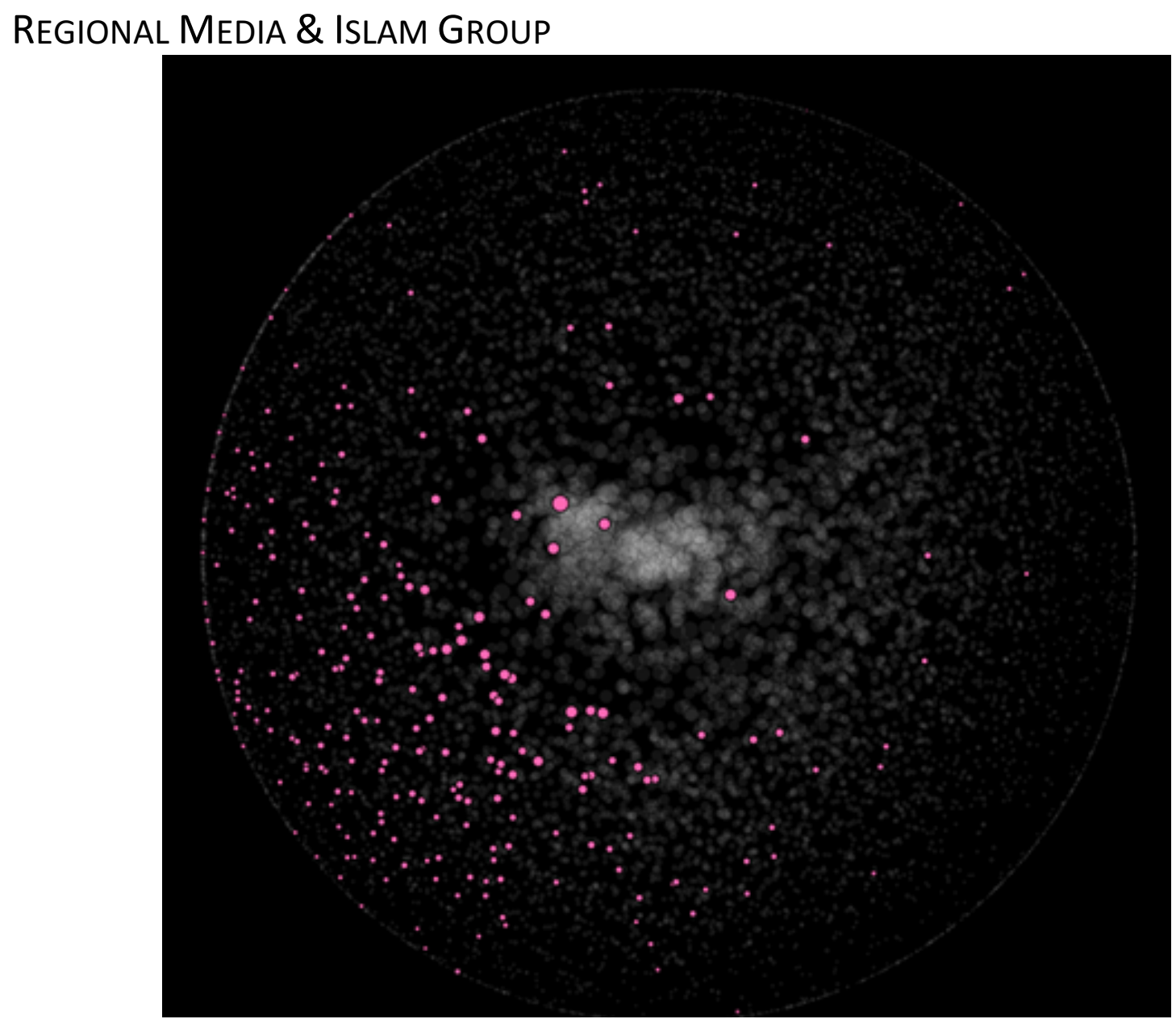

Figure 30: Regional Media \& Islam Group

This group contains various accounts from the region related to Islamist groups, such as the AlNahda Party in Tunisia, the Muslim Brotherhood in Egypt, and individual politicians with an Islamist outlook, such as Turkish president Recep Tayyip Erdoğan. The cluster also includes accounts of prominent religious clerics from the Gulf countries, such as those of Mohamad Alarefe and Salman Alodah. Also in the cluster are accounts from regional media organizations such as Al-Jazeera TV and various journalists. The common theme in this cluster is interest in political Islam. Conversation is limited in this cluster, as the tweets are mostly statements, news, and views from the account holders. Posts in this cluster touch upon many related issues, including Nakba Day, the situation in Palestine, the Morsi trial in Egypt, and the plight of the Rohingya people from Myanmar. Twitter users in this cluster tend to post in Arabic. 


\section{INTERNATIONAL FOCUS GROUP}

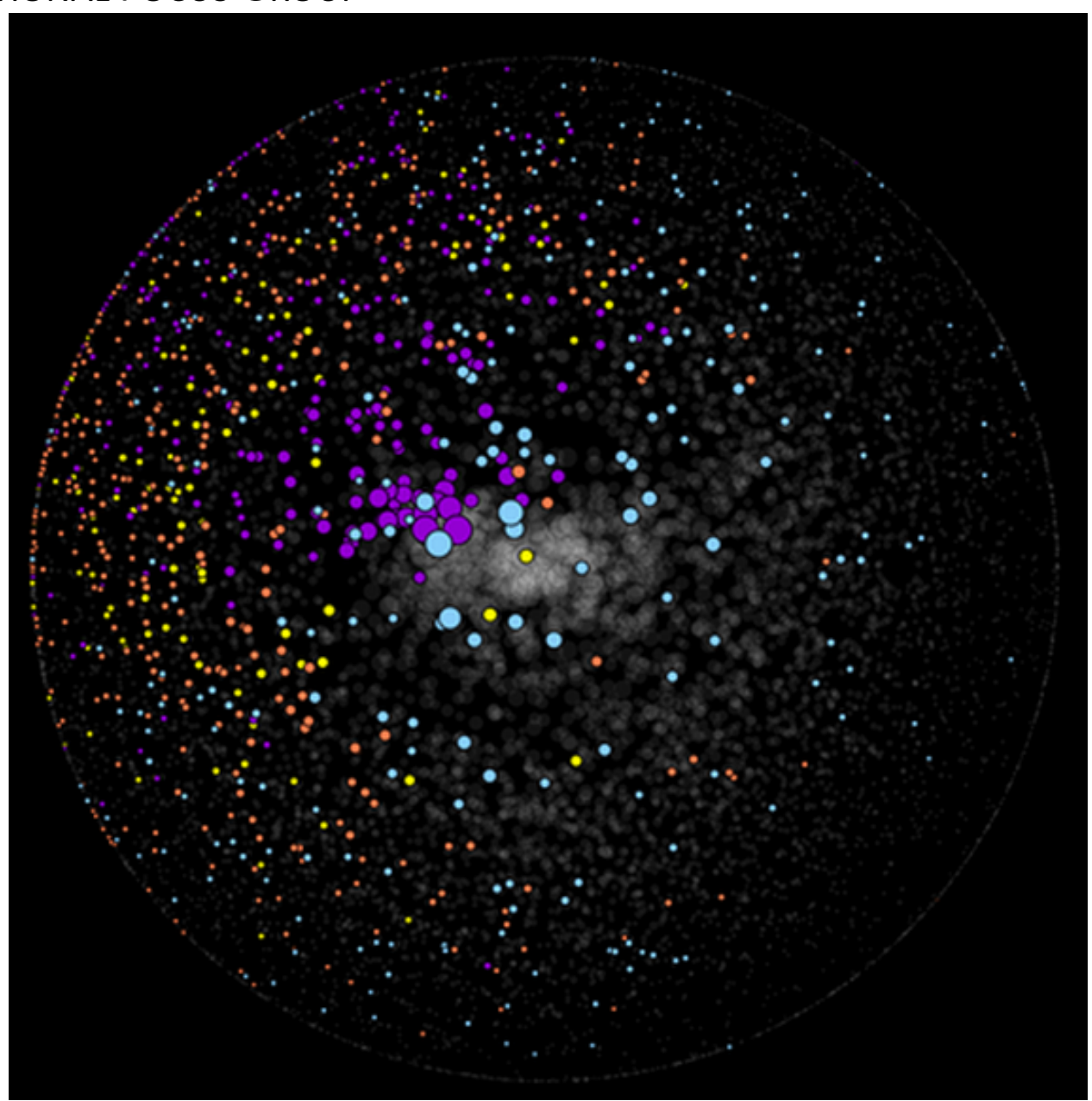

Figure 31: International Focus Group

The group is populated by regional and international media and regional and Western (especially US and French) journalists. The common interest is Middle East and North African and international affairs, French politics, and UN-related issues such as aid assistance. There is a strong human rights-oriented slant to the discourse, and advocacy-oriented sources are shared. The group is not conversational.

One set of users in this group follows individuals such as Nicholas Kristof, feminist writer Mona Eltahawy, and Jillian C. York as well as major international news groups such as Global Voices, Foreign Policy, and The New Yorker, along with international bloggers. This cluster often posts in English and has a distinct focus on potential human rights violations outside of Tunisia, specifically in Egypt, Saudi Arabia, Morocco, Iraq, Oman, Bahrain, and elsewhere in the Middle East. Another cluster show more interest in French politicians and political media. A third cluster mainly follows and retweets French politicians affiliated with the Socialist Party (namely, François Hollande, Ségolène Royal, and Anne Hidalgo, the mayor of Paris). A fourth cluster is distinctive in that it follows mainly news sites rather than individuals (i.e., CNN Arabic, France 24, Al Arabiya, BBCWorld, and RTLFrance). Most of the linked URLs are to left-leaning 
media sources in French and Arabic (with some links occasionally to Turkish journalists and newspapers like Hürriyet).

\section{ENTERTAINMENT \& CULTURE GROUP}

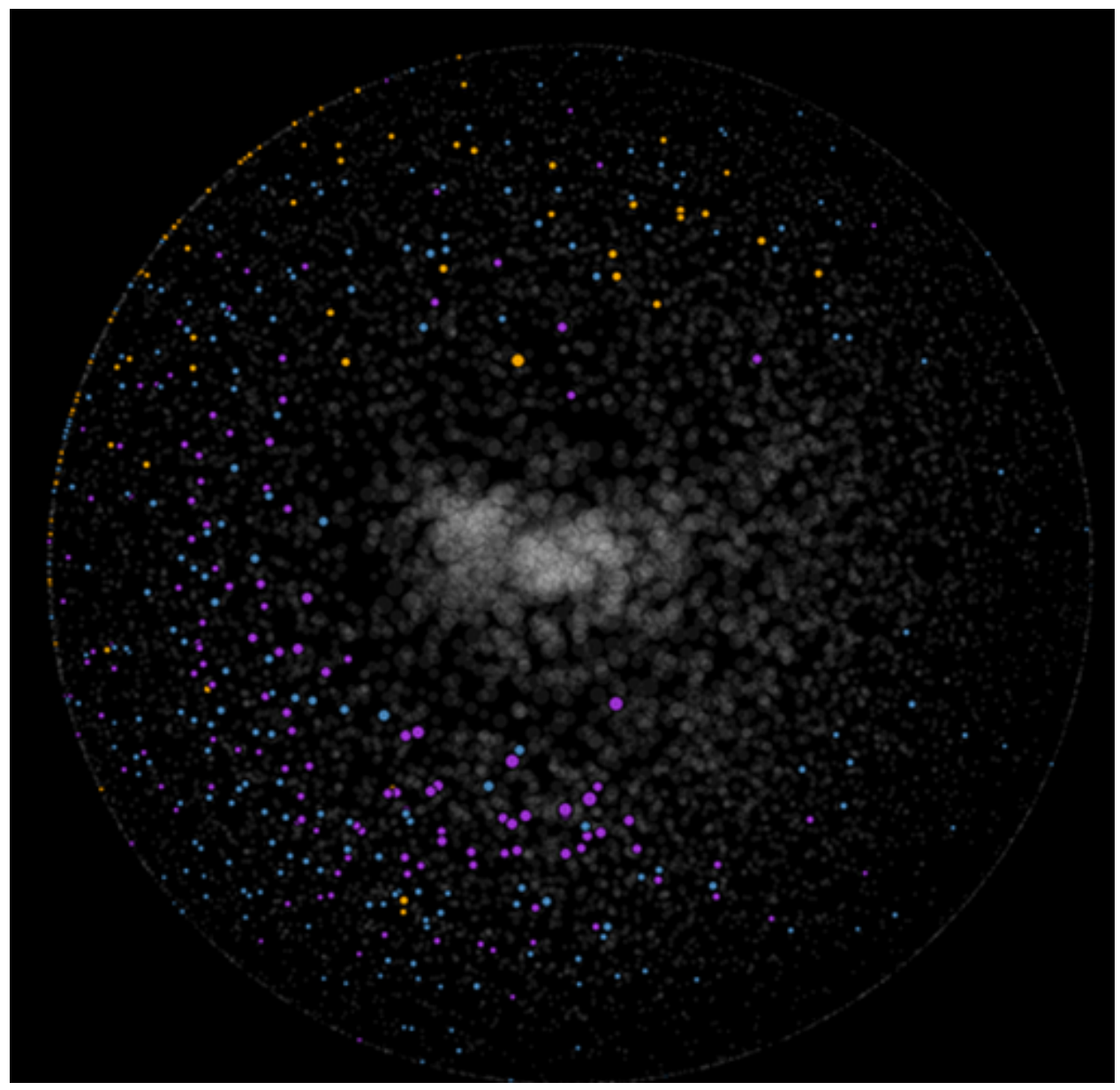

Figure 32: Entertainment \& Culture Group

The primary focus of this group is on entertainment, pop culture, and popular public figures in the region, France, and the US. Some of the users direct their attention to North African and European pop culture, though many also follow American pop stars (such as Will I Am, Justin Bieber, and 50 Cent) and public figures (e.g., Jamel Debbouze, Bassem Youssef, Faisal al Qasim, Bill Gates, and Oprah Winfrey). Prominent political figures are also followed in this group (e.g. Barack Obama, Mohamed ElBaradei), but there is little connectivity with political parties or activist groups. Mentions of sports teams are common. There is little conversation in this cluster.

\section{IMPLICATIONS AND DISCUSSION}

The mapping of online spaces in the Arab world offers a distinctive perspective on the political and social issues that occupy the political discourse of the region. Digital media offers a particularly strong representation of the topics and ideas that citizens are motivated to share in a public forum. Although this certainly does not capture the full spectrum of preferences and 
perspectives in a society - there are opinions and interests that are not shared publicly for any number of reasons - it renders well the interests of those that are vocal and engaged. It is not surprising to find the voices of activists, political leaders, and public figures at the forefront of many online discussions.

In Egypt and Bahrain, accounts from government, government officials, and politicians form an important portion of the most followed accounts (Table 1). In Tunisia, there are relatively more voices from civil society that occupy the top positions. Media organizations and journalists are important across all three networks. Public figures from arts and entertainment make up a significant portion of the most popular accounts in the Egyptian Twitter network. This includes poets, actors, and film industry professionals. Bassem Youssef has the highest number of followers in the network.

\begin{tabular}{|l|r|r|r|r|r|r|}
\hline & \multicolumn{3}{|c|}{ Top 20 } & \multicolumn{3}{c|}{ Top 100 } \\
\cline { 2 - 7 } & Egypt & \multicolumn{1}{|c|}{ Tunisia } & Bahrain & Egypt & Tunisia & \multicolumn{1}{c|}{ Bahrain } \\
\hline Government & 0 & 1 & 3 & 0 & 5 & 13 \\
\hline Politicians & 6 & 1 & 4 & 15 & 3 & 13 \\
\hline Media Organizations & 2 & 4 & 5 & 13 & 23 & 20 \\
\hline Journalists & 4 & 3 & 2 & 24 & 19 & 15 \\
\hline NGOs & 0 & 1 & 0 & 2 & 8 & 5 \\
\hline Civil Society Actors & 4 & 10 & 6 & 25 & 26 & 26 \\
\hline Arts \& Entertainment & 4 & 0 & 0 & 11 & 4 & 1 \\
\hline Miscellaneous & 0 & 0 & 0 & 9 & 12 & 7 \\
\hline
\end{tabular}

Table 1: Types of organizations and individuals that are most followed by users in the Egyptian, Tunisian, and Bahraini Twitter networks. ${ }^{126}$

The prominence of some of the most popular figures in the 3 country networks can be traced back to their activities offline and traditional media attention. One such example is the Bahraini political activist Nabeel Rajab, whose arrest by the Bahraini regime was widely covered by regional and international media and advocacy groups. Also among the top accounts in the Bahraini network are those affiliated with political opposition groups such as Al Wefaq and Al Wafa, known to work within state political and legal constraints.

Similarly, many of the most followed accounts in the Egyptian network belong to users who are critical of the state political system and the restrictive measures on civil society, free speech, and political action. Some figures, for example Egyptian political science professor Amr Hamzawy, occasionally appear on TV channels as political commentators, which might have helped in

\footnotetext{
${ }^{126}$ Researchers manually reviewed the top 100 accounts and placed them into the categories listed in the table. The Government category includes government agencies, government spokespeople, and individuals currently holding office. The Politician category refers to those who do not currently hold office. Media organizations include both domestic and foreign media. Civil society actors broadly include individual voices from civil society, including bloggers and digital activists. Miscellaneous includes private companies and suspended accounts.
} 
raising visibility to their online presences. Egyptian political satirist, Bassem Youssef, had his own TV show, which would have enlarged their online audience.

The Tunisian network has far fewer accounts of TV personalities among the top followed as many seem to be primarily known for their activities in the digital space with the exception to the politicians and political party members.

As more citizens come online, following and participating in discourse, the digital public sphere is fueled and shaped by a wider set of voices, perhaps better reflecting the interests and opinions of societies at large. The structure of the communities that form online denote social, religious, and political divisions as expressed by online users. The comparisons across different countries are illuminating; in comparing the networks of Twitter communities in Egypt, Tunisia, and Bahrain - an important but incomplete portion of the networked public sphere in each of these countries - the differences we see far exceed the similarities. The structure of Twitter networks in Egypt pivots upon the political polarization that has emerged over the past several years with three distinct poles: those aligned with the military, those that side with the Muslim Brotherhood, and those that prefer a civilian government not aligned with the military or Islamists (which we label non-aligned). ${ }^{127}$ In Bahrain, the map is also defined by political polarization. The divide between the government and opposition in Bahrain drives a wedge through the entire network and is exacerbated by the sectarian affiliations and strong rhetoric of the two sides. The Tunisian Twitter networks present a sharp contrast. The clusters in the Tunisian map are not so clearly articulated, and where they are strongest, they revolve around technology, digital rights, and civil society. The political rivalries in Tunisia are not yet evident in the structure of Twitter networks, although political rivalries in Tunisia are apparent in Facebook. ${ }^{128}$

Focusing on the most popular accounts in each network that are engaged in political issues shows that Twitter leans decisively towards a distinct end of the political spectrum in all three countries. In Egypt, accounts for the non-aligned group account for 35 of the 37 most popular politically-oriented accounts (Table 2). In Tunisia, none of the popular political accounts are associated with an Islamist party (Table 3). In Bahrain, 45 out of the 50 popular political accounts are affiliated with or supportive of the opposition (Table 4).

Accounts with a defined political agenda constitute 50 of the 100 most popular accounts in Bahrain. In Egypt, the number is 37 with more focus on arts and entertainment, and religion. In Tunisia, 37 of the top 100 accounts have a political orientation. In both Egypt and Tunisia, voices from civil society are an important part of the conversation. Politicians make up a smaller portion of the list, and accounts affiliated with the current government are not among the most popular accounts. The evidence suggests that Twitter is primarily a venue for civil society discussants.

\footnotetext{
127 This tripolar political mapping aligns closely with the analysis of online and offline civic engagement detailed in a companion paper. See: Nagla Rizk, et al., "The Networked Public Sphere and Civic Engagement, Egypt Study," July 2015.

${ }^{128}$ Escander Nagazi and Jazem Halioui, "An accelerated story of the emergence and transformation of the Networked Public Sphere: Tunisia case in point,” July 2015.
} 


\begin{tabular}{|l|r|r|r|r|}
\hline & Civil Society Actors & NGOs & Politicians & Government \\
\hline Government-aligned & 0 & 0 & 0 & 0 \\
\hline Non-aligned & 20 & 2 & 13 & 0 \\
\hline Muslim Brotherhood-aligned & 0 & 0 & 2 & 0 \\
\hline
\end{tabular}

Table 2: Politically aligned organizations and individuals among the 100 most followed accounts in the Egyptian Twitter network. $^{129}$

\begin{tabular}{|l|r|r|r|r|}
\hline & Civil Society Actors & NGOs & Politicians & Government \\
\hline Non-Islamist & 21 & 8 & 8 & 0 \\
\hline Islamist & 0 & 0 & 0 & 0 \\
\hline
\end{tabular}

Table 3: Politically aligned organizations and individuals among the 100 most followed accounts in the Tunisian Twitter network.

\begin{tabular}{|l|r|r|r|r|}
\hline & Civil Society Actors & NGOs & Politicians & Government \\
\hline Local Government-aligned & 0 & 0 & 0 & 4 \\
\hline Regional Government-aligned & 0 & 0 & 1 & 0 \\
\hline Local Opposition & 18 & 5 & 15 & 5 \\
\hline Regional Opposition & 1 & 0 & 1 & 0 \\
\hline
\end{tabular}

Table 4: Politically aligned organizations and individuals among the 100 most followed accounts in the Bahraini

Twitter network.

\section{ALTERNATIVE MEDIA AND ACCOUNTABILITY}

The networked public sphere continues to offer users a broad range of information sources and alternative views less subject to the influence of government and powerful institutions. Government online resources do not appear among the most followed accounts, and in Bahrain, where there is pervasive political Internet filtering, many of the blocked websites such as that of Bahrain Mirror are among the frequently used websites. User-generated content websites such as YouTube appear among the top used resources in Bahrain, Egypt, and Tunisia.

We see examples of civil society activists working to hold their governments more accountable through online media. An example is the "Where is the Oil" campaign that claimed mismanagement and corruption in the government handling of the country's national wealth in Tunisia. ${ }^{130}$ Political and human rights activists debated the issue on Twitter, with some tweeting photos of public demonstrations and police arrest of demonstrators. In Egypt, Twitter campaigns to free political activists, especially those who participated in the political activities that led to the January 2011 revolution, continue to emerge. Civil society activists hold the government responsible for the safety of the arrested ones and demand amendment of the demonstration law, which requires prior permission from the police to organize public demonstrations. In the

\footnotetext{
${ }^{129}$ Based on the manual review of the 100 accounts in each network with the most followers within the network, in Tables 2, 3, and 4, we tabulate those users that explicitly align with a political group and place them into categories.

${ }^{130}$ Eileen Byrne, “'Where's the oil?' ask wary Tunisians,” The National, June 17, 2015, http:/www.thenational.ae/world/middle-east/wheres-the-oil-ask-wary-tunisians.
} 
Bahrain map, some clusters are made up almost exclusively of anti-government campaigns to free jailed activists and demand political reform and equal citizenship rights.

\section{Politicization and Polarization in the Networked Public Sphere}

A trend across the region is the increasing politicization and polarization of online spaces, coinciding with rising political and social polarization offline. In both Egypt and Bahrain, political contention is reflected in the structure of the Twitter maps. This research is helpful in evaluating and documenting polarization by providing a window into processes that are difficult to view and aggregate by other means. It may also provide a useful avenue by which to assess efforts to bridge social divides and the success of different strategies to foster more civil and productive dialogue between partisan groups.

As well documented, ${ }^{131}$ the current online environment in Egypt is viewed by many of the early Internet adopters as less civil and less conducive for collective action. The tone and substance of dialogue between different factions in both Egypt and Bahrain indicate that the current online environment is not particularly conducive for deliberation. The politicization and polarization of online spaces is not unique to the region. In many respects, we are seeing the realization of many of the hopes for the networked public sphere as it offers a forum for the articulation and debate of different viewpoints by their adherents. The emergence of coalitions and communities online that represent different political perspectives is a natural and desirable step in any transition towards greater democratization. ${ }^{132}$ The concern-here and anywhere - is that growing partisanship fuels hostility, reduces the willingness to consider opposing views, and diminishes opportunities for political compromise.

The decision of users to follow others with similar views - a phenomenon known as homophily ${ }^{133}$-is readily apparent in the network maps. There is no reason to believe that the affordances or features of online platforms are responsible for the polarization seen in these networks. The underlying political and social forces provide ample explanation for the current political environment without resorting to explanations that suggest that digital communication itself is at the root of the problem. Digital platforms do offer a venue to communicate deeply felt sentiments. The ability to express opinions anonymously is important here as well. In the Bahraini network, a substantial portion of the accounts that are responsible for offensive sectarian attacks are pseudonymous. Many observers may conclude that the plentiful polarizing rhetoric found in some political conversations on Twitter exacerbates distrust and enmity between rival communities and increases polarization. It is true that hostile sentiments on Twitter are open for all to see and that some of these sentiments might not be so visible otherwise. We do not, however, have sufficient evidence to conclude whether this polarizing rhetoric indeed makes matters worse. It is possible that the polarization online is simply a reflection of the underlying reality, and that it has no further impact. It is even plausible that heavily loaded rhetoric might even inspire rivals to work together to engender greater civility. This research does not buoy hopes that online spaces could somehow be buffered from offline animosity.

\footnotetext{
${ }^{131}$ Nagla Rizk, et al., “The Networked Public Sphere and Civic Engagement, Egypt Study,” July 2015.

${ }^{132}$ Rosenblum, Nancy L. (2008). On the Side of the Angels: An Appreciation of Parties and Partisanship. Princeton NJ: Princeton University Press.

${ }^{133}$ Miller McPherson, Lynn Smith-Lovin, and James M Cook (2001). Birds of a Feather: Homophily in Social Networks, Annual Review of Sociology Vol. 27: 415-444.
} 
Understanding how the online and offline manifestations of partisan and sectarian divisions may exacerbate or mitigate one another is in all likelihood an unanswerable question, and this question is less meaningful as online and offline social processes become better integrated. Partisanship online might be best viewed as a stage in the maturation and filling out of online spaces. One prime example is the active presence of government actors and their supporters in the Twitter maps. This is a recent phenomenon; governments are almost entirely absent from the 2009 blogosphere map. In Egypt, a cluster of accounts that support the Sisi government is a major part of the 2014 Twitter network. Six years earlier, there was little to no support for the Mubarak government visible in the blogosphere. In Bahrain, the government presence is still limited on Twitter and confined to issuance of statements. The government accounts are not conversational. When conversation between government actors and opponents occurs, it is mostly confrontational, and the opponents invoke grievances from the offline world.

\section{MigRATING TO SOCIAL MEDIA}

The shrinking Arabic blogosphere marks a generational shift in the networked public sphere in the region, coinciding with a marked rise in the adoption of social media and social networking platforms. A preponderance of activity in the Arab networked public sphere now appears to be on Facebook and Twitter, with adoption of other platforms such as Instagram and WhatsApp on the rise. Two prominent Egyptian bloggers, for example, stated in September 2014 that they have shifted from traditional blogging to short posting using social media websites. ${ }^{134}$

There are likely a number of reasons behind this migration, and the reasons will vary by the individual. Given the broad global popularity of Twitter and Facebook, this comes as no surprise. Once a critical mass of early adopters established themselves, the strong network effects associated with both Facebook and Twitter would have undoubtedly prompted further migration. The increasing penetration of mobile phones and high rates of broadband on mobile devices likely plays a role. The ease of posting short messages on Facebook and Twitter on mobile devices could be pushing users away from longer blog posts.

The relative ease of forming groups and expressing affiliations on Twitter and Facebook may also explain their rapid adoption of these platforms and the apparent shift of activist activity to these venues. On social media platforms, organizers and activists have a built-in audience and one can leapfrog from existing pages with similar orientations. For participants, the threshold for engagement is significantly lower and the platforms are designed to make is simple for users to comment, share, retweet, or "like" content, or to join a group on Facebook. Commenting on blogs or posting a post in response takes considerably more effort.

Compared to the era preceding the Arab spring, there is little evidence of civil society organizing in the blogosphere. In the survey of blogosphere activity conducted as a part of this study, we found no efforts to aggregate individual actors and promote social and political change. The decline in traditional blogging does not necessarily mean that there is a decrease in the use of Internet for civic engagement. The evidence suggests rather a shift in social mobilization from

\footnotetext{
134 al-Arabyal-Jazeed, Misr: "Zaman altadween lam yantahi ba'd”, Blogging age is not over yet, Sept 5, 2014 http://www.alaraby.co.uk/medianews/57e51c4e-f6bb-4bb9-b83b-78b456665a4d.
} 
traditional blogging to microblogging and social media. Publicly visible online organizing, such as issue-based campaigns, promoting political protests and strikes, and election activities, appear to have moved almost entirely to Facebook and Twitter. Many of the citizen-organized political campaigns that used to be conducted on blogs now occur on social media. In August 2014, for example, activists launched a social media campaign in support of Egyptian activists Alaa Abd El Fattah, Ahmed Douma, Mohamed Adel, Wael Metwally and Mohamed Abdel Rahman, who had started hunger strikes to protest their detentions. ${ }^{135}$

Twitter, Facebook, blogs, and digital media outlets, along with other online platforms, will continue to compete for the attention of readers and authors. And as part of the digital media landscape, these various platforms will not only crowd out one another but will also play complementary roles. Despite its decline, the Arab blogosphere still serves as a platform for sharing ideas via a distributed network and enables users to bypass traditional unidirectional media structures. The Arab blogosphere appears likely to continue as a platform for long-form writing, even if it is less often the center of political debates and less important for organizing collective action.

The growing importance of large social media platforms may have important implications for the function and structure of the networked public sphere in the region. One set of issues relate to the governance of these platforms and the impact of company policies on freedom of expression. Specific actions and policies by Facebook to remove the accounts of activists have drawn much criticism. Facebook's real name policy has often been at the center of controversy as activists have adopted pseudonyms to address legitimate security concerns only to see their accounts suspended for violated the company's real name policy. This policy made these activists easy targets for opponents, who by flagging these accounts to Facebook could instigate their removal. In Egypt, for example, the We Are All Khaled Said Facebook page, one of the more important rallying points for the 2011 protests, was temporarily taken down in late 2010 because its administrators were using pseudonyms. ${ }^{136}$ While Facebook has taken steps to address these concerns and has begun to loosen the real name requirement, ${ }^{137}$ users on private platforms will always be subject to the company policies with limited recourse. Another longstanding issue is the content restrictions of private platforms. A prime example is human rights activists reporting on police torture and abuse who have seen their content taken down based on policies designed to limit violent content. ${ }^{138}$

When activists and citizens use social media platforms, they are trusting these firms with their personal data, and in doing so are effectively outsourcing their data security to these firms. ${ }^{139} \mathrm{~A}$ lingering concern for many is the willingness of companies to cooperate with government

\footnotetext{
135 "More detainees join hunger strike as activists start campaign," Mada Masr, August 20, 2014, http://www.madamasr.com/content/more-detainees-join-hunger-strike-activists-start-campaign.

${ }^{136}$ Brendan Greeley, "The Fallacy of Facebook Diplomacy,” Bloomberg Business, February 2, 2011, http://www.bloomberg.com/bw/magazine/content/11_07/b4215008414536.htm.

${ }^{137}$ Vindu Goel, "Facebook to Ease Policies on Using Real Names for Accounts," New York Times, October 1, 2014, http://bits.blogs.nytimes.com/2014/10/01/facebook-agrees-to-ease-rules-on-real-names/.

${ }^{138}$ YouTube shuts down Egyptian anti-torture activist's account, http:/edition.cnn.com/2007/WORLD/meast/11/29/youtube.activist/.

${ }^{139}$ Bruce Schneier, "Feudal Security," December 3, 2012, https:/www.schneier.com/blog/archives/2012/12/feudal_sec.html.
} 
requests for identifying information. Warding off attacks by malicious hackers is another concern. Activists that use social networking platforms may be particularly vulnerable if adversaries are able to gain access to their accounts or accounts of their associates, which list all of their friends. Governments in both Egypt and Tunisia have reportedly sought this information to identify protesters. ${ }^{140}$ There is a strong argument that large platforms may provide better security for users than the practical alternatives, though many contest whether activists are better served by large platforms or decentralized open source alternatives.

Although Twitter is not blocked in Bahrain, Egypt, or Tunisia, the restrictive legal frameworks used by the regimes in the region and the prosecution of activists for their political activities likely contribute to shaping the overall discourse online. In Bahrain for example, the authorities arbitrarily arrested dissident information providers. Users may resort to self-censorship to avoid confrontation with the authorities on sensitive topics. It is hard to measure the extent of selfcensorship practice, but a study of the Saudi Twittersphere finds evidence that users temper the expression of sentiments online on certain sensitive issues when they fear retribution from authorities. ${ }^{141}$ The Twitter maps therefore should not be viewed as inclusive of all sentiments on political and social issues. Users are expected to adjust their online activities to take risk factors into consideration.

Less well studied is the impact of the architecture and structural features of large platforms such as Facebook and Twitter on public discourse and how these structural elements interact with user behavior to influence the shape and function of the networked public sphere. Facebook's own studies suggest how subtle cues can influence user behavior. ${ }^{142}$ There are many similarities between blogging and microblogging, and these similarities translate into a degree of overlap in the functional and structural elements of the blogosphere and Twittersphere as described in this study. Dhiraj Murthy asserts that the narrative style and substance of Twitter more closely resemble that of longer-form blogs when tweets are considered not individually but as a corpus of short communiqués. ${ }^{143} \mathrm{He}$ adds that the corpus is qualitatively different from individual tweets, and once the stream of tweets is aggregated, this can comprise a coherent narrative.

There are, however, many substantial differences between different platforms. The most obvious is the relative investment of time in each post. In most respects, the hurdle for participation is lower on Twitter, and that has both potentially positive and negative impacts on public discourse. It is that much easier to make positive contributions or to engage in harassment and counterproductive attacks. The mechanisms in blogs, microblogs, and social networking

\footnotetext{
${ }^{140}$ Alexis C. Madrigal, “The Inside Story of How Facebook Responded to Tunisian Hacks,” The Atlantic, January 24, 2011, http://www.theatlantic.com/technology/archive/2011/01/the-inside-story-of-how-facebook-responded-totunisian-hacks/70044/.

${ }^{141}$ Noman, Helmi and Faris, Robert and Kelly, John, Openness and Restraint: Structure, Discourse, and Contention in Saudi Twitter (December 2015). Berkman Center Research Publication No. 2015-16. Available at SSRN: http://ssrn.com/abstract=2700944 or http://dx.doi.org/10.2139/ssrn.2700944

${ }^{142}$ Adam Kramer, Jamie Guillory, and Jeffrey Hancock, "Experimental evidence of massive-scale emotional contagion through social networks," PNAS, March 24, 2015, http://www.pnas.org/content/111/24/8788.full. See also: J. Nathan Matias, "Were All Those Rainbow Profile Photos Another Facebook Study?," The Atlantic, June 28, 2015, http:/www.theatlantic.com/technology/archive/2015/06/were-all-those-rainbow-profile-photos-anotherfacebook-experiment/397088/.

${ }^{143}$ Dhiraj Murthy, Twitter: Social Communication in the Twitter Age. S.1.: Polity Press, 2012.
} 
platforms for citing and amplifying the ideas and work of others have both similarities and differences. Each platform offers mechanisms for amplifying the writing of specific users or particular posts. There are also potentially important differences in the interplay between visibility and vulnerability for users. Blogs are highly visible but also have a high degree of control over the manner in which others can respond and interact with them. Users on Twitter and Facebook who are highly visible are also vulnerable to harassment. Steps that can be taken to reduce vulnerability on social media also reduce visibility, and often move conversations out of the public sphere into more private areas. Another key difference is the nature of communities that emerge on different platforms. Communities that are defined topically or around professional interests play different functional roles in the networked public sphere compared to those that are primarily based on social connections. This is not well understood.

The paths and prospects for digitally mediated social mobilization in the Arab world are markedly different from the first generation of digital activism and engagement via the networked public sphere. The networked public sphere is no longer solely steered by the early majority of reform-oriented activists and technologists. It is increasingly reflecting more traditional and mainstream viewpoints as late adopters join the space. Currently, a host of diverse voices are present including those of competing activists from dissidents to loyalists, Islamists to secularists, and rebels to conformists. The most consequential changes have occurred offline and the current digital landscape is a reflection of the wider social and political climate. It is not readily apparent whether the potential for leveraging digital technologies for civic engagement and collective action have risen or fallen over the past several years. It is almost certainly more complex and more challenging. 